NBER WORKING PAPER SERIES

EXCHANGE RATES AND INTEREST PARITY

\author{
Charles Engel \\ Working Paper 19336 \\ http://www.nber.org/papers/w19336 \\ NATIONAL BUREAU OF ECONOMIC RESEARCH \\ 1050 Massachusetts Avenue \\ Cambridge, MA 02138 \\ August 2013
}

This essay is to appear as a chapter in the Handbook of International Economics, vol. 4 (Elsevier), edited by Gita Gopinath, Elhanan Helpman, and Kenneth Rogoff. I thank Philippe Bacchetta and Fabio Ghironi, as well as Gita Gopinath and Ken Rogoff for helpful comments. The views expressed herein are those of the author and do not necessarily reflect the views of the National Bureau of Economic Research.

NBER working papers are circulated for discussion and comment purposes. They have not been peerreviewed or been subject to the review by the NBER Board of Directors that accompanies official NBER publications.

(C) 2013 by Charles Engel. All rights reserved. Short sections of text, not to exceed two paragraphs, may be quoted without explicit permission provided that full credit, including $\odot$ notice, is given to the source. 
Exchange Rates and Interest Parity

Charles Engel

NBER Working Paper No. 19336

August 2013

JEL No. F31,F41,G15

\title{
ABSTRACT
}

This paper surveys recent theoretical and empirical contributions on foreign exchange rate determination. The paper first considers monetary models under uncovered interest parity and rational expectations. Then the paper considers deviations from UIP/rational expectations: foreign exchange risk premium, private information, near-rational expectations, and peso problems.

\author{
Charles Engel \\ Department of Economics \\ University of Wisconsin \\ 1180 Observatory Drive \\ Madison, WI 53706-1393 \\ and NBER \\ cengel@ssc.wisc.edu
}




\section{Exchange Rates and Interest Parity}

This chapter surveys empirical and theoretical research since 1995 (the publication date of the previous volume of the Handbook of International Economics) on the determination of nominal exchange rates. This research includes innovations to modeling based on new insights about monetary policymaking and macroeconomics. While much work has been undertaken that extends the analysis of the effects of traditional macroeconomic fundamentals on exchange rates, there have also been important developments that examine the role of non-traditional determinants such as a foreign exchange risk premium or market dynamics.

This chapter follows the convention that the exchange rate of a country is the price of the foreign currency in units of the domestic currency, so an increase in the exchange rate is a depreciation in the home currency. $S_{t}$ denotes the nominal spot exchange rate, and $s_{t} \equiv \log \left(S_{t}\right)$.

A useful organizing feature for this chapter is the definition of $\lambda_{t}$ :

$$
\lambda_{t} \equiv i_{t}^{*}+E_{t} s_{t+1}-s_{t}-i_{t}
$$

In this notation, $i_{t}$ is the nominal interest rate on a riskless deposit held in domestic currency between periods $t$ and $t+1$, while $i_{t}^{*}$ is the equivalent interest rates for foreign-currency deposits. ${ }^{1} E_{t} s_{t+1}$ is the rational expectation of $s_{t+1}$ - the mean of the probability distribution of $s_{t+1}$, conditional on all information available to the market at time $t . \quad \lambda_{t}$ is the difference between (approximately) the expected return on the foreign-currency deposit expressed in units of the domestic currency, $i_{t}^{*}+E_{t} s_{t+1}-s_{t}$, and $i_{t}$. It can be called the deviation from uncovered interest parity ${ }^{2}$, the expected excess return, or less generally, the foreign exchange risk premium. Rearrange equation (1.1) to get:

$$
s_{t} \equiv-\left(i_{t}-i_{t}^{*}\right)-\lambda_{t}+E_{t} s_{t+1} .
$$

An increase in the domestic to foreign short-term interest differential, $i_{t}-i_{t}^{*}$, ceteris paribus is associated with an appreciation. An increase in the expected excess return on the foreign deposit, $\lambda_{t}$, is also associated, ceteris paribus, with an appreciation. Holding interest rates and $\lambda_{t}$ constant, a higher expected future exchange rate implies a depreciation.

Models of the exchange rate for the past 40 years have often focused on the case in which $\lambda_{t}=0$. Let $q_{t}$ be the log of the real exchange rate (the relative foreign to domestic consumer price levels, expressed in common units, where $p_{t}$ is the log of the domestic consumer price index (CPI), and $p_{t}^{*}$ is the log of the foreign CPI in foreign currency units), so $q_{t}=s_{t}+p_{t}^{*}-p_{t}$, and set $\lambda_{t}=0$. Equation (1.2) can be written as:

$$
s_{t} \equiv-\left(i_{t}-i_{t}^{*}\right)+E_{t} \pi_{t+1}-E_{t} \pi_{t+1}^{*}+p_{t}-p_{t}^{*}+E_{t} q_{t+1}=-\left(r_{t}-r_{t}^{*}\right)+p_{t}-p_{t}^{*}+E_{t} q_{t+1},
$$

where $\pi_{t+1} \equiv p_{t+1}-p_{t}$ is approximately the domestic inflation rate and $r_{t} \equiv i_{t}-E_{t} \pi_{t+1}$ is approximately the

1 Generally, a superscript * in the chapter refers to a foreign-country variable.

${ }^{2}$ This is a version of uncovered interest parity that assumes rational expectations. 
domestic ex ante real interest rate (with analogous definitions for the foreign variables.) Iterate equation (1.3) forward to get:

$$
\begin{aligned}
s_{t} & \equiv-\sum_{j=0}^{\infty} E_{t}\left(i_{t+j}-i_{t+j}^{*}\right)+\lim _{j \rightarrow \infty} E_{t} s_{t+j+1} \\
& =-\sum_{j=0}^{\infty} E_{t}\left(i_{t+j}-i_{t+j}^{*}\right)+\sum_{j=0}^{\infty} E_{t}\left(\pi_{t+j+1}-\pi_{t+j+1}^{*}\right)+p_{t}-p_{t}^{*}+\lim _{j \rightarrow \infty} E_{t} q_{t+j+1} . \\
& =-\sum_{j=0}^{\infty} E_{t}\left(r_{t+j}-r_{t+j}^{*}\right)+p_{t}-p_{t}^{*}+\lim _{j \rightarrow \infty} E_{t} q_{t+j+1}
\end{aligned}
$$

This equation summarizes the concerns of the literature that sets $\lambda_{t}=0$, and also helps to demarcate the scope of this essay. Monetary models of exchange rates have focused on the role of monetary policy in setting interest rates and determining inflation. These models have also emphasized the macroeconomic forces that determine expected future interest rates, real and nominal, and expected future inflation. We will survey recent developments in this line of research.

The term $\lim _{j \rightarrow \infty} E_{t} q_{t+j+1}$ can be thought of as the long-run real exchange rate. This survey will not attempt to encompass the large literature that examines the neoclassical determinants of equilibrium real exchange rates. The chapter is about nominal exchange rates, but economists, policymakers and individuals are concerned about nominal exchange rates mostly because they believe that their fluctuations matter for real exchange rates and other relative prices such as the terms of trade, so we focus on models in which the determination of real prices depends integrally on the nominal exchange rate level.

We are also not concerned with the $p_{t}-p_{t}^{*}$ term. This term is of course important in nailing down the level of nominal exchange rates - it helps to answer the question of why a dollar buys 80 yen instead of 8 yen. It also is important in high-inflation countries for understanding shocks to the nominal exchange rate, $s_{t}-E_{t-1}\left(s_{t}\right)$. Here we stipulate that in these high-inflation countries, monetary growth is most influential in determining the variance of $p_{t}-E_{t-1}\left(p_{t}\right)$. There is little need to go further than that for high-inflation countries; and for low-inflation countries, the behavior of $p_{t}-E_{t-1}\left(p_{t}\right)$ contributes little to our understanding of nominal exchange rate shocks, so we set it aside.

Much recent theorizing about exchange rate determination focuses on $\lambda_{t}$. There are a number of reasons why $\lambda_{t}$ may not equal zero. If agents require a higher expected return on foreign compared to domestic deposits, because of a foreign exchange risk premium or some sort of liquidity premium, then $\lambda_{t} \neq 0$. The definition of $\lambda_{t}$ used rational expectations, but participants in the market may form expectations using some other algorithm. There might be private information relevant for the demand for foreign and home deposits, so even if agents all form their expectations rationally on the basis of their own information, the market equilibrium condition might not aggregate to $i_{t}^{*}+E_{t} s_{t+1}-s_{t}=i_{t}$. Individuals might have "rational inattention", 
so that they do not act continuously on publicly available information. The market microstructure - how foreign currency demand and supply gets translated into a price for foreign exchange - might affect the market equilibrium. The modern "asset-market" approach is built off the assumption that capital flows freely between markets, but capital controls or other transactions costs can upset the asset-market equilibrium, as could other limits to arbitrage such as collateral constraints. Equation (1.4) can be generalized to:

$$
\begin{aligned}
S_{t} & \equiv-\sum_{j=0}^{\infty} E_{t}\left(i_{t+j}-i_{t+j}^{*}\right)-\sum_{j=0}^{\infty} E_{t} \lambda_{t+j}+\lim _{j \rightarrow \infty} E_{t} s_{t+j+1} \\
& -\sum_{j=0}^{\infty} E_{t}\left(i_{t+j}-i_{t+j}^{*}\right)+\sum_{j=0}^{\infty} E_{t}\left(\pi_{t+j+1}-\pi_{t+j+1}^{*}\right)-\sum_{j=0}^{\infty} E_{t} \lambda_{t+j}+p_{t}-p_{t}^{*}+\lim _{j \rightarrow \infty} E_{t} q_{t+j+1} \\
& =-\sum_{j=0}^{\infty} E_{t}\left(r_{t+j}-r_{t+j}^{*}\right)-\sum_{j=0}^{\infty} E_{t} \lambda_{t+j}+p_{t}-p_{t}^{*}+\lim _{j \rightarrow \infty} E_{t} q_{t+j+1}
\end{aligned}
$$

which demonstrates that it is not only current but also expected future values of $\lambda_{t}$ that matter for the exchange rate.

Of special interest are the theories of $\lambda_{t}$ that might account for the uncovered interest parity puzzle. This is the empirical puzzle that finds over many time periods for many currency pairs the slope coefficient in the regression:

$$
s_{t+1}-s_{t}=a+b\left(i_{t}-i_{t}^{*}\right)+u_{t+1}
$$

is less than one and often negative. Under the null hypothesis that $\lambda_{t}=0$ in equation (1.1), the regression coefficients should be $a=0$ and $b=1$. This survey will draw the link between models that are derived to explain the empirical findings concerning regression (1.6) and the implications of the implied behavior of $\lambda_{t}$ for the exchange rate. In addition to the theoretical reasons noted in the previous paragraph for why we might have $\lambda_{t} \neq 0$, the literature has also raised the possibility that empirical work mismeasures $E_{t} S_{t+1}$ (the "peso problem"), or that econometric issues lead to spurious rejection of the null hypothesis.

The plan of the chapter is to consider first the "traditional" asset market approach, in which $\lambda_{t}=0$. We survey how the New Keynesian literature has given theoretical and empirical insights into nominal exchange rate behavior. We consider exchange rate dynamics and volatility, and whether models are useful for forecasting exchange rate changes.

Then we consider different exchange-rate regimes and survey the large empirical literature on sterilized foreign exchange market intervention in floating-exchange rate countries.

The last part of the survey turns to models of $\lambda_{t}$. We take up the literature that has modeled foreign exchange risk premiums, and approaches that allow for violations of the representative-agent rationalexpectations framework. Both have implications for the determination of exchange rates and the resolution of the uncovered interest parity puzzle. 


\section{Monetary Sticky-Price Models of Exchange Rates}

\section{2.a New Keynesian monetary models}

In this section, we ignore deviations from uncovered interest parity, $\lambda_{t}=0$ and we give scant attention to determinants of the equilibrium long-run level, $\lim _{j \rightarrow \infty} E_{t}\left(q_{t+j+1}\right)$. Equation (1.4) shows that $q_{t}$ in this case depends only on the behavior of current and expected future real interest rates in the domestic and foreign countries. In sticky-price monetary models, the proximate determinant of ex ante real interest rates is monetary policy. A tight monetary policy increases the real interest rate, and an easy monetary policy lowers it. If real interest rates are positively serially correlated, expected future real interest rates tend to move in the same direction as the current real interest rate. Then a monetary contraction leads to a real appreciation, and monetary easing to a real depreciation.

This is the conclusion reached in the textbook Mundell-Fleming model, in Dornbusch's (1976) classic contribution to the asset-market approach to exchange-rates, and in modern New Keynesian models, but this description only presents part of the picture. Real exchange rates and real interest rates are endogenous macroeconomic variables. Their dynamic path, and the determination of expected future real interest rates, depend on the structure of the macroeconomy. There are differences in the structure of the models and in the dynamics of real exchange rates in Dornbusch's approach versus the standard New Keynesian model. The New Keynesian models are derived from optimizing behavior by households and firms under uncertainty, while Dornbusch's model is behavioral and derived under perfect foresight with no shocks except an initial monetary policy surprise. If firms are slow to adjust prices, they must have enough power in the market to set their own prices. They cannot be perfectly competitive price takers. New Keynesian models posit that firms are monopolistic, with the economy populated by many such firms whose products are imperfect substitutes for each other. The models assume that not all firms are able to adjust nominal prices every period. Because firms are monopolists, when they are able to set prices, they set them above average and marginal cost, and earn profits. When the firm subsequently cannot change its price, it is willing to sell the amount demanded (for small enough changes in demand) because the firm makes a profit on each unit sold.

In Dornbusch, the money supply is the instrument of monetary policy, and the price level is determined in the long-run independently of initial prices. In many New Keynesian models, the interest rate is the instrument of monetary policy. Inflation rates are determined in the model, but the price level even in the long run depends on past prices. Finally, monetary policy is exogenous in the Dornbusch model - it is determined as an exogenous path for the money supply. In many New Keynesian model, the interest rate is set according to a policy rule, where the interest rate reacts to inflation, the output gap and possibly other variables.

We consider here a simple New Keynesian two-country model (the countries are designated Home and Foreign). It assumes uncovered interest parity holds. In terms of equation (1.1), $\lambda_{t}=0$ :

$$
i_{t}=i_{t}^{*}+E_{t} s_{t+1}-s_{t} .
$$


Monetary policy sets the interest rate endogenously. A simple Taylor rule for the Home country takes the form:

$$
i_{t}=\tilde{r}_{t}+\sigma \pi_{t}+\alpha\left(i_{t-1}-\tilde{r}_{t-1}\right)+\varepsilon_{t}, \quad \sigma+\alpha>1, \quad 0 \leq \alpha<1 .
$$

The Home country policymaker tightens monetary conditions by increasing the nominal short-term interest rate, but it practices interest-rate smoothing so that the current interest rate depends on the previous period's rate. $\tilde{r}_{t}$ is the "Wicksellian" real interest rate - here it is the real interest rate that would prevail if prices fully adjusted instantaneously. In other words, if the central bank hit its target of zero inflation at all times, and $\varepsilon_{t}=0$, it would want $i_{t}$ to equal $\tilde{r}_{t}$. $\varepsilon_{t}$ accounts for other influences in setting the interest rate, so that higher values of $\varepsilon_{t}$ mean tighter money. Taking into account the gradual adjustment of the interest rate, the ultimate effect of an increase in inflation on the nominal interest rate is, ceteris paribus, equal to $\sigma /(1-\alpha)$. The condition $\sigma+\alpha>1$ amounts to a condition that an increase in inflation leads policymakers eventually to increase the nominal interest rate more than one for one.

The aggregate relationships in New Keynesian models are derived from the underlying decisions of households and firms. Each country produces a range of products, with each good being produced by a monopolist. In this model, labor markets are competitive and workers are mobile between sectors within an economy.

We assume that the two countries are symmetric, and to keep with a simple example, that they have identical preferences so there is no "home bias" in consumption. $\pi_{t}$ is the consumer price index inflation rate, which is the simple average of the inflation rates in the Home country of the goods produced in each country.

We assume the Foreign policymaker follows a rule similar to (2.2), with the same parameters. Foreign monetary policy targets the Foreign inflation rate, $\pi_{t}^{*}$, and includes other exogenous factors, $\varepsilon_{t}^{*}$. The Foreign policy rule is given by:

$$
i_{t}^{*}=\tilde{r}_{t}^{*}+\sigma \pi_{t}^{*}+\alpha\left(i_{t-1}^{*}-\tilde{r}_{t-1}^{*}\right)+\varepsilon_{t}^{*} .
$$

Since Home and Foreign consumers have identical preferences, if faced with the same price they would consume the same basket, and purchasing power parity would hold all the time. However, we can assume that there is pricing to market that arises from a particular type of nominal price stickiness. Assume that firms set different prices for their goods sold in each country, and each of those prices is sticky in the currency in which it is set - "local-currency pricing" or LCP. This contrasts to the New Keynesian models of Obstfeld and Rogoff (1995a) and Clarida, Gali and Gertler (2002) that assume producers set nominal prices in their own currency, and the law of one price holds. The price of imported goods for consumers then fluctuates with the exchange rate. That type of price stickiness is known as "producer-currency pricing" or PCP.

We assume Calvo price setting. Under this price-setting mechanism, any given firm has a constant hazard rate of changing its two prices in a given period. The firm cannot adjust prices at all during a given period unless it receives a signal that it "won the lottery" and is allowed to change prices in the period. Because 
preferences are identical, the only source of movements in the real exchange rate is attributable to the LCP price stickiness, which engenders deviations from the law of one price as the nominal exchange rate fluctuates. These deviations are expected to converge toward zero, so long run purchasing power parity holds.

Consider the evolution of the price for Home firms for sale in the Home market. The log of the aggregate price of these goods is given by

$$
p_{H t}=(1-\theta) \tilde{p}_{H t}+\theta p_{H t-1} .
$$

$\tilde{p}_{H t}$ is the $\log$ of the price of firms that reset their price in period $t$. A fraction $1-\theta$ reset their price, so equation (2.4) describes the evolution of the aggregate price of Home goods at Home.

Firms produce output using only labor, so $w_{t}-a_{t}$ is the log of the unit cost. $w_{t}$ is the log of the nominal wage, and $a_{t}$ is the $\log$ of labor productivity. If prices were completely flexible, $p_{H t}$ would be set equal to $w_{t}-a_{t}$ (plus a constant mark-up.) With a discount factor of $\beta$ and a probability $\theta$ that the price will not change, the firms that reset prices in time $t$ set them to maximize the expected present discounted value of profits, which implies that (to a log-linear approximation) the optimal price satisfies the recursion:

$$
\tilde{p}_{H t}=(1-\theta \beta)\left(w_{t}-a_{t}\right)+\theta \beta E_{t} \tilde{p}_{H t+1} .
$$

With a bit of manipulation, equations (2.4) and (2.5) give us:

$$
\pi_{H t}=\delta\left(w_{t}-a_{t}-p_{H t}\right)+\beta E_{t} \pi_{H t+1}, \quad \delta \equiv(1-\theta)(1-\theta \beta) / \theta,
$$

where $\pi_{H t} \equiv p_{H t}-p_{H t-1}$. The larger the probability that a firm will be able to adjust its price, the larger is $\delta$.

The cost per unit in Foreign currency terms of the Home good is $w_{t}-s_{t}-a_{t}$. Following similar steps as in the derivation of (2.6), we can find an equation for the evolution of prices of Home goods sold in the Foreign country, priced in Foreign currency, $p_{H t}^{*}$ :

$$
\pi_{H t}^{*}=\delta\left(w_{t}-a_{t}-s_{t}-p_{H t}^{*}\right)+\beta E_{t} \pi_{H t+1}^{*},
$$

where $\pi_{H t}^{*} \equiv p_{H t}^{*}-p_{H t-1}^{*}$. Then (2.6) and (2.7) give us:

$$
\pi_{H t}-\pi_{H t}^{*}=\delta\left(s_{t}+p_{H t}^{*}-p_{H t}\right)+\beta E_{t}\left(\pi_{H t+1}-\pi_{H t+1}^{*}\right) .
$$

In a symmetric model, the deviations from the law of one price are equal for Home- and Foreign-produced goods:

$$
p_{H t}-s_{t}-p_{H t}^{*}=p_{F t}-s_{t}-p_{F t}^{*}
$$

which also implies

$$
p_{F t}-p_{H t}=p_{F t}^{*}-p_{H t}^{*} .
$$

Under the assumption of identical preferences, $p_{t}=\left(p_{H t}+p_{F t}\right) / 2$, and $p_{t}^{*}=\left(p_{H t}^{*}+p_{F t}^{*}\right) / 2$. In this case, $\pi_{H t}-\pi_{H t}^{*}=\pi_{F t}-\pi_{F t}^{*}=\pi_{t}-\pi_{t}^{*}$. Also, $q_{t} \equiv s_{t}+p_{t}^{*}-p_{t}=s_{t}+p_{H t}^{*}-p_{H t}=s_{t}+p_{F t}^{*}-p_{F t}$. We can then derive the relationship:

$$
\pi_{t}-\pi_{t}^{*}=\delta q_{t}+\beta E_{t}\left(\pi_{t+1}-\pi_{t+1}^{*}\right)
$$


Uncovered interest parity, equation (2.1), along with the Taylor rule, (2.2), and its Foreign equivalent, (2.3) , and the price adjustment equation (2.11), allow us to derive a three-equation dynamic system for the real exchange rate, and Home relative to Foreign inflation: ${ }^{3}$

(2.12) $\quad E_{t} z_{t+1}=B z_{t}+w_{t}$,

where $z_{t}=\left[\begin{array}{c}\pi_{t}-\pi_{t}^{*} \\ q_{t} \\ i_{t-1}\end{array}\right], w_{t}=\left[\begin{array}{c}0 \\ \varepsilon_{t}-\varepsilon_{t}^{*} \\ \varepsilon_{t}-\varepsilon_{t}^{*}\end{array}\right], B=\left[\begin{array}{ccc}1 / \beta & -\delta / \beta & 0 \\ (\sigma \beta-1) / \beta & (\beta+\delta) / \beta & \alpha \\ \sigma & 0 & \alpha\end{array}\right]$.

At time $t$, only one element of $z_{t}$ is predetermined. Both $\pi_{t}-\pi_{t}^{*}$ and $q_{t}$ may jump in response to contemporaneous Home or Foreign monetary shocks. Algebraically, for the dynamic system (2.12) to have a unique stable solution, two roots of the matrix $B$ must be greater than one, which requires $\sigma+\alpha>1$. $^{4}$ This is the familiar "Taylor condition" that the central banks ultimately raise nominal interest rates more than one-forone with an increase in inflation.

The solution to equation (2.12) in general is somewhat complicated. We will consider some special cases. In the first case, we will assume that the errors to the monetary policy rules are i.i.d. random variables that have mean zero; i.e., $E_{t} \varepsilon_{t+j}=E_{t} \varepsilon_{t+j}^{*}=0$ for $j>0$. We will also make the following assumption on the parameters: $\sigma+\alpha=1 / \beta$. We make this assumption only because it allows for a simpler algebraic solution, but make two observations. First, this assumption on the parameters does satisfy the condition for a stable unique solution. Second, the equations in (2.12) can be rewritten under this assumption to give us:

$$
i_{t}-E_{t} \pi_{t+1}-\left(i_{t}^{*}-E_{t} \pi_{t+1}^{*}\right)=\left(\frac{\delta}{\beta}\right) q_{t}+\alpha\left[i_{t-1}-\pi_{t}-\left(i_{t-1}^{*}-\pi_{t}^{*}\right)\right]+\varepsilon_{t}-\varepsilon_{t}^{*}
$$

We can interpret this equation as saying that the Home less the Foreign real interest rate is set by policymakers to rise when there is a home real depreciation (an increase in $q_{t}$ ). There is real interest rate smoothing in which the ex ante real interest rate at time $t$ responds to the lagged ex post real interest rate. Under this assumption on parameters, the eigenvalues of the matrix $B$ in equation (2.12) are given by $1 / \beta, \mu_{1}$, and $\mu_{2}$, where

$$
\mu_{1}=\frac{1}{2}\left(1+\alpha+\delta / \beta+\sqrt{(1+\alpha+\delta / \beta)^{2}-4 \alpha}\right)>1
$$

and $\mu_{2}=\alpha / \mu_{1}<1$.

The solution for the real exchange rate in this case is given by:

$$
q_{t}=\mu_{2} q_{t-1}+\frac{(1-\beta)(1-\alpha \beta)-\delta}{(1-\alpha \beta)\left[(1-\beta)\left(\alpha-\mu_{1}\right)+\delta \mu_{1}\right]}\left(\varepsilon_{t}-\varepsilon_{t}^{*}\right)
$$

\footnotetext{
${ }^{3}$ In this derivation, we have used the fact that $\tilde{r}_{t}^{*}-\tilde{r}_{t}=0$. The difference in the Wicksellian real interest rates equals the expected change in the real exchange rate under flexible prices, which here is zero given identical preferences.

${ }^{4}$ See Blanchard and Kahn (1980) for the method of solving a system of rational expectations difference equations such as (2.12),
} 
With some labor, it can be shown that the coefficient in front of the monetary shocks is negative. This means that a Home monetary policy contraction (or a Foreign monetary expansion) leads to a Home real appreciation.

The expected rate of convergence of the real exchange rate toward purchasing power parity is determined by the eigenvalue $\mu_{2}$. We see from (2.14) that $E_{t} q_{t+1}=\mu_{2} q_{t}$. Since $\mu_{2}=\alpha / \mu_{1}<1$, we have that $\mu_{2} \leq \alpha$. The real exchange rate can be no more persistent than the degree of interest rate smoothing. If there is no interestrate smoothing, the real exchange rate adjusts immediately to its purchasing power parity level even when prices are sticky through movements in the nominal exchange rate. Benigno (2004) first pointed out how real exchange rate persistence might be independent of the sluggishness of price adjustment in a New Keynesian model, and illustrated the role of interest-rate smoothing. We have assumed that the frequency of price adjustment for home and foreign goods is identical. Benigno shows that when the speed of adjustment is different, then relative prices and hence real exchange rates adjust more slowly.

It is also the case that $\mu_{2} \leq \theta$, where $\theta$ is the probability that a firm's price will not change during the period. In other words, an upper limit for the persistence of the real exchange is given by the persistence of nominal price stickiness. Rogoff (1996) coined the phrase the "purchasing power parity puzzle" to refer to the fact that real exchange rates in advanced countries converge very slowly (an estimated half life of three to five years) yet are very volatile. As we will see, potentially monetary sticky-price models can account for the volatility of the real exchange rate, but the implication of many models is that real exchange rate adjustment should be no more sluggish than nominal price adjustment. It is not plausible that nominal prices have a halflife of three to five years, so the models seem incapable of accounting for real exchange rate persistence. One extension of the model is to allow for different preferences in the Home and Foreign countries, allowing the possibility that even in the long run purchasing power parity does not hold. Let $u_{t}=\lim _{j \rightarrow \infty} E_{t}\left(q_{t+j+1}\right)$ be the longrun equilibrium real exchange rate. We can write

$$
q_{t}=\left(q_{t}-u_{t}\right)+u_{t} .
$$

In the model we have considered so far, $u_{t}=0$, but more generally nominal price adjustment may explain persistence in $q_{t}-u_{t}$. The overall slow convergence of the real exchange rate might be governed by the persistence of the equilibrium real exchange rate, $u_{t}$, so a resolution to the purchasing power parity puzzle may require a fleshed-out model of equilibrium deviations from purchasing power parity. ${ }^{5}$

We move on to another special case of (2.12). We will allow for persistence in the monetary policy errors, but will now assume there is no interest rate smoothing, so $\alpha=0$. In this case, the system (2.12) reduces to two equations. The inflation differential, $\pi_{t}-\pi_{t}^{*}$ and the the real exchange rate, $q_{t}$, have forward-looking solutions. Each can be expressed as the sum of two infinite sums. Each infinite sum can be interpreted as a

\footnotetext{
${ }^{5}$ Engel (2000), however, argues that in practice the variance of $u_{t}$ is so small relative to the variance of $q_{t}-u_{t}$ that it cannot plausibly account for the measured persistence of the real exchange rate.
} 
present discounted value of current and expected future exogenous variables, $\varepsilon_{t}-\varepsilon_{t}^{*}$ (the relative errors in the Taylor rules), with the discount factors being the inverses of the two eigenvalues of $B$. Because the solutions are entirely forward-looking, as we noted above, there is no "endogenous persistence" in the real exchange rate. It will only be persistent if $\varepsilon_{t}-\varepsilon_{t}^{*}$ is persistent.

A special case helps to illustrate this point. We can express the solution for $q_{t}$ very simply in the special case in which $\sigma \beta=1$, the special case of our assumption above that $\sigma+\alpha=1 / \beta$, when $\alpha=0$ :

$$
q_{t}=\frac{-\beta}{\delta+\beta} \sum_{j=0}^{\infty}\left(\frac{\beta}{\delta+\beta}\right)^{j} E_{t}\left(\varepsilon_{t+j}-\varepsilon_{t+j}^{*}\right) .
$$

The dynamics of $q_{t}$ are determined by the dynamics of $\varepsilon_{t}-\varepsilon_{t}^{*}$. For example, suppose $\varepsilon_{t}-\varepsilon_{t}^{*}$ follows a firstautocorrelation, with an autocorrelation coefficient of $\rho_{\varepsilon}$, (and $0<\rho_{\varepsilon}<1$ ). The solution for the real exchange rate is given by:

$$
q_{t}=-\frac{\beta}{\delta+\left(1-\rho_{\varepsilon}\right) \beta}\left(\varepsilon_{t}-\varepsilon_{t}^{*}\right)
$$

In this relationship, $q_{t}$ follows a first-order autoregression, and its persistence is determined by the persistence of $\varepsilon_{t}-\varepsilon_{t}^{*}$.

The sluggishness of prices does not affect the persistence of the real exchange rate in this New Keynesian model, but stickier prices do lead to a more volatile exchange rate. A smaller value of $\delta$ indicates less frequent price adjustment. From equation (2.16), we can see that smaller $\delta$ leads to a higher variance of $q_{t}$. A smaller $\delta$ in equation (2.15) increases the weight on expected future fundamentals in the discounted sum, which magnifies the effect of a change in those fundamentals on the real exchange rate.

We must find a solution for $\pi_{t}-\pi_{t}^{*}$ to get a solution for the nominal exchange rate. Keeping with the case of $\sigma \beta=1$, we find:

$$
\pi_{t}-\pi_{t}^{*}=\delta E_{t} \sum_{j=0}^{\infty} \beta^{j} q_{t+j}
$$

When $\varepsilon_{t}-\varepsilon_{t}^{*}$ follows a first-order auto regression, we have:

$$
\pi_{t}-\pi_{t}^{*}=-\left(\frac{\delta \beta}{\delta+\beta\left(1-\rho_{\varepsilon}\right)}\right)\left(\frac{1}{1-\beta \rho_{\varepsilon}}\right)\left(\varepsilon_{t}-\varepsilon_{t}^{*}\right) .
$$

We see from (2.16) and (2.18) that the real exchange rate and the relative inflation rates are stationary when the exogenous variables are first-order autoregressions. ${ }^{6}$ The relative consumer price level, $p_{t}-p_{t}^{*}$, clearly has a unit root. This implies that the nominal exchange rate also has a unit root:

(2.19) $s_{t}=q_{t}+\pi_{t}-\pi_{t}^{*}+p_{t-1}-p_{t-1}^{*}$.

\footnotetext{
${ }^{6}$ And, more generally, when they are stationary.
} 
Combining equation (2.19) with the solutions for the real exchange rate in (2.16) and the relative inflation rate in (2.18) gives a full solution for the nominal exchange rate in terms of the current values of exogenous variables $\left(\varepsilon_{t}-\varepsilon_{t}^{*}\right)$ and the lagged endogenous variable, $p_{t-1}-p_{t-1}^{*}$.

While there are many variants of open-economy New Keynesian models, most have not focused on the implications of the model for exchange-rate dynamics ${ }^{7}$. Benigno and Benigno (2008) examine the dynamics of the nominal exchange rate in a PCP model similar to the one considered here. They show that when not targeted by monetary policy, the nominal exchange rate will have a unit root. If monetary policy targets a particular level for the nominal exchange rate, it will be stationary. Policy rules that target the real exchange rate or the terms of trade (perhaps indirectly, by targeting output gaps that depend on these variables) will influence the volatility and persistence of those variables.

Betts and Devereux $(1996,2000)$ examine the implications of LCP for nominal exchange rate behavior. Because prices are set in the buyers' currencies, they are not as sensitive to nominal exchange rates as they are under PCP. As a result, nominal exchange rates have a small effect in the short run on relative prices faced by consumers. The expenditure-switching effect of exchange rates on demand is diminished. There still may be wealth effects on consumer demand - for example, the profits of Home firms (owned by households) increase in Home currency terms with a depreciation of the Home currency. Or there may be wealth effects operating through the effects of exchange rates on the value of securities that are denominated in either the Home or Foreign currency. Overall, however, the equilibrating role of the exchange rate appears to be smaller under LCP, which in turn means that larger exchange rate changes are required to bring markets into equilibrium. Betts and Devereux find that nominal exchange rates may be substantially more volatile under LCP. ${ }^{8}$ Devereux and Engel (2002) push this idea farther by minimizing or eliminating wealth effects through various assumptions. Then they show that the exchange-rate volatility can be unboundedly high, because in the limit the exchange rate is "disconnected" from the real economy.

Obstfeld and Rogoff (2001) coin the term "exchange-rate disconnect" to encapsulate two puzzles. On the one hand, as in the context above, changes in the exchange rate seem to have only small effects on the real economy. Even very large swings in nominal exchange rates in advanced countries seem to have quite small effects on output, inflation, unemployment and even the trade balance. On the other hand, there seems to be very little evidence that the supposed determinants of exchange rates - monetary policy and the determinants of real income and inflation - can explain exchange-rate movements. This is true in two senses: the correlation of the exchange rate with the economic fundamentals is low, and the economic models are not very useful for

\footnotetext{
${ }^{7}$ Note, however, that the first of the open-economy New Keynesian models, Obstfeld and Rogoff (1995a), emphasizes the comparison of exchange rate dynamics in their model to the Dornbusch model. Kollman (2001) examines exchange rate dynamics in a model with Calvo price setting. Hau (2000) and Dotsey and Duarte (2008) show how the presence of nontraded goods influences exchange rate dynamics in New Keynesian models. Landry (2009) considers a two-country model with state-dependent pricing, and demonstrates the effects of monetary shocks on exchange rates.

${ }^{8}$ The benchmark is the PCP model of Obstfeld and Rogoff (1995a), which is the original open-economy New Keynesian model.
} 
forecasting changes in the exchange rate. We will return to the latter problem below. As to the contemporaneous correlation between exchange rates and fundamentals, some insight can be gotten by considering the solution for the real exchange rate in equation (2.15). As above, assume that the relative monetary shocks follow a first-order autoregression (define $\varepsilon_{t}^{R} \equiv \varepsilon_{t}-\varepsilon_{t}^{*}$ ):

$$
\varepsilon_{t}^{R}=\rho_{\varepsilon} \varepsilon_{t-1}^{R}+\omega_{t}, \quad 0<\rho_{\varepsilon}<1 .
$$

In the solution (2.16), we assumed in effect that $E_{t} \omega_{t+j}=0$ for all $j>0$, but now we assume that potentially there is a signal at time $t$ of future monetary policy shocks. We assume the signals are uncorrelated with the current and past values of $\varepsilon_{t}^{R}$. We find:

$$
q_{t}=-\left(\frac{\beta}{\delta+\beta\left(1-\rho_{\varepsilon}\right)}\right)\left[\varepsilon_{t}^{R}+N_{t}\right], \quad \text { where } N_{t} \equiv E_{t} \sum_{j=1}^{\infty}\left(\frac{\beta}{\delta+\beta}\right)^{j} \omega_{t+j} .
$$

$N_{t}$ is the component of the real exchange rate that incorporates news about the future. Let $q_{t}^{N}$ represent the solution for the real exchange rate when there is news, in equation (2.21) and $q_{t}^{N N}$ be the solution when there is no signal about the future, as in equation (2.16).

Since $N_{t}$ is uncorrelated with $\varepsilon_{t}^{R}$, then clearly

$$
\operatorname{var}\left(q_{t}^{N}\right)>\operatorname{var}\left(q_{t}^{N N}\right)
$$

When markets have sources of news beyond the current realization of the economic fundamentals, the variance of the real exchange rate increases. It is also less correlated with the current fundamentals, which follows from the fact that $\operatorname{cov}\left(q_{t}^{N}, \varepsilon_{t}^{R}\right)=\operatorname{cov}\left(q_{t}^{N N}, \varepsilon_{t}^{R}\right)$, but $\operatorname{var}\left(q_{t}^{N}\right)>\operatorname{var}\left(q_{t}^{N N}\right)$. Potentially, news plays an important role in accounting for the lack of correlation between the current values of economic fundamentals and the real exchange rate, as with any asset price that is forward-looking.

News may play a smaller role in accounting for real exchange rate volatility. Equation (2.22) is an example of the general result (extending Shiller (1981)) that when an asset price is given by a present value of expected fundamentals that are stationary, the variance of the asset price increases when the market has more information about the future. However, West (1988) shows that the variance of innovations (unexpected changes) in the asset price fall when there is more information, a result that does not depend on stationarity of the fundamentals. Maybe even more surprisingly, Engel (2005) shows that the variance of changes in the asset price falls with more information, so that, if the fundamentals or stationary or have a unit root:

$$
\operatorname{var}\left(q_{t}^{N}-q_{t-1}^{N}\right)<\operatorname{var}\left(q_{t}^{N N}-q_{t-1}^{N N}\right) .
$$

That is, news can account for a high variance in the real exchange rate, but not for a high variance in the change in the real exchange rate.

In sum, because asset prices (such as exchange rates) are forward-looking, their correlation with the current fundamentals may be low because there is a news component driving the asset price. This same news component can account for a high unconditional variance of the real exchange rate, but not for a high variance 
in the change in the real exchange rate.

An alternative view of the exchange rate disconnect puzzle is that exchange rates are driven by noise something other than the economic fundamentals. Jeanne and Rose (2002) and Devereux and Engel (2002) examine models in which a small amount of noise trading can lead to a sizeable component of exchange rate movements that is unrelated to fundamentals. A related literature examines how order flow aggregates information of different traders. In the models of Evans and Lyons (2002a, 2008), Evans (2002, 2010), and Bacchetta and van Wincoop (2006), this imperfect knowledge, not only of the economic fundamentals but also imperfect knowledge by one agent of another's expectations, leads to fluctuations in exchange rates that are greater than those predicted from simple models based on economic fundamentals.

\section{2.b Current account balances and exchange rates}

In policy-related work and in older descriptive models, the current account balance is often identified as an important determinant of exchange rates. From a general equilibrium viewpoint, this is difficult to interpret current account balances and exchange rates are both determined in the macroeconomic system as a whole, and are functions ultimately of exogenous variables. However, there are intuitive links between the two variables that suggest that there might be dynamic relationships between them. As exchange rates change, when goods prices are sticky, relative international costs and prices change, which in turn might influence import demand and export supply. In reverse, to unwind a current account imbalance, some exchange-rate adjustment might be required. In addition, current account imbalances lead to changes in wealth in one country relative to another, which might have feedback effects on exchange rates.

A simple generalization to the model presented in the previous section illustrates how these forces might work. Allow "home bias" in consumption - each country's households put a relatively higher weight on consumption of the good produced within their own country:

$$
p_{t}=v p_{H t}+(1-v) p_{F t}, \quad p_{t}^{*}=v p_{F t}^{*}+(1-v) p_{H t}^{*} .
$$

Under home bias, $v>1 / 2$. Expressing things in terms of inflation:

$$
\pi_{t}=v \pi_{H t}+(1-v) \pi_{F t}, \pi_{t}^{*}=v \pi_{F t}^{*}+(1-v) \pi_{H t}^{*} .
$$

Using equations (2.6) and (2.7) and their counterparts for pricing of Foreign goods, we obtain:

$$
\pi_{t}-\pi_{t}^{*}=\delta(2 v-1)\left(w_{t}-s_{t}-w_{t}^{*}\right)+\delta\left(q_{t}-u_{t}\right)+\beta E_{t}\left(\pi_{t+1}-\pi_{t+1}^{*}\right)
$$

As in section 2.a, $u_{t}$ is the level the real exchange rate would take on if prices were flexible. In this case, $u_{t}=(2 v-1)\left(a_{t}-a_{t}^{*}\right)$. Under flexible prices, an increase in Home productivity relative to Foreign reduces the price of Home goods, $p_{H t}-p_{F t}$, proportionately. Under home bias, this reduces the relative price of Home's consumption basket, implying an increase in $u_{t}$.

Suppose in each country, the utility each period is a power function of consumption, and linear in labor input. In the Home country, for example, this is given by 


$$
\frac{1}{1-\sigma} C_{t}^{1-\sigma}-L_{t}, \sigma>0
$$

where $C_{t}$ is consumption and $L_{t}$ is labor supply. The first-order condition that sets the marginal rate of substitution between consumption and leisure to the real wage is, in logs,

$$
\text { (2.26) } w_{t}=p_{t}+\sigma c_{t} \text {. }
$$

We can now define:

$$
\vartheta_{t} \equiv w_{t}-s_{t}-w_{t}^{*}=\sigma\left(c_{t}-c_{t}^{*}\right)-q_{t} .
$$

The log of the purchasing power of a unit of Home currency is given by $-p_{t}$, so the log of the marginal utility of of consumption of a unit of Home currency for Home consumers is $-\sigma c_{t}-p_{t}$. The $\log$ of the marginal utility of a unit of Home currency for Foreign consumers is $-\sigma c_{t}^{*}-s_{t}-p_{t}^{*}$. So $\sigma\left(c_{t}-c_{t}^{*}\right)-q_{t}$ is the $\log$ of the ratio of the marginal utility of consumption of a unit of Home currency for Foreign consumers relative to Home consumers. Similarly, $w_{t}-s_{t}-w_{t}{ }^{*}$ is the $\log$ of the marginal utility of leisure that can be bought for a unit of Home currency, in the Foreign country relative to the Home country. If financial markets are complete, so there is a nominal contingent claim traded for each state of the world, $\vartheta_{t}$ is a constant (set equal to zero when countries have equal wealth.) Equation (2.12) still completely describes the dynamics of the economy when markets are complete, except that $q_{t}$ in (2.12) is replaced with $q_{t}-u_{t}$. (The relative monetary policy rules in this case are given by $i_{t}-i_{t}^{*}=\tilde{r}_{t}-\tilde{r}_{t}^{*}+\sigma\left(\pi_{t}-\pi_{t}^{*}\right)$, where the relative Wicksellian real interest rates equal the expected change in the expected Wicksellian real exchange rate by interest parity: $\left.\tilde{r}_{t}-\tilde{r}_{t}^{*}=E_{t} u_{t+1}-u_{t} \cdot\right)$

When markets are incomplete, $\vartheta_{t}$, varies over time. $\vartheta_{t}$ is the marginal utility of an additional unit of wealth for Home relative to Foreign households, so it falls when Home wealth rises relative to Foreign wealth. There is a role for current account imbalances to influence the macroeconomy in general, and the exchange rate in particular, because when a country runs a current account imbalance, its net claims on the rest of the world change. Ceteris paribus, if Home has a current account surplus at time $t$, its wealth increases between $t$ and $t+1$, so $\vartheta_{t+1}-\vartheta_{t}$ will be positive. In the New Keynesian model, higher relative wealth in the Home country is associated with higher relative wages in Home (by equation (2.27).) An increase in wealth changes the marginal rate of substitution between consumption and leisure, tending to raise consumption and reduce labor supply. This leads to higher relative inflation in the prices of Home-produced goods, which in turn implies higher relative consumer price inflation in the Home country (equation (2.25)) under home bias. Monetary policymakers react to higher inflation by raising nominal interest rates, which will appreciate the currency. There is a self-equilibrating mechanism at work here. If some exogenous shock depreciates Home's currency in real terms, the current account of Home will rise and it will accumulate claims on the Foreign country. We have decribed how that real depreciation is reversed as wealth accumulates. 
The particular way in which current account balances correlate with exchange rates depends on the specifics of the model - the structure of asset markets and goods markets. The channel through which the current account affects the economy is somewhat different than in the descriptive models of the 1970s. Some models posited a portfolio balance channel - changes in relative wealth affected relative demands for risky assets - but that link is not present under our uncovered interest parity assumption. ${ }^{9}$ Another channel in the 1970s models was a link from wealth to money demand. If the money demand includes a wealth term, then current account balances may affect money demand. In contrast, in the New Keynesian model, an increase in wealth affects the marginal utility of leisure. Under our utility specification, the wage is driven up, which increases the relative cost of producing goods in the Home country.

Cavallo and Ghironi (2002) investigate the properties of exchange rates in a New Keynesian model in which asset markets are incomplete in that only nominal non-state-contingent bonds are traded. ${ }^{10}$ The set-up of the model is similar to the one described here, except that there is population growth in an overlappinggenerations framework as new households are born into the economy. Households maximize utility that depends on consumption of Home and Foreign goods, and there is home bias in preferences. Cavallo and Ghironi assume that the law of one price holds for all goods: goods prices are set in the currency of the producer. There is a quadratic cost to adjusting prices which results in aggregate price dynamics that are identical to those under Calvo pricing. The accumulation of claims on foreigners affects exchange rates through a channel similar to the one described above. However, different assumptions on preferences and monetary policy imply that an accumulation of claims on the Foreign country leads to a Home real depreciation. Cavallo and Ghironi assume identical Home and Foreign preferences, so purchasing power parity holds at all times. However, monetary policy targets domestic output. When wealth increases, labor supply falls, leading to lower Home output and therefore a drop in the Home interest rate, which in turn causes a depreciation.

Ganelli (2005) examines a similar model to trace the effects of fiscal policy on exchange rates. One important difference between Ganelli's model and the New Keynesian models such as Cavallo and Ghironi is that Ganelli assumes that the money supply is the instrument of monetary policy, and that money supply growth is exogenous. Money demand depends on home consumption and the home interest rate. The effects of a fiscal expansion, however, work through familiar channels. A tax cut, for example, leads to an expansion in Home demand. Home households expand demand in an overlapping generations framework because they will not bear the full burden of future taxes that must be raised to pay off government debt. The increase in home consumption results in an increase in money demand. For a given Home money supply, interest rates must increase, which leads to a Home currency appreciation.

In a representative agent two-country New Keynesian model with imperfect capital markets, Benigno and Thoenissen (2003) examine the effects of productivity shocks on exchange rates. In this model, there are three

\footnotetext{
${ }^{9}$ Blanchard, Giavazzi and Sa (2005) use such a model to analyze the dynamics of the needed U.S. dollar exchange rate change that might facilitate adjustment of the U.S. current account deficit.

${ }^{10}$ See also Ghironi (2008).
} 
factors that influence the behavior of real and nominal exchange rates. First, there are nontraded goods. In the long run, an increase in productivity in the traded sector leads to a real appreciation through the traditional Balassa-Samuelson effects. Second, there is home bias in preferences. This channel tends to promote a real depreciation in the long run in response to Home productivity shocks in the traded sector. As supply of the Home good increases, its price relative to Foreign traded goods falls. This reduces the aggregate consumer price level in the Home country relative to the Foreign because Home goods are weighted more heavily in the Home consumption basket (the home bias assumption.) These two channels work in opposite directions for the long-run determination of real exchange rates. In the short run, firms set prices in the currency of consumers. A Home productivity increase leads to higher potential Home output. As potential output rises, inflationary pressures decline, which in turn leads policymakers to reduce interest rates. This reduction in interest rates contributes to a short run real and nominal Home currency depreciation.

An important related contribution is Gourinchas and Rey (2007). They begin with the accounting identity: (2.28) $N A_{t+1}=R_{t+1}\left(N A_{t}+N X_{t}\right)$

where $N A_{t}$ is the country's net foreign assets, and $N X_{t}$ refers to net exports. $R_{t+1}$ is the gross return on the country's portfolio of net foreign assets. Imposing a no-Ponzi condition, Gourinchas and Rey then derive an approximation around values in a deterministic economy in which variables may be trending:

$$
n x a_{t} \approx-\sum_{j=1}^{\infty} \rho^{j} E_{t}\left(r_{t+j}+\Delta n x_{t+j}\right) .
$$

The specifics of the approximation are complex, but we can think of $n x a_{t}$ as a weighted sum of the log of foreign assets and the log of exports less a weighted sum of the log of foreign liabilities and the log of imports. Gourinchas and Rey call this the "cyclical external imbalance". Equation (2.29) tells us that, subject to approximation error, $n x a_{t}$ should predict perfectly the discounted sum of $r_{t+j}+\Delta n x_{t+j}$, where $r_{t+j}$ is a measure of the return on foreign assets. Equation (2.29) is derived only from the budget identity (2.28), and so must hold up to the approximation error.

The equation has the following interpretation. Suppose a country has a negative value for its cyclical external imbalance, perhaps because it is a net debtor. There are two possible sources of adjustment toward cyclical balance. On the one hand, the country could run trade surpluses in the future, which Gourinchas and Rey call the "trade channel". Alternatively, the country may adjust through the "valuation channel": returns on net foreign assets may be higher than average. An important possible avenue for higher expected returns is through currency depreciation.

Equation (2.29) shows that $n x a_{t}$ is the market's best forecast of $-\sum_{j=1}^{\infty} \rho^{j}\left(r_{t+j}+\Delta n x_{t+j}\right)$. Gourinchas and Rey are particularly interested in the hypothesis that the predictability of this sum arises because of predictability of future returns. Especially relevant for our purposes is the possibility that a particular 
component of the returns, the currency depreciation, may be predictable. Gourinchas and Rey present several types of empirical evidence that support this hypothesis using data on $n x a_{t}$ constructed for the U.S., quarterly, 1952:I to 2004:I.

Using the methods of Campbell and Shiller (1988), Gourinchas and Rey find that they cannot reject the intertemporal restrictions implied by equation (2.29). In a sense, this is a test of whether a budget constraint holds (along with the approximations used to derive equation (2.29)), so perhaps this finding is not surprising. But Gourinchas and Rey go further, to test whether $n x a_{t}$ can forecast returns and exchange rate changes. Consider their findings for an FDI-weighted U.S. exchange rate. There is evidence of in-sample predictability derived from regressing $s_{t+1}-s_{t}$ on $n x a_{t}$ and other controls over the sample, with a finding of a statistically significant coefficient on $n x a_{t}$. This predictability remains even over longer horizons. That is, $n x a_{t}$ is a significant (in-sample) predictor of exchange rate changes over horizons as long as 24 quarters. Moreover, as we will discuss in the next section, they find that $n x a_{t}$ is able to forecast the change in this dollar exchange rate out of sample.

We next turn to a more comprehensive survey of recent empirical work on exchange rates.

\section{Empirical Studies of Exchange-Rates}

Much of the earliest empirical work on testing models of exchange rates evaluated models by their insample fit. While this work continues to be valuable, ever since the seminal paper of Meese and Rogoff (1983) the "gold standard" for evaluation of exchange-rate models has been their usefulness in predicting exchange rates. We first survey recent in-sample evaluation of exchange-rate models before turning to the out-of-sample exercises.

\section{3.a In-sample exchange-rate model evaluation}

We can further divide the within-sample evaluations into methods that rely on single-equation methods (such as in the early work of Frankel, 1979); methods that use VARs or evaluate general equilibrium models; and the approach of using the model's implications about the response of exchange rates to market news.

\section{Single-equation empirical models}

Most empirical work on exchange rate models has focused on finding better tests for uncovering the link, if any, between the monetary fundamentals and exchange rates outlined in the models of section 2 . Few recent papers have looked for new economic variables that are important in accounting for exchange rate movements. As has been noted already, Gourinchas and Rey (2007) have explored the role that external imbalances play in driving exchange rates. Another line of research has related exchange rates for commodity-exporting countries to prices of those commodities. Chen and Rogoff (2003) uncover empirical links between the real exchange rates of Canada, Australia, and New Zealand, and the real prices of commodities that they export (measured as weighted averages of the world prices of commodities, with weights determined by their shares in each 
country's total commodity exports.) Chen et. al. (2010) extend this finding with evidence that exchange rates have forecasting power for commodity prices at short horizons in these countries.

A literature has developed that asks whether nominal exchange rates are related in the long-run to the monetary and real variables that the models say are supposed to drive them. Since exchange rates and the fundamentals are non-stationary unit root (I(1)) random variables, the research question has been posed: are exchange rates and the fundamentals cointegrated? A key contribution in this area is Groen (2000). Using a panel of quarterly data for fourteen major currencies from 1973:I to 1994:I with the U.S. dollar, and alternatively the German mark, as numeraire, Groen rejects the null hypothesis that the exchange rate is not cointegrated with relative log money supplies and relative log GDPs. Mark and Sul (2001) use quarterly data for a panel of 19 countries from 1973:I to 1997:I, and test the null hypothesis is $s_{t}-\left(m_{t}-m_{t}^{*}\right)+\left(y_{t}-y_{t}^{*}\right)$ contains a unit root. They consider the U.S., Switzerland, and Japan as numeraire countries, and they strongly reject the null of no cointegration. Rapach and Wohar (2002) find cointegration between U.S. dollar exchange rates and these economic fundamentals using annual data for fourteen countries with samples of over 100 years. ${ }^{11}$ Cerra and Saxena (2010) extend the analysis to an unbalanced panel of 98 developing and developed countries with annual data from 1960 to 2004. They find strong evidence for cointegration in their entire sample, as well as sub-samples consisting only of developing and of developed countries.

Tests for cointegration assume a linear process for the adjustment of exchange rates and the economic fundamentals. Several papers have found evidence of non-linear adjustment - specifically, when the exchange rate is far out of line with its "fundamental value", the exchange rate and fundamentals converge more quickly. Suppose $s_{t}-f_{t}$ is stationary, where $f_{t}$ is a linear combination of economic variables that determine the exchange rate in the long run. When the absolute value of $s_{t}-f_{t}$ is large, the convergence between $s_{t}$ and $f_{t}$ may be faster then when $s_{t}-f_{t}$ is much smaller. Taylor and Peel (2000), and others, find nonlinear relationships between the exchange rate and $\left(m_{t}-m_{t}^{*}\right)-\left(y_{t}-y_{t}^{*}\right)$ using various nonlinear models and exchange rates. Taylor and Peel, for example, estimate models for the dollar/pound and dollar/mark exchange rates using quarterly data from 1973:I to 1996:IV. They find evidence to support an exponential smoothedtransition autoregression (ESTAR) specification. Under this specification, the speed of adjustment declines smoothly as $s_{t}-f_{t}$ declines to zero.

So far, the discussion has been about the empirical fit of the monetary model. The implication is that monetary policy exogenously sets money supply growth, and the exchange rate is ultimately determined by monetary growth and output growth in one country relative to another. Monetary policy research in the last twenty years has conformed more to the reality that central banks use the interest rate as the policy instrument rather than money supply growth, and that monetary policy is endogenous. The interest rate is set to react to

\footnotetext{
${ }^{11}$ However, in country by country tests, this paper finds the exchange rate is not cointegrated with fundamentals for Australia, Canada, Denmark, Norway, Sweden and the U.K.
} 
inflation, the output gap, and potentially other important economic variables. The New Keynesian models have developed to analyze open economies under such monetary regimes. Engel and West (2006) and Mark (2009) present similar empirical models based on Taylor rules such as (2.2) and uncovered interest parity. Both papers emphasize the forward-looking nature of the determinants of exchange rates. Engel and West specify a more sophisticated monetary policy rule than (2.2), with monetary policymakers setting interest rates to react to expected inflation, rather than current inflation, in their own countries. In addition to consumer price inflation, central banks in the Home and Foreign country are each concerned about the output gap $\left(\tilde{y}_{t}\right.$ and $\left.\tilde{y}_{t}^{*}\right)$ in their respective countries. Also they assume at least one of the countries reacts to exchange rate misalignments, and that purchasing power parity holds in the long run equilibrium, so that the interest rate responds to movements in the real exchange rate. Then we can specify the Home relative to Foreign monetary policy rules as:

$$
i_{t}-i_{t}^{*}=\gamma_{q} q_{t}+\gamma_{\pi} E_{t}\left(\pi_{t+1}-\pi_{t+1}^{*}\right)+\gamma_{y}\left(\tilde{y}_{t}-\tilde{y}_{t}^{*}\right)+\varepsilon_{t} . \quad \gamma_{q}>0, \gamma_{\pi}>1, \gamma_{y}>0
$$

By adding and subtracting Home relative to Foreign inflation, uncovered interest parity can be expressed as:

$$
i_{t}-i_{t}^{*}=E_{t} q_{t+1}-q_{t}+E_{t}\left(\pi_{t+1}-\pi_{t+1}^{*}\right) .
$$

Equations (3.1) and (3.2) can be two equations in a general equilibrium New Keynesian model. We discuss estimation of general equilibrium models below. To close the system, we would need to add price adjustment equations in each country and equations relating the output gap to the real exchange rate in each country.

Instead, Engel and West substitute (3.2) into (3.1) and rearrange to obtain

$$
q_{t}=\frac{1}{1+\gamma_{q}} E_{t} q_{t+1}-\frac{\left(\gamma_{\pi}-1\right)}{1+\gamma_{q}} E_{t}\left(\pi_{t+1}-\pi_{t+1}^{*}\right)-\frac{\gamma_{y}}{1+\gamma_{q}}\left(\tilde{y}_{t}-\tilde{y}_{t}^{*}\right)-\frac{1}{1+\gamma_{q}} \varepsilon_{t} .
$$

Then, solving the model forward, we obtain an expression for the real exchange rate in terms of present values of current and expected future relative inflation rates and output gaps (here, assuming $\varepsilon_{t}$ is mean-zero, i.i.d.):

$$
q_{t}=-\sum_{j=0}^{\infty}\left(\frac{1}{1+\gamma_{q}}\right)^{j} E_{t}\left\{\frac{\left(\gamma_{\pi}-1\right)}{1+\gamma_{q}}\left(\pi_{t+j+1}-\pi_{t+j+1}^{*}\right)+\frac{\gamma_{y}}{1+\gamma_{q}}\left(\tilde{y}_{t+j}-\tilde{y}_{t+j}^{*}\right)\right\}-\frac{1}{1+\gamma_{q}} \varepsilon_{t} .
$$

This equation shows that the real exchange rate is determined as a discounted present value of current and expected future output gaps and inflation rates (Home relative to Foreign in both cases). The equation delivers an interesting message: expected higher Home inflation (or expected higher Home output gaps) leads to a Home real appreciation. This surprising relationship holds because of the endogeneity of monetary policy. When expected inflation or the output gap is higher, the central bank raises the interest rate. When the stability condition, $\gamma_{\pi}>1$, holds, the interest rate rises sufficiently to increase real interest rates, precipitating a real appreciation.

Engel and West estimate the present value from a VAR that contains relative inflation rates, relative output gaps, and interest rate differentials. Using standard VAR forecasting equations, the forecasted discounted sum is constructed at each point in time. The paper uses monthly data for the U.S. and Germany from 1979:10 to 1998:12. The present value is estimated over this period, then compared with the actual dollar/deutschemark 
real exchange rate. That paper finds mildly positive support for the model: the model's implied real exchange rate has a correlation of 0.32 with the actual real exchange rate, though the correlation of changes in the model's implied real exchange rate with the actual real exchange rate is only 0.09. Mark's (2009) study uses similar techniques, though the details differ, producing a model real exchange rate for U.S./Germany, quarterly from 1976:I to 2007:III. A key innovation in Mark's study is to allow for a changing monetary policy rule, which the public learns about only over time by observing outcomes of economic variables. While the correlation of the model's implied real exchange rate with the actual real exchange rate is similar to Engel and West's in levels and slightly worse for short-horizon changes, it vastly improves on their fit in two ways. First, the model real exchange rate fit by Mark has volatility that is similar to that of the actual real exchange rate, while Engel and West's implied real exchange rate is much less volatile. Second, Mark's implied real exchange rate has relatively high correlation for long-horizon changes, in the range of 0.40 .

\section{VARs and Structural Macroeconomic Models}

An important strand of the empirical literature has attempted to measure the effects of monetary shocks on exchange rates in "structural" vector autoregressions (VARs). The seminal paper in this literature is Eichenbaum and Evans (1995), which considers a five variable VAR on U.S. data, containing a measure of output, inflation, nonborrowed reserves (assumed to be the policy instrument), U.S. relative to foreign interest rates, and the CPI real exchange rate. For various advanced countries relative to the U.S., Evans and Eichenbaum find that a U.S. monetary contraction leads to higher U.S. interest rates in the short run. The dollar appreciates in the short run. The key finding is that the maximum appreciation of the dollar does not occur immediately following the monetary policy shock. Depending on the currency, the maximum real appreciation occurs 24 to 39 months after the shock. ${ }^{12}$

As Eichenbaum and Evans note, this behavior of exchange rates is not consistent with uncovered interest parity. According to interest parity, if $i_{t}-i_{t}^{*}$ increases, then $E_{t} s_{t+1}-s_{t}$ should rise. If all other sources of interest rate variation are held constant and only monetary shocks lead to the increase in $i_{t}-i_{t}^{*}$, then the impulse response of the exchange rate to that shock should show a depreciation of the currency between period $t$ and period $t+1$. But Eichenbaum and Evans empirical finding is that the currency continues to appreciate after the initial monetary contraction, contradicting the implications of uncovered interest parity. This phenomenon has been dubbed "delayed overshooting."

Delayed overshooting could potentially account for the empirical puzzle noted at the outset of this essay, that the slope coefficient in equation (1.6) is generally estimated to be negative, implying $\operatorname{cov}\left(E_{t} s_{t+1}-s_{t}, i_{t}-i_{t}^{*}\right)<0$. The intuition of this line of reasoning is clear: when $i_{t}-i_{t}^{*}$ rise from a monetary shock, if $s_{t}$ falls and then $s_{t+1}$ falls even more, there is a drop in $s_{t+1}-s_{t}$ associated with the positive shock to

\footnotetext{
${ }^{12}$ However, Kim and Roubini (2000), using a different identification scheme, find that the maximum appreciation occurs within a few months of the monetary policy shock.
} 
$i_{t}-i_{t}^{*}$. However, it is important to note two caveats. First, monetary shocks are not the only determinant of interest rate and exchange rate movements. Even if monetary shocks tend to lead to a negative correlation of $i_{t}-i_{t}^{*}$ with $s_{t+1}-s_{t}$, there may be other forces that are important in driving these variables. The second caveat is that, even if monetary shocks are the most important or even the sole driver of exchange rates and interest rates, the logic of the dynamics we have described refers to innovations in $i_{t}-i_{t}^{*}$ and $s_{t+1}-s_{t}$. Even if innovations in $i_{t}-i_{t}^{*}$ and $s_{t+1}-s_{t}$ are negatively correlated, we may not have $\operatorname{cov}\left(E_{t} s_{t+1}-s_{t}, i_{t}-i_{t}^{*}\right)<0$.

Faust and Rogers (2003) cast doubt on the robustness of the delayed overshooting finding. They argue that there are a large number of plausible assumptions on the structure of VARs that can be used to identify monetary policy shocks. Considering various plausible identification assumptions, and taking into account parameter uncertainty, Faust and Rogers find no robust evidence to support delayed overshooting. Moreover, they conclude that it is unlikely that monetary policy shocks account for very much of the variance of the dollar exchange rate against the U.K. pound or German mark in the 1974:1 to 1997:12 period.

There continues to be a dispute in the literature over whether delayed overshooting is a robust feature of the data. Scholl and Uhlig (2008) use a sign restriction identification scheme and consider a VAR with the same variables as in Eichenbaum and Evans' study. They identify a U.S. monetary contraction by making the following assumptions on the first twelve impulse responses: the impulse response function of nonborrowed reserves (relative to borrowed reserves) is negative; U.S. interest rates relative to foreign interest rates are positive; and, prices are negative. They estimate the model with monthly data over the original EichenbaumEvans sample period, as well as a sample that is updated through 2002. In both samples, they find significant delays in the maximal response of the exchange rate, though the maximum delay is somewhat shorter in the longer sample compared to the original sample.

Bjornland (2009) instead uses long-run restrictions to identify monetary policy shocks. The assumption here is that monetary shocks have no effect on the long run real exchange rate. Then, in VARs using quarterly data from 1983:I to 2004:IV for four small countries (Australia, Canada, New Zealand, and Sweden), Bjornland finds that the maximum appreciation in response to a monetary shock occurs within one or two quarters.

The structural VARs are not fully specified dynamic models, in contrast to the general equilibrium New Keynesian models discussed in previous sections. Unfortunately, the New Keynesian models do not seem capable of explaining exchange rate movements. Calibrated versions of the model fail to match the volatility of exchange rates. For example, see Chari, Kehoe and McGrattan (2002) or Jung (2007). Models which include an exogenous (not modeled) shock to the uncovered interest parity relationship, such as Kollmann (2001), Bergin (2006), or Adolfson et. al. (2007), are more successful in accounting for exchange rate volatility.

Bergin (2006) performs structural estimation of New Keynesian models using maximum likelihood techniques, while Lubik and Schorfheide (2006) and Adolfson et. al. (2007) use Bayesian estimation methods. 
Both papers find some success with the models in accounting for exchange rate movements. Bergin in particular finds that the model fits the data better than a random walk model for exchange rates, in the sense that the in-sample one-period ahead forecast of the exchange rate outperforms the random walk forecast of no change. Moreover, it is not the case that the interest parity shocks are the primary drives of the exchange rate. More than half of the variance in exchange rates in the estimated model ise due to monetary shocks. Lubik and Schorfheide (2006) find less encouraging results for the exchange rate, but their model does not allow for endogenous deviations from purchasing power parity. The estimated model of Adolfson et. al. (2008) is able to match the persistence and volatility of real exchange rates by allowing time-varying pricing to market.

It is probably a fair assessment that rarely have estimated open-economy New Keynesian models been put to very rigorous tests of their ability to match the data. For example, none of these papers have reported the correlation of the implied model exchange rate with the actual exchange rate. More rigorous tests would include investigation of whether the model can capture the dynamic relationship between exchange rates and other macroeconomic variables, and whether the model is useful in producing forecasts of exchange rates. There are exceptions to this statement, however. Adolfson et. al. (2008) considers the ability of a New Keynesian model to forecast real exchange rates compared to several alternative statistical models. It finds the estimated New Keynesian structural model provides the best out-of-sample forecasts (as measured by lowest root mean-squared-error) at horizons of 1 to 8 quarters.

Juvenal (2011) presents an interesting hybrid between the structural VAR analysis and full model estimation. That paper builds a fully-specified New Keynesian model with multiple sources of shocks. Then, Juvenal simulates the model to derive the response of endogenous variables to exogenous shocks. The dynamics of the responses then are used to impose sign restrictions as in the approach of Scholl and Uhlig (2008). Juvenal finds that in fact monetary shocks account for a very small fraction of the variance of real exchange rates, while preference shocks (to the utility discount factor) account for a large fraction. A very similar approach is taken by Enders et. al. (2011). The primary focus of the paper is to investigate the effects of government spending and technology shocks on real exchange rates. They find that shocks to government spending lead to a real depreciation while a positive productivity shock in the trade sector leads to a real appreciation. Note that these reactions contrast to the predictions of the models of Ganelli (2005) and Benigno and Thoenissen (2003) discussed above. The reversal in sign of the response is possible within the New Keynesian model when the elasticity of substitution between Home and Foreign goods is sufficiently low and there is home bias in preferences, as in Corsetti et. al. (2008). In that case, for example, in the long run a Home productivity shock must lead to an increase in the price of the Home traded good. This leads to an increase in Home's wealth, which allows them to absorb the increased production of Home goods.

\section{Response to News}

The exchange rate is determined in general equilibrium and macroeconomic aggregates such as interest rates and output are not exogenous with respect to the exchange rate. The empirical work of the previous 
section is all aimed at identifying exogenous shocks - to monetary policy, exchange rates, technology - and tracing the effects of these shocks on exchange rates.

The literature that looks at the effects of news announcements on exchange rates takes another approach to finding exogenous variation. This literature examines exchange rate changes over very short time intervals at the time of news announcements. Over these intervals, the economic fundamentals that drive exchange rates are not likely to have changed much or at all, so that the primary driver of the exchange rate change is the news itself. Take the change in the exchange rate between time $t-\Delta$ and $t+\Delta$ from the Taylor rule model of Engel and West (2006), equation (3.4). A time period is one month in their model, while $\Delta$ is a fraction of an hour. We can write approximately

$$
s_{t+\Delta}-s_{t-\Delta} \approx-\sum_{j=1}^{\infty}\left(\frac{1}{1+\gamma_{q}}\right)^{j}\left(E_{t+\Delta}-E_{t-\Delta}\right)\left\{\frac{\left(\gamma_{\pi}-1\right)}{1+\gamma_{q}}\left(\pi_{t+j+1}-\pi_{t+j+1}^{*}\right)+\frac{\gamma_{y}}{1+\gamma_{q}}\left(\tilde{y}_{t+j}-\tilde{y}_{t+j}^{*}\right)\right\} .
$$

Because prices of consumer goods do not adjust over very short intervals, the change in the real exchange rate comes exclusively from changes in the nominal exchange rate, , so comparing this equation to equation (3.4), on the left-hand-side, the change in $q_{t}$ is taken to be $s_{t+\Delta}-s_{t-\Delta}$. On the right-hand-side, we have assumed that $u_{t}, \pi_{t}-\pi_{t}^{*}$, and $\tilde{y}_{t}-\tilde{y}_{t}^{*}$ do not change between $t-\Delta$ and $t+\Delta$. The notation $\left(E_{t+\Delta}-E_{t-\Delta}\right) z_{t+j}$ for any variable $z$ means $E_{t+\Delta} z_{t+j}-E_{t-\Delta} z_{t+j}$. According to (3.5), the change in the exchange rate over the very short interval is driven only by changes in expectations of future relative inflation rates and output gaps.

As noted above, the Taylor rule model has the implication that higher expected inflation or a higher output gap in the Home country leads to a Home real appreciation, assuming that the central bank follows a sufficiently stabilizing monetary policy $\left(\gamma_{q}>0, \gamma_{\pi}>1, \gamma_{y}>0\right)$. This prediction of the Taylor rule model tends to be borne out in empirical work on the impact of news.

The methods of studies of news announcements are all similar. Let $x_{t}$ be an announcement at time $t$. Some measure of the expected value of $x_{t}$ is required in order to measure the news content of the announcement. Typically studies use surveys that ask traders what they expect the announcement to be. Suppose $x_{t}$ is the announcement in July of the U.S. unemployment rate in June. $x_{t}^{e}$ is a survey measure of what traders expect the announced June unemployment number to be. Usually the survey is completed a few days before the announcement. The studies then examine the change in the exchange rate from immediately before to immediately after the announcement, by regressing $s_{t+\Delta}-s_{t-\Delta}$ on $x_{t}-x_{t}^{e}$. This regression is not looking at the change in the June unemployment rate on the exchange rate. Instead, it is looking at the impact effects on the exchange rate of news about unemployment that is contained in the announcement (which comes in July) of the unemployment rate that prevailed the previous month. $x_{t}^{e}$ is not a measure of the market's expectation of some future unemployment rate. It is the market's expectation of the announcement of a past unemployment rate. 
Andersen et. al. (2003) use exchange rate data recorded in 5-minute intervals for the U.S. dollar against five major currencies, in the period January, 1992 - December, 1998. They take announcements of 28 American economic news: data on GDP, employment, consumer prices, etc. In addition, they consider the effects on the dollar/deutschemark exchange rate of 13 German economic variables. They measure expectations of the U.S. variables from a survey of 40 money managers, conducted by International Money Market Services (MMS). Not surprisingly, news that the Federal Reserve has raised its target interest rate above expectations leads to a dollar appreciation within five minutes of the announcement. But also, any U.S. news that might be interpreted as the economy being stronger than expected, or inflationary pressures greater than expected, also leads to a dollar appreciation. On the other hand, news of greater than expected activity in Germany leads to an immediate dollar depreciation. Andersen et. al. (2007) confirm these findings in an extended sample that runs through the end of 2002.

Faust et. al. (2007) consider five-minute windows around the announcements of ten U.S. economic variables. They examine the response of dollar exchange rates and interest rates, and also use MMS to measure $x_{t}^{e}$. Their data run from January 1987 to December 2002. In all of the statistically significant cases, news that the economy is stronger than expected leads to a dollar appreciation, and also an increase in expected future interest rates as captured by the yield curve.

Ehrmann and Fratzscher (2005) make similar findings, for data covering Janary 1993 to Feburary 2003. They look at the daily changes in the exchange rate, measured at 6 p.m. New York time. They also use MMS to measure $x_{t}^{e}$. In general, they find that good news for the U.S. economy appreciates the dollar, while good news for the German economy appreciates the German currency.

Clarida and Waldman (2008) compare the response of exchange rates to news about inflation rates in countries that explicitly follow inflation targeting monetary policy to countries that do not. While they find that news of higher than expected inflation tends to appreciate the currency in all countries, the effect is stronger and more statistically significant in the inflation-targeting countries. Moreover, the effect was small and insignificant in two countries (the U.K. and Norway) before they adopted inflation-targeting but became large and significant when the policy regime changed.

Fatum and Scholnick (2006) take a similar approach to these papers, but they do not use MMS to measure the expectation of the markets. Instead, they look at the Fed Funds futures rate as a measure of the expected interest rate. They then look at how day-to-day changes in the exchange rate relate to changes in the Fed Funds futures rate on days in which the actual Fed Funds rate stays constant. The change in the exchange rate might be attributed to changes in expectations of monetary policy. The paper controls for six U.S. economic news announcements, changes in interest rates in other countries, and foreign exchange intervention by foreign central banks. The study looks at the U.S. dollar relative to the yen, pound, and deutschemark from March 
1989 to April 2001. ${ }^{13}$ The paper finds strong evidence that changes in expectations of future monetary policy affect exchange rates. When the market increases its expectations of the Fed Funds rate, the dollar appreciates.

\section{3.b Out-of-Sample Forecasting}

With a few exceptions, the studies surveyed above evaluate the in-sample fit of exchange-rate models. In recent years, tests of the out-of-sample forecasting power of exchange-rate models have become the gold standard for model assessment. The predecessor of this approach is the famous Meese and Rogoff (1983) paper, though that paper actually tested the out-of-sample fit of the models, rather than their forecasting ability. Mark (1995) is the progenitor of the more recent forecasting literature.

\section{Empirical studies}

Mark (1995) hypothesizes that an equation of the form:

$$
s_{t+k}-s_{t}=\alpha_{k}+\beta_{k}\left(f_{t}-s_{t}\right)+u_{k, t+k}
$$

will be useful in forecasting the exchange rate at a $k$-period horizon. $f_{t}$ is measured as some "fundamental" value of the nominal exchange rate. Mark considers two different candidates for $f_{t}$. One is the purchasing power parity value for the exchange rate, $p_{t}-p_{t}^{*}$. The other is taken from the monetary model, assuming money demand has a unitary income elasticity: $m_{t}-y_{t}-\left(m_{t}^{*}-y_{t}^{*}\right)$. Equation (3.6) is not derived from the dynamics of any specific exchange rate model. Instead, Mark makes the intuitive assumption that $f_{t}$ represents the long-run equilibrium value for the exchange rate. Equation (3.6) has the interpretation that, for some unmodeled reasons, the exchange rate is not always equal to its equilibrium value, and between periods $t$ and $t+k$ the log change in the exchange rate will be linearly related to the gap between the exchange rate and its fundamental value at time $t . u_{k, t+k}$ is the error for the $k$ th horizon regression. Equation (3.6) is a simple equation that can be estimated within a sample, and used to forecast outside the sample.

Mark (1995) makes two uses of the equation. First, the study estimates (3.6) over the entire sample (quarterly observations from 1973:II to 1993:IV for the U.S., Canada, Germany, Japan and Switzerland) and tests the null that $\beta_{k}=0$. It is the second exercise that has sired the literature on out-of-sample forecasts as a tool for model evaluation. Mark estimates equation (3.6) for horizons of 1, 4, 8, 12, and 16 quarters, using only the data through 1981:III. The estimated model is then used to construct forecasts of exchange rates, which are compared to the actual exchange rates in the remainder of the sample. Mark calculates the root-mean-squared error (RMSE) of the model forecast compared to the random walk forecast (of no change in the exchange rate). He finds that for the U.S. dollar exchange rate relative to Germany, Japan, and Switzerland, the forecasting model has lower RMSE at many horizons, and always at the longer horizons (12 and 16 quarters). The model does not beat a random walk for the Canadian dollar exchange rate. Mark evaluates the significance of the forecasting power using Diebold-Mariano (1995) statistics, and bootstrapped statistics, concluding that there is

\footnotetext{
${ }^{13}$ The end date for the deutschemark is December 1998.
} 
significant evidence of forecasting power.

Mark's (1995) finding that equation (3.6) can be used to forecast exchange rates, currency-by-currency, out of sample did not hold up well to subsequent investigations. Kilian (1999) finds that Mark's results are not robust when the sample is extended, and when an error in Mark's bootstrap for the significance of the out-ofsample forecasts is corrected. Faust et. al. (2003) re-examined Mark's forecasting model making two changes. First, they introduced the use of "real time" data. Even though Mark estimated the model using data only through 1981:III, and tested the model's ability to forecast exchange rate changes in subsequent periods, Faust et. al. point out that some of the data used by Mark was revised by statistical agencies after the end of the estimation window. That is, the data would not have been available to forecasters in 1981:III. So Faust et. al. use archives of data published in previous years to construct real time data that would have been available to forecasters. They find that using the real-time data actually tends to produce better forecasts (lower RMSE) than using the revised data. However, they also find that the usefulness of equation (3.6) for forecasting exchange rates is very sensitive to the time period being examined. The equation loses forecasting power in most time periods except those around the time that Mark's study used.

Cheung et. al. (2005) casts further doubt on the forecasts generated by estimation of equation (3.6) currency-by-currency. In fact, Cheung et. al. consider not only the two measures of $f_{t}$ that Mark examines, but also measures that include interest rate differentials, trade balances, inflation differentials, and productivity differentials between countries. These other variables are included in various combinations to match singleequation models of the exchange rate that had been proposed in earlier literature. The models do not perform well in out-of-sample RMSE comparisons to the random-walk forecast. While Mark's models of $f_{t}$ do not require any parameter estimation, Cheung et. al. use rolling sample estimation of the parameters of the models. They consider forecasts at horizons of 1, 4 and 20 quarters, using the same currencies as Mark (1995), using data over the period 1973:II to 2000:IV. They look at forecast windows of 1987:II to 2000:IV and 1983:II to 2000:IV. In general, Cheung et. al. find little consistent evidence of forecasting power of the models. For some models, and some currencies, over some windows, the RMSE of the models' forecasts are lower than the random walk, but there is no consistent evidence that any model can outforecast the random walk consistently for any currency or horizon. ${ }^{14}$

Mark and Sul (2001) find better success using eighteen exchange rates and panel methods to estimate equation (3.6). In particular, their method forces the slope coefficient in equation (3.6) to be the same for all exchange rates in the panel, and also allows for a common time effect, but allows the intercepts to be different currency-by-currency. Mark and Sul estimate the model for both the monetary and the PPP measures of $f_{t}$, allowing alternatively the U.S. dollar, Japanese yen and Swiss franc to be the numeraire currency. The model is estimated on data from 1973:I to 1983:I, and then used to construct forecasts that can be compared to actual

\footnotetext{
${ }^{14}$ See Abhyankar et. al. (2005), who use an alternative measure of forecasting performance to find support for the monetary model over a random walk.
} 
exchange rate data that run through 1997:I. They again compare the RMSE of the model to the RMSE of the random walk forecast for each exchange rate, and construct bootstrap tests of significance. They find strong forecasting power both at the 1-quarter ahead and 16-quarter ahead horizon, for both models of fundamentals. However, the results are especially favorable for the monetary model, and especially at the longer horizon. At the 16-quarter horizon, the monetary model produces a lower RMSE for seventeen of the eighteen dollar exchange rates, and the improvement over the random walk is significant in fifteen of those cases.

Groen (2005) considers a small panel of exchange rates, involving the euro exchange rates of the yen, Canadian dollar and U.S. dollar, using data from 1975:I to 2000:IV. ${ }^{15}$ Rolling estimates of the model are used to produce forecasts beginning in 1989:I. ${ }^{16}$ In comparison with the random walk, the monetary model generally produces forecasts with lower RMSE at horizons of 12 and 16 months. Groen produces bootstrapped tests of significance that find the model significantly outforecasts the random walk at the 16-month horizon for most currencies.

McCracken and Sapp (2005) employ a test statistic that takes into account the fact that the forecasts generated by equation (3.6) require estimation of parameters, while the random-walk forecast does not. The parameter uncertainty will tend to increase the RMSE of the model's forecast if the model is true, thus biasing results against the model in comparisons with the random walk. Clark and West (2006) propose a simple test statistic to deal with this bias that has become popular in subsequent papers that test the power of models to beat the random walk in out of sample forecasting exercises. McCracken and Sapp find that the corrected statistics offer more power to reject the random walk, using the same sample and bootstrap proceure as Kilian (1999).

Cerra and Saxena (2010) find strong evidence of out-of-sample forecasting power in their panel of 98 countries. Using annual data to estimate the model initially over the 1960-1983 period, and then updating estimates using a rolling window, they find that the monetary model has strong forecasting power at 1- and 5year horizons. They find that the RMSE of the monetary model is significantly lower (using the Clark-West test) than that of the random walk at both horizons when the model is estimated and tested on the entire panel of countries. Moreover, that forecasting power does not come just from a small subset of countries. The model has forecasting power when fit over different geographical regions, or when countries are grouped together by income levels. The forecasting power holds for both high-inflation and low-inflation subsets of countries.

Engel et. al. (2008) update the panel estimates of Mark and Sul (2001) for the monetary and PPP models for U.S. dollar exchange rates against the eighteen countries in the original panel. They also use a model based on Taylor rules, as in Engel and West (2006). They begin by noting that uncovered interest parity says that the interest differential should be an unbiased predictor of exchange rates: $E_{t} s_{t+1}-s_{t}=i_{t}-i_{t}^{*}$. In the context of

\footnotetext{
${ }^{15}$ Groen constructs a synthetic euro for the pre-1999 data, and constructs weighted-average money supplies and income levels to use as European fundamentals, although Groen also uses the German variables as an alternative measure in the pre-1999 era.

${ }^{16}$ Groen's model is a vector error correction model with a slightly different specification than Mark and Sul (2001).
} 
equation (3.6), this implies that when the forecast horizon is $k=1$, that $i_{t}-i_{t}^{*}+s_{t}$ (which is approximately the $\log$ of the one-period ahead forward exchange rate) is a candidate for the economic fundamental, $f_{t}$. But rather than use the actual interest rate differential, Engel et. al. assume the interest rates are set by Taylor rules as in (3.1), but replacing expected inflation differentials between $t$ and $t+1$ with the actual inflation differential between $t-1$ and $t$. They set $\gamma_{q}=0.1, \gamma_{y}=0.1$, and $\gamma_{\pi}=1.5$, based on Taylor-rule estimates from the literature, implying $f_{t}=0.1 q_{t}+1.5 E_{t}\left(\pi_{t+1}-\pi_{t+1}^{*}\right)+0.1\left(\tilde{y}_{t}-\tilde{y}_{t}^{*}\right)+s_{t}$. They use quarterly data beginning in 1973:I. The models are estimated in-sample, then used to produce 1-quarter and 16-quarter ahead forecasts. The estimation sample is updated recursively to produce forecasts for 1983:I-2005:IV. As in previous studies, the monetary model and PPP model produce significantly better out of sample forecasts (using the Clark-West statistic) at the 16-quarter horizon than either the driftless random walk or a random walk with drift (where the estimate of the drift is updated recursively.) The Taylor rule model also beats the random walk with drift at the 16-quarter horizon, but not the driftless random walk.

Molodtsova and Papell (2009) use the Taylor rule model to forecast exchange rates one month ahead. However, unlike Engel et. al. (2008), Molodtsova and Papell do not impose the coefficients of the Taylor rule. Instead, they estimate a model of the form:

$$
s_{t+1}-s_{t}=\alpha_{0}+\alpha_{1} \pi_{t}+\alpha_{2} \pi_{t}^{*}+\alpha_{3} \tilde{y}_{t}+\alpha_{4} \tilde{y}_{t}^{*}+\alpha_{5} q_{t}+\alpha_{6} i_{t-1}+\alpha_{7} i_{t-1}^{*}+u_{t},
$$

with the coefficients unrestricted. In particular, they do not impose any sign restrictions in the model. They argue that since in fact uncovered interest parity does not hold in the data, and many empirical studies find that $s_{t+1}-s_{t}$ is negatively correlated with $i_{t}-i_{t}^{*}$, we should not impose the signs of the parameters a priori. Equation (3.7) is estimated over the March 1973 to December 1998 period, then used to produce 1-month ahead forecasts for the dollar against twelve different currencies from January 1999 to June 2006. The model is estimated using several different specifications, and using different methods of producing a measure of the output gap in each country. The version of the model that performs best in out-of-sample forecasts produces a significantly lower RMSE than the random walk for nine of the twelve exchange rates. Related papers by Molodtsova et. al. $(2008,2011)$ find the Taylor rule model can forecast the dollar/deutschemark exchange rate in the pre-euro era and dollar/euro exchange rate, using real-time data. Also, Wang and Wu (2012) develop evidence based on forecast intervals that is favorable toward the Taylor rule model.

Gourinchas and Rey (2007) find the approximate measure of the net foreign asset position, $n x a_{t}$, from equation (2.29) can be used to forecast exchange-rate changes out of sample. They construct $n x a_{t}$ beginning with the period 1952:I to 1978:I, and use the variable to forecast exchange rate changes from 1 to 16 quarters ahead (for weighted average dollar exchange rates). They then update the estimate of $n x a_{t}$ using rolling windows, and construct forecasts for the period up until 2004:I. They find, using the Clark-West statistic, that forecasts based on $n x a_{t}$ have significantly lower RMSE than the random-walk forecast at all horizons. 


\section{Exchange-rate Forecastability}

Is out-of-sample forecasting power a valid way to test exchange rate models? Engel and West (2005) show that even if the model is true, under some circumstances exchange rates cannot be forecast.

To motivate the class of models they consider, consider a standard monetary model (such as Frankel, 1979) in which money demand equations with identical parameters hold in both the Home and Foreign countries, so we have:

$$
m_{t}-m_{t}^{*}-\left(p_{t}-p_{t}^{*}\right)=-\gamma\left(i_{t}-i_{t}^{*}\right)+v_{t}-v_{t}^{*}
$$

Now take the definition of ex ante excess returns given in equation (1.1), $\lambda_{t} \equiv i_{t}^{*}+E_{t}\left(s_{t+1}\right)-s_{t}-i_{t}$, and assume purchasing power parity holds $\left(s_{t}=p_{t}-p_{t}^{*}\right)$ to arrive at:

$$
s_{t}=(1-b)\left(m_{t}-m_{t}^{*}-\left(v_{t}-v_{t}^{*}\right)\right)-b \lambda_{t}+b E_{t} s_{t+1}, \quad b \equiv \gamma /(1+\gamma) .
$$

This model is an example of a typical model in which the exchange rate is determined by some current economic fundamentals $\left(m_{t}, m_{t}^{*}, v_{t}, v_{t}^{*}, \lambda_{t}\right)$ and the expected future exchange rate. The future expected exchange rate is "discounted" by the factor $b$, where $0<b<1$. Some of the fundamental economic variables are multiplied by $1-b$, but the risk premium is multiplied by $b$.

The general class of models considered by Engel and West (2005) takes the form: ${ }^{17}$

$$
s_{t}=(1-b) f_{1 t}+b f_{2 t}+b E_{t} s_{t+1}, \quad 0<b<1 .
$$

where $f_{1 t}$ and $f_{2 t}$ are linear combinations of "fundamental" economic variables that determine the exchange rate. In the example of equation (3.9), $f_{1 t}=m_{t}-m_{t}^{*}-\left(v_{t}-v_{t}^{*}\right)$ and $f_{2 t}=-\lambda_{t}$. Engel and West note that many variants of the monetary model, as well as models in which the interest rate is the instrument of monetary policy take on the form of equation (3.10). Engel and West assume the solution for the exchange rate in this model is the forward-looking, no-bubbles solution that expresses the exchange rate as a present discounted value (with discount factor $b$ ) of current and expected future values of the fundamentals.

Engel and West show that under some circumstances, as the discount factor gets large, the exchange rate approaches a random walk. Formally, they show that $\lim _{b \rightarrow 1}\left(s_{t+1}-s_{t}\right)$ is an i.i.d. random variable. There are two possible conditions under which this result holds: (1) $f_{2 t}=0$, and $f_{1 t}$ has a unit root (is I(1)); or, (2) $f_{2 t} \neq 0$, $f_{2 t}$ has a unit root (with no restriction on $f_{1 t}$.) The exchange rate will nearly follow a random walk when either there are no $f_{2 t}$ variables and the other economic fundamentals have a unit root, or $f_{2 t}$ has a unit root. $f_{2 t}$ may include a risk premium, or the error in a Taylor rule equation, such as $\varepsilon_{t}$ in equation (3.1).

The conditions of the theorem do not require that $f_{1 t}$ or $f_{2 t}$ themselves be random walks, but only that they have a permanent component. The intuition of the theorem can be gleaned by recognizing that any I(1) random variable can be written as the sum of a pure random walk (call it $x_{t}$ ) and a stationary, $\mathrm{I}(0)$, component

\footnotetext{
${ }^{17}$ Constant terms are suppressed in this discussion for simplicity.
} 
(call it $y_{t}$ ). Since the exchange rate is the present discounted sum of I(1) fundamentals, it is a present discounted sum of $x_{t}$ plus $y_{t}$. When the discount factor is close to one, expected values of the fundamentals far into the future matter for the exchange rate. $E_{t} x_{t+j}$ is a random variable even as the horizon $j$ goes to infinity, but $E_{t} y_{t+j}$ converges to a constant. More and more of the variance of the expected fundamentals in the future is attributable to the random walk component as the horizon increases. As the discount factor goes to one, the random walk term dominates the variance of the present value, so the exchange rate approaches the behavior of a variable that is determined simply as the infinite discounted sum of pure random walk fundamentals - which would behave as a random walk.

The practical question is whether the models actually do imply that the exchange rate is so close to being a random walk that the change in the exchange rate cannot be forecasted. If the discount factor is very close to one, or if the fundamentals themselves are very close to being pure random walks, the exchange rate will look very unforecastable. Engel and West turn to implied estimates of the discount factor in various models, and estimates of the serial correlation of the changes in the fundamentals. They show that even with relatively low values for the discount factor and high values for serial correlation of the changes in fundamentals, the change in the exchange rate will exhibit very low serial correlation and low correlation with lagged fundamentals. They also show that even if the fundamentals are I(0), not I(1), that the exchange rate will look nearly like a random walk if the largest root driving the fundamental is close to one.

An example in which the fundamentals obey the assumptions of the Engel-West theorem is:

$$
\begin{aligned}
& f_{1 t}-f_{1 t-1}=\phi\left(f_{1 t-1}-f_{1 t-2}\right)+\varepsilon_{t}, \quad 0<\phi<1, \\
& f_{2 t}-f_{2 t-1}=\eta\left(f_{2 t-1}-f_{2 t-2}\right)+u_{t} \quad 0<\eta<1,
\end{aligned}
$$

where $\varepsilon_{t}$ and $u_{t}$ are mean-zero, i.i.d. random variables. The solution to the model given in (3.10) is:

$$
s_{t}-s_{t-1}=\frac{(1-b) \phi}{1-b \phi}\left(f_{1 t-1}-f_{1 t-2}\right)+\frac{1}{1-b \phi} \varepsilon_{t}+\frac{b \eta}{1-b \eta}\left(f_{2 t-1}-f_{2 t-2}\right)+\frac{b}{(1-b)(1-b \eta)} u_{t} .
$$

In the case in which $f_{2 t}=0$, we can see that as $b \rightarrow 1, s_{t}-s_{t-1} \rightarrow \frac{1}{1-\phi} \varepsilon_{t}$. For values of $b$ close to, but not equal to one, $s_{t}-s_{t-1}$ can be forecast using $f_{1 t-1}-f_{1 t-2}$, but the forecasting power will be low. When $f_{2 t} \neq 0$, as $b \rightarrow 1$ the variance of the innovation in $s_{t}-s_{t-1}$ goes to infinity. For values of $b$ that are nearly equal to one, the term multiplying $u_{t}$ is very large, so the forecastable component of $s_{t}-s_{t-1}$ has a very small variance relative to the unforecastable component. It is also clear from this example that the further $f_{1 t}$ and $f_{2 t}$ are from being random walks - i.e., the larger are $\phi$ and $\eta-$ the more forecastable is $s_{t}-s_{t-1}$ for a given value of $b$.

Suppose the assumptions on the stochastic processes for the fundamentals in this example applies to the model in equation (3.9), with $f_{1 t}=m_{t}-m_{t}^{*}-\left(v_{t}-v_{t}^{*}\right)$, and $f_{2 t}=-\lambda_{t}$. This model assumes that the change in 
the exchange rate is predictable, because one of the building blocks of the model is $E_{t}\left(s_{t+1}\right)-s_{t}=i_{t}-i_{t}^{*}+\lambda_{t}$. Both $i_{t}-i_{t}^{*}$ and $\lambda_{t}$ should be useful in forecasting $s_{t+1}-s_{t}$, so why does the Engel-West theorem tell us the exchange rate is nearly a random walk? We can solve to find:

$$
i_{t}-i_{t}^{*}=\frac{(1-b) \phi}{1-b \phi}\left(f_{1 t}-f_{1 t-1}\right)+\frac{1}{1-b \eta} f_{2 t}-\frac{b \eta}{1-b \eta} f_{2 t-1}, \quad \lambda_{t}=-f_{2 t} .
$$

The forecast error is given by

$$
s_{t+1}-E_{t} s_{t+1}=\frac{1}{1-b \phi} \varepsilon_{t+1}+\frac{b}{(1-b)(1-b \eta)} u_{t+1} .
$$

In the case of no risk premium $\left(f_{2 t}=0\right)$, as $b$ approaches one in value, the variance of the forecastable part of $s_{t+1}-s_{t}, \frac{(1-b) \phi}{1-b \phi}\left(f_{1 t}-f_{1 t-1}\right)$, relative to the variance of the unforecastable component, $\frac{1}{1-b \phi} \varepsilon_{t+1}$, goes to zero.

So even if uncovered interest parity holds, a regression of $s_{t+1}-s_{t}$ on $i_{t}-i_{t}^{*}$ has a very low R-squared. In fact, West (2012) argues that the estimator of the regression coefficient in this classic regression is inconsistent as $b \rightarrow 1$. Even if $f_{2 t} \neq 0$, and even if the econometrician could observe the risk premium, the variance of the predictable component of $s_{t+1}-s_{t}$ relative to the variance of the forecast error goes to zero as $b \rightarrow 1$.

Suppose $f_{2 t}$ is stationary, but has a root that is close to one in absolute value. For example, replace the stochastic process in the example above with:

$$
f_{2 t}-\alpha f_{2 t-1}=\eta\left(f_{2 t-1}-\alpha f_{2 t-2}\right)+u_{t} \quad 0<\eta<1,0<\alpha<1
$$

Then we find:

$$
s_{t}-s_{t-1}=\frac{(1-b) \phi}{1-b \phi}\left(f_{1 t-1}-f_{1 t-2}\right)+\frac{1}{1-b \phi} \varepsilon_{t}+\frac{b(\alpha-1+\eta(1-b \alpha))}{(1-b \alpha)(1-b \eta)} f_{2 t-1}-\frac{b(1-b) \alpha \eta}{(1-b \alpha)(1-b \eta)} f_{2 t-2}+\frac{b}{(1-b \alpha)(1-b \eta)} u_{t} .
$$

We have that $\lim _{b \rightarrow 1}\left(\lim _{\alpha \rightarrow 1}\left(s_{t+1}-s_{t}\right)\right)$ is the same as $\lim _{b \rightarrow 1}\left(s_{t+1}-s_{t}\right)$ in equation (3.12). For large enough values of $\alpha$ and $b, s_{t}-s_{t-1}$ will be approximately i.i.d.

Engel and West suggest an alternative means of assessing the models, instead of the out-of-sample forecasting power. Equation (3.10) has the forward-looking solution:

$$
s_{t}=(1-b) \sum_{j=0}^{\infty} b^{j}\left(E_{t} f_{1 t+j}\right)+b \sum_{j=0}^{\infty} b^{j}\left(E_{t} f_{2 t+j}\right)
$$

If all of the economic fundamentals, $f_{1 t}$ and $f_{2 t}$ were observable to the econometrician, the exchange rate itself should provide an optimal forecast of the discounted sum of ex post fundamentals in equation (3.15). If the data generating processes for the fundamentals can be represented by linear processes, then the method of Campbell and Shiller (1988) can be used to test the model directly. However, Engel and West argue that in the case of exchange rate models, many of the fundamentals are not measurable, so the Campbell-Shilller method 
cannot be applied directly. Nonetheless, it might be reasonable to conclude that the exchange rate contains information that is useful in forecasting the observable economic fundamentals. So one testable implication turns the forecastability question on its head - are economic fundamentals forecastable using the exchange rate? Engel and West find some weakly favorable evidence using Granger-causality tests.

In light of the Engel-West theorem, how do we interpret the evidence summarized above that we can use the models to forecast exchange rates at long horizons? Does that mean the models are not true? Or perhaps the conditions of the Engel-West theorem are not satisfied, but then why do the models have success only at long horizons and not short horizons? One answer to these questions is that even the evidence of long-horizon predictability is not unshakeable. As Cheung et. al. (2005) demonstrate, it may appear that the exchange rate change is forecastable over some periods, but that outcome may simply be luck. The current evidence of longrun forecastability might be overturned.

Another answer arises from the possibility that there is a driving variable for exchange rates - possibly the ex ante excess return, $\lambda_{t}$ - for which the econometrician does not have a measure. If $\lambda_{t}$ is persistent but stationary, the change in the exchange rate may be nearly unforecastable in the short-run, but there may be more forecasting power over longer horizons.

If the conditions of the Engel-West theorem are satisfied, there is no reason to expect that long-horizon predictability will be greater than short-horizon. That theorem simply states that $\lim _{b \rightarrow 1}\left(s_{t+1}-s_{t}\right)$ is an i.i.d. random variable, which would mean that the change in the exchange rate is unpredictable at all horizons. On the other hand, suppose $f_{2 t}$ is a stationary variable. Then from equation (3.10), we can conclude that $s_{t}$ and $f_{1 t}$ are cointegrated, and that $s_{t}-f_{1 t}$ is stationary. This means that $s_{t+k}-f_{1 t+k}$ is predicatble at time $t$, $E_{t}\left(s_{t+k}-f_{1 t+k}\right)$ converges to a constant. If $f_{1 t}$ is an exogenous random variable, then the predictability of $s_{t+k}-f_{1 t+k}$ must arise out of our ability to forecast the exchange rate. In other words, if $s_{t}-f_{1 t}$ deviates from its unconditional mean, we can predict that $s_{t}$ will converge toward the sum of $f_{1 t}$ and the unconditional mean of $s_{t}-f_{1 t}$. At very short horizons, the change in the exchange rate may still be nearly unpredictable if $f_{2 t}$ is stationary, as example (3.14) shows. At longer horizons, $s_{t+k}-s_{t}$ may be predictable because of the convergence of $s_{t+k}-f_{1 t+k}$. At the longest horizons, we know $s_{t+k}-s_{t}$ will be unpredictable because the exchange rate has a unit root.

This logic suggests that if the econometrician observes $f_{1 t}$ but not $f_{2 t}$, and estimates Mark's regression (3.6) using $f_{1 t}$ as the measure of the fundamental, a plot of the R-squareds against the horizon $k$ will be humpshaped. At the shortest and longest horizons, the change in the exchange rate should be almost unpredictable, but at some intermediate horizons there may be some forecasting power. Engel et. al. (2008) consider the example in which $f_{1 t}$ is a pure random walk, so $\phi=0$ in equation (3.11), and $f_{2 t}$ follows an $\operatorname{AR}(1)$ with serial correlation $\alpha$, so $\eta=0$ in equation (3.13). We can solve to find: 


$$
s_{t}=f_{1 t}+\frac{b}{1-b \alpha} f_{2 t}
$$

Then we can see that the error-correction term from Mark's regression (3.6), $f_{1 t}-s_{t}$ is proportional to the unobserved fundamental $f_{2 t}: f_{1 t}-s_{t}=\frac{-b}{1-b \alpha} f_{2 t}$.

The $k$-period change in the exchange rate is given by:

$$
s_{t+k}-s_{t}=\left(1-\alpha^{k}\right)\left(f_{1 t}-s_{t}\right)+\sum_{i=1}^{k} \varepsilon_{t+i}+\frac{b}{1-b \alpha} \sum_{j=1}^{k} \alpha^{k-j} u_{t+j}
$$

The R-squared for the $k$-horizon regression of $s_{t+k}-s_{t}$ on $f_{1 t}-s_{t}$ is given by:

$$
R_{k}^{2}=\frac{\left(1-\alpha^{k}\right)^{2} \operatorname{var}\left(u_{t}\right)}{2\left(1-\alpha^{k}\right) \operatorname{var}\left(u_{t}\right)+\left[k\left(1-\alpha^{2}\right)(1-b \alpha)^{2} / b^{2}\right] \operatorname{var}\left(\varepsilon_{t}\right)}
$$

When $b$ and $\alpha$ are large, $R_{1}^{2}$ may be quite small, but $R_{k}^{2}$ may rise to fairly large values before ultimately converging toward zero as $k \rightarrow \infty$. For example, if we set $\operatorname{var}\left(u_{t}\right)=\operatorname{var}\left(\varepsilon_{t}\right)=1$, and set $\alpha=b=.95$, we find $R_{1}^{2} \approx 0.025$, so the short-run forecasting power of $f_{1 t}-s_{t}$ is low. At a horizon of 25 periods, the forecasting power has increased to $R_{25}^{2} \approx 0.35$. Ultimately a maximum $\mathrm{R}$-squared is reached at the 92-period horizon, $R_{92}^{2} \approx 0.473$, and then the forecasting power declines slowly toward zero.

A possible explanation for the finding of low forecasting power at short horizons and higher power at longhorizons is a stationary $\lambda_{t}$. Section 4 examines the evidence on the failure of uncovered interest parity empirically, and the theoretical literature that has been built to account for it. As equation (1.5) shows, $\lambda_{t}$ is potentially an important determinant of exchange rates. Before turning to the literature on uncovered interest parity, we turn to the empirical evidence on foreign-exchange market intervention, and exchange-rate regimes. From a theoretical perspective, understanding the factors behind $\lambda_{t}$ may be important in understanding channels through which sterilized foreign-exchange intervention can be effective.

\section{3.c Exchange-rate regimes and exchange-rate intervention}

The preceding analysis has assumed that exchange rates are floating and determined by market forces. There are many real-world alternatives to fully flexible exchange rates - "hard pegs", monetary union, dollarization, crawling pegs, managed floating, etc. ${ }^{18}$

Both in academic studies and in policymaking circles in the past twenty years, there has been increasing recognition that monetary policy can and perhaps should be defined by the targets of policy. Many central banks have adopted inflation-targeting regimes, in which central banks explicitly announce desired level of inflation that monetary policy tries to achieve. Sometimes central banks implicitly or explicitly adopt "flexible inflation targeting". For example, the inflation rate is targeted but allowed to deviate from the target under

\footnotetext{
${ }^{18}$ See Tavlas et. al. (2008) for a discussion of types of exchange-rate regimes, and a survey of the literature on exchangerate regime classification.
} 
exceptional circumstances such as a financial crisis. Other central banks may trade off different goals. For example, the Federal Reserve has a dual mandate to keep inflation low and employment high. In this context, targeting the exchange rate can be seen as one form of flexible inflation targeting. A managed float is simply a form of a monetary policy rule in which an exchange-rate target is included.

If sterilized intervention can be used to stabilize exchange rates, policymakers have the luxury of using an instrument separate from monetary policy to achieve their exchange-rate goals. Sterilized intervention may only be available as an independent tool when a country has capital controls in place. In fact, Eichengreen and Razo-Garcia (2006) argue that control of the exchange rate and control of capital flows are ineluctably linked. On the one hand, when capital flows freely between a pair of countries, the well-known "trilemma" tells us that the countries must either have monetary policy that is tightly linked or there must be flexibility in the exchange rate. Eichengreen and Razo-Garcia further argue that it is difficult to maintain floating exchange rates when capital controls are in place. A country that introduces floating exchange rates must cope with currency volatility. Firms with foreign-currency exposure will want to be able to buy financial instruments that hedge their risk. There must be a banking system in place that can provide the forward cover to firms. None of this is very feasible in a country that maintains tight capital controls.

\section{Classification of exchange-rate regimes}

The International Monetary Fund has maintained an "official" classification of exchange-rate regimes since the breakdown of the Bretton Woods system. It is official in the sense that countries report their exchange rate regime to the IMF. Since 1999 that classification scheme has included eight categories: no separate legal tender; currency board arrangements; other conventional fixed pegs; horizontal bands; crawling pegs; crawling bands; managed floating with no pre-announced path for the exchange rate; and, independently floating. ${ }^{19}$ But the adequacy of the IMF classification scheme has long been questioned. On the one hand, Obstfeld and Rogoff (1995b) noted that countries that are classified as having fixed exchange rates very rarely maintain the same exchange rate peg for as long as five consecutive years. On the other hand, Calvo and Reinhart (2002) find that many countries that claim to have floating exchange rates in fact do not. They often use foreign exchange reserves or interest rates to target exchange rate movements.

These observations have led to some attempts to provide "de facto" (as opposed to "de jure") classification schemes in which the exchange-rate regime is determined by the actual behavior of the policymakers rather than what they claim.

Reinhart and Rogoff (2004) make several adjustments to the official classification of regimes based on the actual performance of exchange rates. One important distinction they make is between the behavior of the official exchange rate and the exchange rate that prevails on black markets. They note that these dual or parallel market rates are much more prevalent than had previously been acknowledged over some periods. In the 1940s and 1950s, they were prevalent in industrialized countries, and they have remained important in

\footnotetext{
${ }^{19}$ See Hagen and Zhou (2007) for a discussion.
} 
developing countries until the present. They also introduce a new category of exchange rates, "freely falling". In countries that have very high inflation, the currency depreciates at a very rapid rate. It is misleading to lump such countries in with those that have stable monetary policy and freely floating rates. For example, if we were interested in assessing the economic performance of countries with different types of exchange-rate regimes, the freely falling group would clearly be outperformed by the stable floaters on many dimensions. They find that the true exchange-rate regime of countries changes frequently. Their basic classification is finer than the IMF official scheme, allowing for fourteen categories: no separate legal tender; preannounced peg or currency board arrangement; preannounced narrow $( \pm 2 \%)$ horizontal band; de facto peg; preannounced crawling peg; preannounced narrow crawling band; de facto crawling peg; de facto narrow crawling band; preannounced wide crawling band; narrow non-crawling band; managed floating; freely floating; freely falling.

Shambaugh (2004) goes the other direction from Reinhart and Rogoff, in a sense, by classifying countries either as having pegged exchange rates or being non-peggers. He first determines the base currency against which a country has set its peg, which is where there is a role for judgment. Then a country is classified as a pegger during any given year if its official exchange rate stays within a $\pm 2 \%$ band against the base currency. For Shambaugh's set of 155 countries from 1973-2000, there are 4388 country/year observations, of which 2220 are coded as pegged.

Levy-Yeyati and Sturzenegger (2003) classify exchange rates into floats, fixed and intermediate regimes for each year from 1974-2000 for 183 countries. They first calculate measures of exchange rate movements the average absolute monthly percentage change over the year and the standard deviation of the monthly percentage change. They also calculate a measure of the volatility of the country's foreign exchange reserves. Then countries are grouped together using a statistical tool called cluster analysis. They form three groupings ones with high exchange-rate volatility and low reserve volatility, which are classified as floaters; ones with low exchange-rate volatility and high reserve volatility, which are the fixers. Ones with moderate levels of both measures are classified as the intermediate regimes, and ones with low values for all three measures are left unclassified. $^{20}$

These classification schemes have been used to assess economic performance under various exchange-rate regimes. For example, Reinhart and Rogoff measure how output growth, inflation, and volume of trade (relative to GDP) are influenced by the choice of regime. Levy-Yeyati and Sturzenegger (2003) and Dubas et. al. (2010) investigate the effects of exchange-rate regime on growth performance. Shambaugh (2003) and Frankel et. al. (2004) consider how the independence of monetary policy is influenced by the regime. Husain, et. al. (2005) evaluate regimes according to their inflation performance, levels and volatility of output growth, and the probability of banking and currency crises.

\section{Empirical studies of sterilized intervention}

Sterilized intervention in foreign exchange markets by central banks or other government agencies presents

\footnotetext{
${ }^{20}$ See also Dubas et. al. (2010), who use a statistical method for classifying regimes.
} 
an empirical and theoretical challenge. Traditionally sterilized intervention is defined as buying and selling of currencies by central banks, with offsetting operations to leave the money supply unchanged. For example, if Bank of Japan buys U.S. dollars with Japanese yen, it sterilizes the foreign exchange operation by selling some of its holdings of Japanese government bonds. ${ }^{21}$ Some central banks sell "sterilization bonds", an action that reduces the money supply just as would selling government bonds.

Most central banks no longer target monetary aggregates, so instead, sterilized intervention can be thought of as foreign exchange market activity by the central bank that does not change its target interest rate. The theoretical question that has occupied the literature concerns how sterilized intervention can affect exchange rates if it does not change the interest rate. Consider the first line of equation (1.5). If the current interest differential, $i_{t}-i_{t}^{*}$, is held constant, there are still three other channels through which intervention might affect the exchange rate: expected future values of the interest differential; current and expected future values of the ex ante excess return, $\lambda_{t}$; and, the long-run expected future exchange rate. We foucs on the first two as channels through which sterilized intervention may affect the spot exchange rate.

One hypothesis that has been advanced is that sterilized intervention works by signaling to markets the intention of central banks to change monetary policy in the future, so the intervention changes expected future interest rates. ${ }^{22}$ However, to quote Neely (2011), "The literature on intervention has not been kind to the signaling hypothesis. Lewis (1995) and Kaminsky and Lewis (1996) found that intervention generated perverse impacts on monetary policy in their sample. Fatum and Hutchison (1999) found that intervention had no impact on federal funds futures rates."

This leaves changes in current $\lambda_{t}$ or $E_{t} \lambda_{t+j}$ as channels through which intervention can affect foreign exchange rates. We have taken so far a very broad view of the determinants of $\lambda_{t}$, and section 4 surveys some recent models of the determinants. Here we will briefly consider how intervention could work through three possible determinants of $\lambda_{t}$ : a foreign exchange risk premium; imperfections in capital markets; and deviations from the strictest meaning of rational expectations. ${ }^{23}$

The "portfolio balance" channel is one possible way in which intervention could affect $\lambda_{t}$. In this case, $\lambda_{t}$ is interpreted as a risk premium rewarded for holding foreign bonds. Intervention changes the supply of assets denominated in different currencies, and so changes their risk characteristics. Imagine again that the Bank of Japan undertakes sterilized intervention that effectively increases the amount of Japanese government bonds and reduces the amount of U.S. government bonds held by the public. In order to induce the public to hold a greater share of their portfolio of assets in the form of Japanese government bonds relative to U.S. bonds, the

\footnotetext{
${ }^{21}$ The amount of U.S. money in circulation also is ultimately unaffected because the Bank of Japan takes the dollars it has purchased and buys U.S. government bonds.

${ }^{22}$ See Vitale (2003) for a model that explains why a central bank would use foreign exchange intervention to signal future monetary policy.

${ }^{23}$ See Ho (2004) and Pasquariello (2010) for models in which intervention can affect $\lambda_{t}$ via a liquidity effect.
} 
expected return on Japanese bonds must increase. Investors are rewarded with a risk premium for holding Japanese government bonds. $^{24}$

From a theoretical perspective, generating a portfolio balance effect requires some sophistication in model building. A model with an infinitely-lived representative agent that has rational expectations will not allow a role for intervention to affect exchange rates through this channel. In that type of model, the central bank is effectively owned by households - the balance sheet of the central bank is incorporated in the household balance sheet. Consider again the example in which the Bank of Japan sells Japanese government bonds to the public and buys U.S. government bonds. On the one hand, the portfolio held directly by the public becomes more tilted toward Japanese government bonds. On the other hand, the portfolio held by the Bank of Japan has become more tilted toward dollar denominated assets. A dollar depreciation has a smaller effect now on the yen value of assets held by the public, but a larger effect on the yen value of the Bank of Japan's portfolio. If the Bank of Japan suffers a capital loss from dollar depreciation, the loss is ultimately passed on to Japanese taxpayers because the Japanese government must rely more heavily on taxes and less on profits from the central bank to finance expenditures. So while directly households may find their portfolios less exposed to foreign exchange risk, indirectly through the central bank their portfolios are more exposed. On net, Japanese investors with rational expectations will recognize the indirect exposure they have through the central bank, so sterilized intervention will not influence the equilibrium risk premium. This neutrality result can be broken if there is heterogeneity in households, so that the households that bear the ultimate tax burden are in some ways different than investors on average. For example, in a framework of overlapping generations of unrelated households, the burden of taxes is borne by generations that are not yet born and therefore not currently players in international financial markets. ${ }^{25}$ From a practical standpoint, it seems unlikely that sterilized intervention could have a large impact on foreign exchange risk premiums for large financially developed economies. The size of sterilized interventions is small compared to the size of outstanding government bonds. ${ }^{26}$

Another possible reason for a wedge between expected returns on Home and Foreign assets is the presence of capital market imperfections. For example, it is widely acknowledged that China can successfully implement sterilized intervention because China has strong controls on both inflows and outflows of capital. Many emerging markets also employ sterilized foreign exchange intervention as a policy tool. Its effectiveness might depend on the presence of capital controls, or on underdevelopment of financial markets. When markets are thin, speculative forces might not strongly move to push expected returns on Home and Foreign assets into equality even if investors are not very averse to foreign exchange risk. If markets are not very liquid, the size of central bank intervention may be large relative to typical market turnover, and therefore have at least a

\footnotetext{
${ }^{24}$ See, for example, Dominguez and Frankel (1993).

${ }^{25}$ On the other hand, see Kumhof (2010) for a model in which fiscal policy is influenced by foreign exchange intervention through the effects of exchange rates on government liabilities.

${ }^{26}$ However, see Ito (2003) on the massive interventions by the Bank of Japan in the 1990s. See also Dominguez and Frankel (1993) and Fatum (2010).
} 
temporary effect on exchange rates. Unfortunately, there is a relative scarcity of studies of foreign exchange intervention in developing countries, primarily because of a lack of data on official intervention. Disyatat and Galati (2007) survey empirical studies of sterilized intervention in emerging markets. They find that in general, foreign exchange intervention has been found to have some weak influence on exchange rates, and that influence is stronger when capital controls are present and markets are thin. In some cases, the intervention also seems to be more effective when there is communication concerning the intervention.

Our definition of $\lambda_{t}$ includes a role for deviations of expectations held by the market of the interest rate differentials, $i_{t+j}-i_{t+j}^{*}$, from the "rational expectation", $E_{t}\left(i_{t+j}-i_{t+j}^{*}\right)$. In the latter, the expectation is assumed to be the mathematical expectation conditional on all publicly available information. However, expectations of agents in the market might differ from these rational expectations. Perhaps market participants follow rules of thumb in forming expectations, or suffer from overconfidence or other biases. We explore models based on these deviations from rationality in section 4.d. Alternatively, there is a large recent literature that considers models in which the market equilibrium exchange rate depends not only on expectations based on publicly available information but also on the aggregation of differential private information. Of particular note in this regard are the studies of Evans and Lyons (2002b, 2008), Evans (2002, 2010), and Bacchetta and van Wincoop (2006, 2010).

Sarno and Taylor (2001) propose a "coordination channel" through which sterilized intervention can affect exchange rates. As in Bacchetta and van Wincoop (2006), agents in financial markets might have imperfect private information about the economic fundamentals. According to the coordination channel model, the central bank undertakes sterilized intervention as a way to coordinate expectations. This channel is then similar to the signaling channel, in that the intervention works through its effects on expectations of future interest rates. Reitz and Taylor (2008) develop a model in which there are "uninformed" traders whose flow demand for foreign exchange depends on a simple rule of thumb, while "informed traders" have a flow demand that depends on their expectations of the current level of the fundamentals. Informed traders do not observe the actual current fundamentals, and become increasingly less confident of their beliefs about the fundamentals the further the exchange rate is from its fundamental value. Intervention can increase the confidence of the fundamentals traders in their information, and therefore lead to greater demand from the informed traders that pushes the exchange rate toward its fundamental value. This type of model explicitly gives a role to flow demand for foreign exchange, rather than asset market equilibrium, in determining exchange rates. ${ }^{27}$

There is a burgeoning literature on central bank communication that examines the contrary idea that the central bank would like to inform the market about the fundamental value of the exchange rate. Jansen and de Haan (2005) conclude that statements by European Central Bank officials have at most a small effect on the mean level of the exchange rate, but have increased its volatility. In contrast, Fratzscher (2006) examines the

\footnotetext{
${ }^{27}$ See also Dominguez $(2003,2006)$ for a discussion of the role of foreign exchange intervention in influencing expectations of agents with different information sets.
} 
effects of statements regarding the exchange rate by officials in the U.S., Japan, and the euro area from 19902003. That study finds that communication does have a small but significant effect in the desired direction on exchange rates. Using impulse response functions, the effect appears to be short-lived. However, the reaction of forward exchange rates suggests that the influence of the communications may be longer-lived, perhaps up to six months. In addition, verbal interventions work to reduce volatility significantly. ${ }^{28}$

Beine et. al. (2009) find that actual foreign exchange market interventions are more effective when accompanied by communication. Official statements either confirming or commenting on intervention tend to lead to more significant changes in exchange rates in the desired direction, and to reduce the volatility of exchange rates. This finding is confirmed in studies of dollar/yen interventions (1991-2003), and euro area/yen interventions (1989-2002).

Empirical studies of actual interventions, as well as verbal interventions, are hampered by the simultaneous causality problem. Interventions do not occur randomly, but instead always in reaction to conditions in the foreign exchange market. It is generally believed (see, for example, Sarno and Taylor (2001)) that this simultaneity problem biases studies against finding an effect on exchange rates of intervention. That conclusion makes sense when intervention leans against the wind. That is, when markets are bidding up the value of a currency, any central bank intervention to weaken the currency might only slow down the market tide. After the intervention, the currency might continue to strengthen, but a slower rate if the intervention is successful. The problem for the econometrician is in determining what would have happened in the absence of the intervention. If the null is that the exchange rate is not expected to change, then in the leaning-against-the-wind scenario, the intervention might appear to have little or no effect on exchange rates when in fact it stifled the market trend. On the other hand, suppose intervention occurs when policymakers believe the currency is misaligned. Then the intervention might appear to be effective when in fact the exchange rate may be returning to its equilibrium because of market forces that are independent of the intervention. In this case, the econometric analysis would tend to overstate the effects of intervention.

It is difficult to find a valid instrument to deal with this simultaneity problem. Almost any variable that is correlated with the intervention is also correlated with the economic factors that drive the exchange rate. ${ }^{29}$ One way the literature has attempted to reduce the simultaneity problem is to look at very narrow windows around the time of the intervention. The notion is that within the narrow time period, the direct effects of the intervention are likely to be the most important determinants of the exchange rate movements, and dominate any changes being driven by other market forces. That conclusion is especially tenuous during times of foreign exchange market volatility, when trading activity might be high, but those are exactly the times when intervention is likely to occur. In addition, this approach limits our ability to trace out longer-run effects of foreign exchange intervention. Very few studies have found significant evidence of a sustained effect of

\footnotetext{
${ }^{28}$ See also Fratzscher $(2008,2009)$, which bolster these findings.

${ }^{29}$ See Kearns and Rigobon (2005) who identify the effects of foreign exchange intervention by claiming that there was an exogenous change in the size of interventions undertaken by many central banks.
} 
sterilized intervention on the level of the exchange rate.

The literature is filled with dozens of recent studies on the effectiveness of intervention. Sarno and Taylor (2001) and Neely (2005) provide surveys of the empirical work. Most of the studies use very short term data to investigate the effectiveness of intervention. There is almost always evidence that sterilized intervention is effective in changing exchange rates. However, given that the window investigated is very small, it is essentially impossible to ascertain how permanent the effect of intervention is. Typically these studies report that $s_{t+\Delta}-s_{t}$ responds in the desired direction of the intervention, where $\Delta$ is a very small time interval after the intervention. Changes over subsequent short time intervals are generally found to be insignificantly affected. These tests cannot tell us whether the exchange rate is different one week from the time of intervention than it would have been without the intervention. Because of the econometric difficulties of separating out the effects of intervention from other forces driving exchange rates, the empirical studies are not able to provide evidence on whether the policymakers can influence exchange rates over a week, a month, or a quarter with sterilized intervention. Some studies also find that volatility increases at times of intervention. In some cases, the volatility appears to increase prior to the intervention. However, again, simultaneity problems prevail. Does the volatility precipitate the action by the policymaker, so that intervention occurs when markets are volatile? Or does the intervention lead to more volatility, and in some cases cause volatility in anticipation of the intervention?

Despite many empirical studies, it is not clear yet whether sterilized intervention meets the same criteria that regulators use to decide whether to approve a cancer drug - that it is safe and effective.

\section{Ex ante excess returns and the uncovered interest parity puzzle}

We have so far focused attention on models of exchange rates in which uncovered interest parity holds. However, we have noted that there are some reasons to suspect that these models are not adequate. First, there is a weak relationship between exchange rates and the economic fundamentals that are supposed to explain them. In a model with uncovered interest parity, exchange rates are related not only to current economic fundamentals but news about future fundamentals, so there may be "disconnect". ${ }^{30}$ We have also seen that models based on fundamentals are not able to forecast exchange rates out of sample, although the Engel-West (2005) theorem states that in fact under plausible assumptions if uncovered interest parity holds, the models imply that the exchange rate is nearly unforecastable. ${ }^{31}$ However, there is some evidence that exchange rate changes can be forecast at long horizons. One possible way to reconcile the fact that exchange rates are nearly unforecastable at shorter horizons with the long-horizon evidence, is to introduce a stationary but persistent deviation from uncovered interest parity. ${ }^{32}$

\footnotetext{
${ }^{30}$ See the discussion in section $2 . b$, concerning equation (2.21).

${ }^{31}$ See the discussion in section 3.b.

${ }^{32}$ See the discussion in section 3.b., concerning equations (3.17) and (3.18).
} 


\section{4.a Recent empirical evidence}

Exchange rate models that incorporate uncovered interest parity have difficulty accounting for the high volatility of exchange rates across high-income countries. For example, the calibrated variance of the nominal exchange rates in some sticky-price dynamic stochastic general equilibrium models is too low if the model assumes interest parity. Many models simply assume an exogenous stochastic process for $\lambda_{t}$ in equation (1.1) in order to account for the high volatility. ${ }^{33}$ Duarte and Stockman (2005) develop a model in which news drives exchange rates. As in the example given in equation (2.21), the news leads to a disconnect between the exchange rate and the economic fundamentals. But in their model, the news concerns the foreign exchange risk premium. Their model allows for disconnect to occur because the econometrician does not observe the risk premium, which in turn is time varying because it is driven by news.

One reason the literature has focused on the foreign exchange risk premium is to explain exchange-rate volatility and exchange-rate disconnect. ${ }^{34}$ A second reason is the uncovered interest parity puzzle. Equation (1.6), repeated here for convenience, is the regression estimated by Bilson (1981) and Fama (1984) that tests uncovered interest parity

$$
s_{t+1}-s_{t}=a+b\left(i_{t}-i_{t}^{*}\right)+u_{t+1} .
$$

Under the null, the regression coefficients should be $a=0$ and $b=1$. However, a long history of empirical work has found the estimated value of $b$ to be less than one, and usually less than zero. Hodrick (1987), Froot and Thaler (1990), and Engel (1996) are older surveys of the empirical work, but the puzzle is still present in more recent studies. For example, Burnside et. al. (2006) estimate equation (4.1) for nine currencies against the U.K. pound using monthly data from January 1976 to December 2005. In all cases, the estimated slope coefficient is negative. It is always found to be significantly less than one (at the 5 percent level of significance), and usually significantly less than zero. ${ }^{35}$

Several recent studies have measured the economic return to taking positions based on the deviation from uncovered interest parity implied by the empirical findings of regression (4.1). One investment rule is the "carry trade", under which the investor simply takes a long position in the currency with the higher interest rate. Suppose that interest parity does not hold, but that the only time $t$ information that is useful in forecasting the exchange rate is the interest differential, $i_{t}-i_{t}^{*}$. Suppose further that the intercept term in (4.1) is zero: $a=0$. Then

$$
\lambda_{t}=i_{t}^{*}+E_{t} s_{t+1}-s_{t}-i_{t}=(1-b)\left(i_{t}^{*}-i_{t}\right) .
$$

As long as $b<1$, the ex ante excess return on the Foreign bond, $\lambda_{t}$, is positive precisely when $i_{t}^{*}>i_{t}$. If the

\footnotetext{
${ }^{33}$ See for example, Kollmann (2004), Adolfson et. al. (2007), and Wang (2010).

${ }^{34}$ For example, that is the motivation for Bacchetta and van Wincoop (2006). See also Engel and West (2004) for evidence that observed economic fundamentals can only account for a fraction of the variance of the innovation in exchange rates.

${ }^{35}$ Bekaert and Hodrick (2001) also find evidence of $b$ less than one, but note that statistical problems imply that the confidence interval is wider than generally reported.
} 
Foreign interest rate is higher than the Home interest rate, the Foreign deposit has a higher expected return than the Home deposit, and vice versa.

Burnside et. al. $(2008,2011 \mathrm{c})$ consider the payoffs to holding portfolios of short-term bonds based on the carry trade. They assess the return to holding an equal-weighted portfolio of 23 currencies. The strategy is to borrow in the foreign country and invest in the U.S. when the U.S. interest rate is above the interest rate in each of these countries. When the U.S. interest rate is below the interest rate of the other country, the position is reversed. Burnside et. al. (2008) consider monthly returns from January 1976 to June 2007, as well as subsamples. The mean annualized return on this portfolio is $5.4 \%$, with a Sharpe ratio (the ratio of the average return to the standard deviation of the return) of 0.83. Burnside et. al. (2011c) extend the sample period through 2010 , and find an average payoff of $4.6 \%$, with a Sharpe ratio of 0.89 . Both studies find that the volatility of the return on the carry trade is substantially reduced by holding the portfolio (compared to the average Sharpe ratio for the carry trade for individual currencies.)

Lustig and Verdelhan (2007), Brunnermeier et. al. (2009) and Lustig et. al. (2011) all consider returns to a carry trade portfolio in which assets are grouped. For example, Lustig and Verdelhan (2007) use exchange rate data and interest rate data for 81 countries to construct portfolios, and measure returns in the 1953-2002 period and also the subperiod of 1971-2002. At the beginning of each month, they group the countries into eight equal-sized portfolios, ranked by their interest rate in the previous month relative to the U.S. interest rate, and rebalance the portfolio each month. Then they measure the ex post average ex post annualized returns on a long position in each portfolio. The portfolio with the lowest interest rate (portfolio 1) has an average return of 2.99 percent in the 1971-2002 period, while the portfolios with the highest (portfolio 8) and next-highest interest rates (portfolio 7) have average returns of 1.48 and 3.94 percent, respectively. The Sharpe ratios for these three portfolios are $-0.38,0.10$, and 0.39 . Because the highest interest rate portfolio generally contains some very high inflation countries, the most interesting comparison might be between the returns on portfolio 7 and portfolio 1 . Clearly there is a high return and low standard deviation to the strategy of going long in highinterest rate countries and short in low-interest rate countries.

Jorda and Taylor (2012) suggest augmenting the carry trade strategy by includig economic fundamentals. They argue that the profits from the standard carry-trade strategy (using an equal-weighted portfolio of nine currencies relative to the U.S. dollar) disappeared for many currencies, and were even reversed, in the 20072008 period as low interest rate currencies appreciated strongly. However, a strategy that takes into account not only the interest rate differential but also the deviation of the exchange rate from its "fundamental" level remained profitable over that time span. The fundamental value of the currency is measured as the long-run mean real exchange rate. The trading strategy that appears to be most robust across periods is a threshold one in which trades are only made when the absolute values of the interest differential and the deviation of the real exchange rate exceed certain amounts.

An alternative trading strategy that has been examined is a momentum strategy. Under this strategy, if 
returns on, say, the Foreign bond were positive in the previous period: $i_{t-1}^{*}+s_{t}-s_{t-1}-i_{t-1}$, then the investor should go long in the Foreign asset and short the Home bond. Menkhoff et. al. (2012b) and Burnside et. al. (2011c) calculate the profits from following this rule. The former paper considers one-month returns for 48 countries relative to the U.S. dollar from January 1976 to January 2010. They report a return on the portfolio of around $10 \%$, and a Sharpe ratio of around 0.95 . The latter paper reports somewhat lower expected returns and Sharpe ratios, but ones that are still impressively high.

Burnside et. al. (2006, 2011c) and Menkhoff et. al. (2012b) investigate whether the excess returns on carry trade or momentum strategies can be explained by traditional risk factors such as the growth rate of real consumption, the market return, the term structure spread, the spread between LIBOR and Treasury rates, etc. None of these factors are correlated with the excess returns from either strategy in foreign exchange markets. On the other hand, Menkoff et. al. (2012a) do find that the returns to the carry trade are correlated with volatility of exchange rates. Sorting currencies into five portfolios as in Lustig et. al. (2007), they find a high average return to the carry trade. They further find that ex post returns for high interest rate currencies are low during times of high volatility. They interpret this to mean that high interest rate currencies are risky because they have poor payoffs when a measure of global volatility is high.

Clarida et. al. (2009) find regularities similar to those in Menkhoff et. al. (2012a). They examine weekly returns of G10 currencies relative to the dollar. They construct carry trade portfolios that put the investor long in the $n$ currencies with the highest interest rate relative to the U.S. and short in the $n$ lowest return currencies, $n=1,2,3,4,5$. They divide their sample into periods of high, medium and low return volatility for each portfolio using both measures of ex post volatility and volatility implied in options. They find that in the periods of lowest volatility, the slope coefficient in regression (4.1) is negative, but in the periods of highest volatility, the slope coefficient is positive. High interest rate currencies pay a low return in volatile times, but a high return during less volatile times. These results also coincide with the conclusions of Brunnermeier et. al. (2009) that the gains from the carry trade unwind during times of "currency crashes", when there are dramatic depreciations of the high-interest rate currencies.

There are some circumstances under which regression (4.1) does not provide much evidence of deviations from uncovered interest parity. Bansal and Dahlquist (2000) and Frankel and Poonawala (2010) find that the slope coefficient in that regression is much closer to 1 for emerging market currencies relative to the U.S. dollar. Another circumstance in which there is some evidence that uncovered interest parity holds is at longer horizons. Alexius (2001), Chinn and Meredith (2004), and Chinn (2006) all report a regression of long-term changes in exchange rates on long-term interest rate differentials. For example, Chinn (2006) considers a regression of the 10-year change in the log of the exchange rate on the difference in 10-year yields to maturity on quarterly data for Japan, Germany, the U.K. and Canada relative to the U.S. from 1983:I to 2004:IV. The equation is estimated as a panel, imposing the same slope coefficient across currencies. Chinn finds an estimated slope coefficient of 0.708 , and cannot reject the null that the slope coefficient equals one. Similar 
results are found in currency-by-currency regressions, and regressions using 5-year yields. ${ }^{36}$

At the other end of the time spectrum, Chaboud and Wright (2005) find that uncovered interest parity holds well over very short horizons. Specifically, they take into account the fact that a position held during the day does not pay interest, but overnight balances do. A position is deemed to be overnight if it is held past 5 p.m. New York time. So any interest received on a deposit held at 5 p.m. is the same whether the position was held all day or just for a few minutes. The change in the exchange rate from right before until right after 5 p.m. is expected (before 5 p.m.) to equal the interest differential if uncovered interest parity holds. Using data on the Swiss franc, euro, U.K. pound and yen relative to the dollar, Chaboud and Wright estimate regression (4.1) for very short time periods that span 5 p.m. New York time. They find that the slope coefficient is nearly one when the time interval is only an hour or two, but as the time interval increases toward six hours and more, the estimated slope coefficient turns negative.

\section{4.b Risk premium models}

The most direct explanation for the presence of ex ante expected returns is a risk premium. In this case, the risk is from foreign exchange fluctuations. From the outset, we can recognize that there is something different about the logic of foreign exchange risk premiums from the standard intuition about risk premiums. Consider a two-country framework. For Home agents, the Home short-term bond is riskless, and for the Foreign agent, the Foreign short-term bond is riskless. The Home agent bears foreign exchange risk by holding Foreign bonds, and vice-versa. Who should be compensated for bearing foreign exchange risk if all agents can avoid bearing that risk by only holding bonds from their own country?

A key assumption of a useful international model of asset pricing is that different agents get different returns on a given asset. Home agents evaluate nominal returns in units of the Home currency or real returns in units of the Home consumption basket, but Foreign agents evaluate nominal (real) returns in terms of the Foreign currency (consumption basket). This essay does not allow space for a detailed examination of foreignexchange risk, and only can touch on the basics that are relevant for understanding the recent economic literature. We briefly review the basic theory of foreign exchange risk premiums and relate the factors driving the risk premium to the state variables driving stochastic discount factors. See, for example, Backus et. al. (2001) or Brandt et. al. (2006).

Define $D_{t+1} \equiv Q_{t+1} / Q_{t}$ (and $Q_{t}$ is the level of the real exchange rate given by $Q_{t} \equiv \exp \left(q_{t}\right)$ ), and let $d_{t+1} \equiv q_{t+1}-q_{t}$. For simplicity, we will assume in this section that inflation rates are zero, so there is no difference between real and nominal returns in each country. We will assume exchange rates are lognormally distributed.

$\lambda_{t}$ as defined in equation (1.1) is technically not the ex ante excess return for any investor. For Home

\footnotetext{
${ }^{36}$ In contrast, Bekaert et. al. (2007) find no evidence to support the claim that long-horizon uncovered interest parity holds better than short-horizon. A related paper is Clarida et. al. (2003), which develops evidence that term structure spreads are useful in forecasting short-run changes in exchange rates.
} 
agents, who evaluate returns in Home currency, the expected return on Home bonds compared to Foreign bonds is given by $\lambda_{t}^{H} \equiv r_{t}^{*}-r_{t}+E_{t} d_{t+1}+\frac{1}{2} \operatorname{var}_{t} d_{t+1}$. Notice that $\lambda_{t}^{H} \neq \lambda_{t}$ because of the convexity term, $\frac{1}{2} \operatorname{var}_{t} d_{t+1}$. For Foreign investors, the difference between the expected return on Foreign bonds and Home bonds is given by $-\lambda_{t}^{F} \equiv r_{t}^{*}-r_{t}+E_{t} d_{t+1}-\frac{1}{2} \operatorname{var}_{t} d_{t+1}$. Given the sign convention adopted here, $\lambda_{t}^{F}$ is the risk premium earned by Foreign investors on Home bonds. Under these definitions

$$
\lambda_{t}^{H}-\frac{1}{2} \operatorname{var}_{t} d_{t+1}=\lambda_{t}=-\lambda_{t}^{F}+\frac{1}{2} \operatorname{var}_{t} d_{t+1} .
$$

It is possible, in other words, for Home investors to expect a premium for holding Foreign bonds and Foreign investors to expect a premium for holding Home bonds because $\lambda_{t}^{H}=\lambda_{t}+\frac{1}{2} \operatorname{var}_{t} d_{t+1}$ and $\lambda_{t}^{F}=-\lambda_{t}+\frac{1}{2} \operatorname{var}_{t} d_{t+1}$. Note that $\lambda_{t}$ is the simple average of $\lambda_{t}^{H}$ and $-\lambda_{t}^{F}$, so it is the average ex ante risk premium on Foreign bonds.

One of the most famous theorems in asset pricing states that in the absence of opportunities for arbitrage, there exists a stochastic discount factor, $M_{t+1}$ such that the returns on any asset $j$ denominated in units of Home consumption satisfy $1=E_{t}\left(M_{t+1} e^{r_{j, t+1}}\right) \cdot{ }^{37}$ This condition may look familiar as the first-order condition for an agent that is maximizing intertemporal expected utility. $M_{t+1}$ is the agent's intertemporal marginal rate of substitution. But the theorem is much more general than this setting. It says that in the absence of arbitrage, we can always find a strictly positive random variable $M_{t+1}$ that satisfies this condition. Even if agents are not rational, even if there are plenty of market imperfections, as long as pure arbitrage opportunities do not exist, this condition holds. However, as we shall see, the application of this condition in economic models has indeed been to a setting in which agents maximize utility, and in fact generally one in which there are no market imperfections so that markets are complete.

The models we examine assume that in each country there is a short-term bond whose return is riskless in real terms. Applying this relationship to returns on Home and Foreign riskless real bonds, expressing returns in units of Home consumption, we have:

$$
\begin{aligned}
& 1=e^{r_{t}} E_{t} M_{t+1} \text {, and } \\
& 1=e^{r_{t}^{*}} E_{t} M_{t+1} D_{t+1}
\end{aligned}
$$

Under log normality, we can derive from these equations:

$$
\begin{aligned}
& r_{t}=-E_{t} m_{t+1}-\frac{1}{2} \operatorname{var}_{t} m_{t+1}, \\
& r_{t}^{*}=-E_{t} m_{t+1}-E_{t} d_{t+1}-\frac{1}{2} \operatorname{var}_{t} m_{t+1}-\frac{1}{2} \operatorname{var}_{t} d_{t+1}-\operatorname{cov}_{t}\left(m_{t+1}, d_{t+1}\right) .
\end{aligned}
$$

Taking differences, we get

$$
\lambda_{t}=r_{t}^{*}-r_{t}+E_{t} d_{t+1}=-\frac{1}{2} \operatorname{var}_{t} d_{t+1}-\operatorname{cov}_{t}\left(m_{t+1}, d_{t+1}\right)
$$

For returns expressed in units of the Foreign consumption basket, there exists a stochastic discount factor

\footnotetext{
${ }^{37}$ See Cochrane (2005), for example.
} 
$M_{t+1}^{*}$ that satisfies

(4.9) $1=e^{r_{t}^{*}} E_{t} M_{t+1}^{*}$,

(4.10) $1=e^{r_{t}} E_{t} M_{t+1}^{*} D_{t+1}^{-1}$.

Clearly for any $M_{t+1}$ that satisfies (4.5), there must be a $M_{t+1}^{*}$ that satisfies (4.9) defined by $M_{t+1}^{*}=M_{t+1} D_{t+1}$. Or,

(4.11) $d_{t+1}=m_{t+1}^{*}-m_{t+1}$.

In general, there is not a unique stochastic discount factor that satisfies equations (4.4) and (4.5) for returns in Home units, or (4.9) and (4.10) for returns in Foreign units. However, it can be shown that the discount factor is unique when markets are complete. The models we consider in the rest of this subsection assume complete markets.

From the equations above, $\lambda_{t}^{H}=-\operatorname{cov}_{t}\left(m_{t+1}, d_{t+1}\right)$ and $\lambda_{t}^{F}=-\operatorname{cov}_{t}\left(m_{t+1}^{*},-d_{t+1}\right)$. As with any asset, the excess return is determined by the covariance of the return with the stochastic discount factor. If the foreign exchange return, $d_{t+1}$ is negatively correlated with the Home discount factor, $m_{t+1}$, Home investors require a compensation for risk so the Foreign security has an excess return relative to the Home bond. For Foreign investors, the foreign exchange return on a Home bond is $-d_{t+1}$. If $-d_{t+1}$ is negatively correlated with the Foreign discount factor, $m_{t+1}^{*}$, the Home asset is relatively risky for the Foreign investor. Standard empirical methods do not measure $\lambda_{t}^{H}$ or $\lambda_{t}^{F}$ but instead give us more direct evidence on $\lambda_{t}$.

$$
\lambda_{t}=\frac{\lambda_{t}^{H}-\lambda_{t}^{F}}{2}=-\operatorname{cov}_{t}\left(\frac{m_{t+1}+m_{t+1}^{*}}{2}, d_{t+1}\right)
$$

From equation (4.11), we have

$$
E_{t} d_{t+1}=E_{t}\left(m_{t+1}^{*}-m_{t+1}\right),
$$

and from (4.12) we find

$$
\lambda_{t}=\frac{1}{2}\left(\operatorname{var}_{t}\left(m_{t+1}\right)-\operatorname{var}_{t}\left(m_{t+1}^{*}\right)\right) .
$$

From equation (4.14), it is apparent that if the high interest rate currency has the riskier bonds, we must have $\operatorname{cov}\left(r_{t}-r_{t}^{*}, \operatorname{var}_{t}\left(m_{t+1}\right)-\operatorname{var}_{t}\left(m_{t+1}^{*}\right)\right)<0$. A model with this property requires that the variances of the stochastic discount factors be random variables. In the general equilibrium models we discuss, $m_{t}$, for example, is related to moments of Home consumption, and so $\operatorname{var}_{t}\left(m_{t+1}\right)$ is driven by volatility in the Home country consumption. When $\operatorname{var}_{t}\left(m_{t+1}\right)-\operatorname{var}_{t}\left(m_{t+1}^{*}\right)$ is high, in essence the model must incorporate a precautionary saving effect on interest rates, so that $r_{t}-r_{t}^{*}$ tends to be low.

The no-arbitrage conditions, equations (4.4)-(4.5) and (4.9)-(4.10) hold under very general conditions, but do not by themselves give us much insight into the economic determinants of the risk premium. We will next 
turn to two models built on utility-maximizing representative agents with rational expectations in the Home and Foreign countries. In these models, $M_{t+1}$ and $M_{t+1}^{*}$ are the intertemporal marginal rate of substitutions for Home and Foreign agents, respectively.

Generally, models with standard utility functions are not able to account for the uncovered interest parity puzzle. ${ }^{38}$ Some recent papers have employed the representative agent framework, but introduced non-standard preferences. Verdelhan (2010) builds a model based on the Campbell-Cochrane (1999) specification of external habit persistence to explain the familiar uncovered interest parity puzzle. In Verdelhan (2010) there are two symmetric countries. The objective of Home household $i$ is to maximize

$$
E_{t} \sum_{j=0}^{\infty} \beta^{j}\left(C_{i, t+j}-H_{t+j}\right)^{1-\gamma} /(1-\gamma)
$$

where $\gamma$ is the coefficient of relative risk aversion, and $H_{t}$ represents an external habit. $H_{t}$ is defined implicitly by defining the "surplus", $s_{t} \equiv \ln \left(\left(C_{t}-H_{t}\right) / C_{t}\right)$, where $C_{t}$ is aggregate consumption, and $s_{t}$ is assumed to follow the stochastic process:

$$
s_{t+1}=(1-\phi) \bar{s}+\phi s_{t}+\mu\left(s_{t}\right)\left(c_{t+1}-c_{t}-g\right), 0<\phi<1 .
$$

Here, $\phi$ and $\bar{s}$ are parameters, and $c_{t} \equiv \ln \left(C_{t}\right)$ is assumed to follow a simple random walk with drift, $g$ :

$$
c_{t+1}=g+c_{t}+u_{t+1}, \text { where } u_{t+1} \sim \text { i.i.d. } N\left(0, \sigma^{2}\right) .
$$

$\mu\left(s_{t}\right)$ represents the sensitivity of the surplus to consumption growth, and is given by:

$$
\mu\left(s_{t}\right) \equiv \frac{1}{\bar{S}} \sqrt{1-2\left(s_{t}-\bar{s}\right)}-1, \text { when } s_{t} \leq s_{\max }, 0 \text { elsewhere. }
$$

$\bar{S}$ is the steady-state surplus-consumption ratio, and $s_{\max } \equiv \bar{S}+\left(1-\bar{S}^{2}\right) / 2$ is an upper bound on the ratio. The $\log$ of the stochastic discount factor is given by:

$$
m_{t+1}=\ln (\beta)-\gamma\left[g+(\phi-1)\left(s_{t}-\bar{s}\right)+\left(1+\mu\left(s_{t}\right)\right)\left(c_{t+1}-c_{t}-g\right)\right]
$$

When the parameters $\bar{S}$ and $s_{\max }$ are suitably normalized, Verdelhan shows we can write the expected rate of depreciation as:

$$
E_{t} d_{t+1}=-\gamma(1-\phi)\left(s_{t}-s_{t}^{*}\right)
$$

where $s_{t}^{*}$ is the Foreign surplus. The excess return is given by:

$$
\lambda_{t}=-\left(\gamma^{2} \sigma^{2} / \bar{S}^{2}\right)\left(s_{t}-s_{t}^{*}\right)
$$

From the definition of $\lambda_{t}$, we have $r_{t}-r_{t}^{*}=E_{t} d_{t+1}-\lambda_{t}$. Although the empirical evidence that we survey establishes $\operatorname{cov}\left(s_{t+1}-s_{t}, i_{t}-i_{t}^{*}\right)<0$, a relationship for nominal returns, the theoretical literature is largely built to explain real returns. But it is well known that in advanced low-inflation countries, nominal and real exchange rate changes are highly correlated. To a lesser extent, it is agreed that most of the variation in

\footnotetext{
${ }^{38}$ See Bekaert et. al. (1997) on this point.
} 
nominal interest differentials can be attributed to variation in real interest differentials. So the literature builds models to deliver $\operatorname{cov}\left(d_{t+1}, r_{t}-r_{t}^{*}\right)<0$.

Under the assumption of Verdelhan (2010) that $\gamma(1-\phi)<\gamma^{2} \sigma^{2} / \bar{S}^{2}$, this model can account for the finding that $\operatorname{cov}\left(d_{t+1}, r_{t}-r_{t}^{*}\right)<0$. The key to this assumption is that it delivers $\operatorname{var}\left(\lambda_{t}\right)>\operatorname{var}\left(E_{t} d_{t+1}\right)$, which Fama (1984) showed is a necessary condition to account for the uncovered interest parity puzzle. In this model, $E_{t} d_{t+1}$ and $\lambda_{t}$ must be positively correlated, and under the appropriate assumptions $\lambda_{t}$ is more volatile than $E_{t} d_{t+1}$, so the interest differential and $E_{t} d_{t+1}$ move in opposite directions since $r_{t}-r_{t}^{*}=E_{t} d_{t+1}-\lambda_{t}{ }^{39}$

We next turn attention to models based on Epstein-Zin (1989) preferences. Colacito and Croce (2011) have recently applied the model to understand several properties of equity returns, real exchange rates and consumption. Bansal and Shaliastovich (2010) and Backus, et. al. (2010) demonstrate how model based on can account for the interest-parity anomaly, by delivering $\operatorname{var}\left(\lambda_{t}\right)>\operatorname{var}\left(E_{t} d_{t+1}\right)$.

We consider a simplified example based on Bansal and Shaliastovich (2010). In each country, households are assumed to have Epstein-Zin (1989) preferences. The Home agent's utility is defined by the recursive relationship:

$$
U_{t}=\left\{(1-\beta) C_{t}^{\rho}+\beta\left[E_{t}\left(U_{t+1}^{\alpha}\right)^{\rho / \alpha}\right]\right\}^{1 / \rho}
$$

In this relationship, $\beta$ measures the patience of the consumer, $1-\alpha$ is the degree of relative risk aversion, and $1 /(1-\rho)$ is the intertemporal elasticity of substitution.

Assume an exogenous path for consumption in each country. In the Home country (with $c_{t} \equiv \ln \left(C_{t}\right)$ ):

$$
c_{t+1}-c_{t}=\mu+\sqrt{u_{t}^{h}} \varepsilon_{t+1}^{x}
$$

In the Foreign country, we have:

$$
c_{t+1}^{*}-c_{t}^{*}=\mu^{*}+l_{t}^{*}+\sqrt{u_{t}^{f}} \varepsilon_{t+1}^{* x}
$$

The innovation, $\varepsilon_{t+1}^{x}$, is distributed i.i.d. $N(0,1)$, but may be correlated with $\varepsilon_{t+1}^{*_{x}}$. Conditional variances are stochastic and follow first-order autoregressive processes:

$$
u_{t+1}^{i}=\left(1-\varphi_{u}^{i}\right) \theta_{u}^{i}+\varphi_{u}^{i} u_{t}^{i}+\sigma_{u}^{i} \varepsilon_{t+1}^{i u}, \quad i=h, f
$$

Assume for now that the innovations, $\varepsilon_{t+1}^{i u}$, are uncorrelated, distributed i.i.d. with mean zero and unit variance.

We can log linearize the first-order conditions as in Backus et. al. (2010). We will ignore terms that are not time-varying or that do not affect both the conditional means and variances of the stochastic discount factors, lumping those variables into the catchall terms $\Xi_{t}$ and $\Xi_{t}^{*}$.

The Home discount factor is given by:

\footnotetext{
${ }^{39}$ Moore and Roche $(2002,2010)$ also develop a model based on Campbell-Cochrane preferences.
} 


$$
-m_{t+1}=\gamma_{u}^{r} u_{t}^{h}+\lambda_{x}^{r} \sqrt{u_{t}^{h}} \varepsilon_{t+1}^{x}+\Xi_{t}
$$

The Foreign discount factor is given by:

$$
-m_{t+1}^{*}=\gamma_{u}^{*_{r}} u_{t}^{f}+\lambda_{x}^{*_{r}} \sqrt{u_{t}^{f}} \varepsilon_{t+1}^{*_{x}}+\Xi_{t}^{*}
$$

The parameters in these log-linearization are:

$$
\gamma_{u}^{r}=\alpha(\alpha-\rho) / 2 \quad \gamma_{u}^{* r}=\alpha^{*}\left(\alpha^{*}-\rho^{*}\right) / 2 \quad \lambda_{x}^{r}=1-\alpha \quad \lambda_{x}^{* r}=1-\alpha^{*}
$$

Bansal and Shaliastovich (2010) and Backus et. al. (2010) assume agents have a preference for "early resolution of risk" in the sense described by Epstein and Zin, so $\alpha<\rho$. They also assume that the intertemporal elasticity of substitution is greater than one, which requires $0<\rho<1$. As Bansal and Shaliastovich (2010) explain, these parameter choices are needed in order for this model to account for variance asset pricing facts, such as the term structure of interest rates. Further, they assume $\alpha<0$, in which case the model can generate $\operatorname{cov}\left(E_{t} d_{t+1}, r_{t}-r_{t}^{*}\right)<0$.

Bansal and Shaliastovich assume identical parameters for Home and Foreign household preferences, and assume identical parameters in the stochastic processes for consumption growth. In this case, we find:

$$
\begin{aligned}
& E_{t} d_{t+1}=\gamma_{u}^{r}\left(u_{t}^{h}-u_{t}^{f}\right) \\
& \lambda_{t}=\frac{1}{2}\left(\lambda_{x}^{r}\right)^{2}\left(u_{t}^{h}-u_{t}^{f}\right) .
\end{aligned}
$$

Assuming $\alpha<0$ and $0<\rho<1$ as above, we find $\operatorname{cov}\left(E_{t} d_{t+1}, r_{t}-r_{t}^{*}\right)<0$.

Lustig et. al. (2011) consider a version of this model in which idiosyncratic shocks do not play a key role. Instead, it is asymmetric preferences, which imply different loadings on the common factors that deliver the result that $\operatorname{cov}\left(E_{t} d_{t+1}, r_{t}^{d}\right)<0$. Assume now that $u_{t}^{h}$ and $u_{t}^{f}$ are common to the Home and Foreign countries, and relabel them $u_{t}^{c}$ to indicate a common shock to the variance of output growth. Then

$$
\begin{aligned}
& E_{t} d_{t+1}=\left(\gamma_{u}^{r}-\gamma_{u}^{* r}\right) u_{t}^{c} \\
& \lambda_{t}=\frac{1}{2}\left(\left(\lambda_{x}^{r}\right)^{2}-\left(\lambda_{x}^{* r}\right)^{2}\right) u_{t}^{c}
\end{aligned}
$$

This model can account for $\operatorname{cov}\left(E_{t} d_{t+1}, r_{t}-r_{t}^{*}\right)<0$ if we assume there is asymmetry in the degree of risk aversion, $\alpha \neq \alpha^{*}$, but assume $\rho=\rho^{*}$ and, as above, that $\alpha, \alpha^{*}<0$ and $0<\rho<1$.

Recent sophisticated extensions of the model with Epstein-Zin preferences are Gourio et. al. (2013), Colacito and Croce (2013), and Benigno et. al. (2012). The first extends the model by allowing output to be produced using capital and labor, so that agents get utility over both consumption and leisure. They incorporate the possibility of a "disaster" - a very bad outcome for output in both countries. An important assumption in their model is that the two countries have different exposures to the disaster shock, and that the probability of the disaster is time varying. The model is able to account for some of the important empirical regularities, such as a time-varying risk premium, though it does have the implication (counter to the interpretation of the interest 
parity puzzle) that low-interest rate currencies are riskier.

In all of the general equilibrium models discussed so far, there is no actual trade in output. Home consumers, for example, get utility only from home goods. This greatly simplifies the solution for equilibrium consumption since it must equal equilibrium output (less investment). Colacito and Croce (2013) solve a simple two-country endowment model, in which households in each country consume products produced in both countries, though with a home bias in consumption, putting more weight in utility on goods produced in their own country. They show that the uncovered interest parity puzzle and other real exchange rate anomalies can be reconciled when agents have Epstein-Zin preferences and there is a risky persistent component to output growth. Benigno et. al. (2012) also consider a two-country model with home bias in preferences, and, on the production side, a standard New Keynesian model in which a continuum of monopolistic firms produce goods that are imperfect substitutes for other goods produced in the same country. Output is produced using labor, and households get utility from not working. They consider both a neoclassical version of the model with flexible nominal prices and a sticky-price version with Calvo-price setting with firms setting prices in the currency of the country in which they produce. Monetary policy is determined by a simple Taylor rule. There are shocks to productivity and to monetary policy which drive the uncertainty in the economy. They solve the model via an approximation method, and find that under certain parameter assumptions, the model can account for some of the empirical stylized facts. For example, a monetary policy contraction will lead to the delayed overshooting found in Eichenbaum and Evans (1995), and can reproduce the negative correlation of exchange rate changes and interest rate differentials that defines the interest parity puzzle. ${ }^{40}$ The model can also reproduce the high volatility of real exchange rates we see in the data, and the model draws a link between volatility and the levels of real exchange rates.

Lustig and Verdelhan (2007) implement a test of the model of Epstein-Zin preferences. Theirs is not a test of the general equilibrium models described above, but, in essence a test of whether expected returns are consistent with the Euler equation for U.S. investors. They consider an extended version of the preferences given in equation (4.22), where $C_{t}$ can be interpreted as an aggregate over consumption of nondurable goods, $N_{t}$, and durable consumption flows, $K_{t}$ :

$$
C_{t}=\left[(1-\varepsilon) N_{t}^{\phi}+\varepsilon K_{t}^{\phi}\right]^{1 / \phi}
$$

They show that the expected excess return for any asset $j$ (the expected return minus the U.S. real interest rate) can be written as:

$$
E_{t}\left(r_{t+1}^{j}-r_{t+1}\right)=b^{\prime} \Sigma_{f j}
$$

Here, $b$ is a vector of parameters derived from the model. $\Sigma_{f j}$ is the $3 \times 1$ vector of covariances between the "factors", $f_{t}^{\prime}=\left[n_{t}-n_{t-1}, k_{t}-k_{t-1}, r_{t}^{W}\right]$, and $r_{t}^{j}-r_{t}$, where $n_{t}=\ln \left(N_{t}\right), k_{t}=\ln \left(K_{t}\right)$, and $r_{t}^{W}$ is the $\log$ of the

\footnotetext{
${ }^{40}$ See the discussion in section 3.A.
} 
U.S. market return. We can rewrite (4.33) as:

$$
E_{t}\left(r_{t+1}^{j}-r_{t+1}\right)=x^{\prime} \beta_{j}
$$

where $x=\Sigma_{f f} b, \beta_{j}=\Sigma_{f f}^{-1} \Sigma_{f j}$, and $\Sigma_{f f}$ is the variance-coveraince matrix of $f_{t}$. Lustig and Verdelhan (2007) then follow the standard two-step procedure from the finance literature. We can see from the definition of $\beta_{j}$ that it can be estimated by a regression of $r_{t}^{j}-r_{t}$ on $f_{t}$, for the time-series of each asset $j$. They estimate the "factor prices", the elements of $x$, by doing a cross-section regression of the mean of $r_{t+1}^{j}-r_{t+1}$ on the "betas" (the estimataed $\beta_{j}$ ) across the carry-trade portfolios described in section 4 .a above. They find that these betas can explain 87 percent of the cross-section variation in the average annual return on their eight portfolios. ${ }^{41}$

Alvarez, et. al. (2009) do assume standard constant relative risk aversion preferences but do not assume a representative agent in each country. Instead, there is a cost to accessing asset markets which varies across individuals in the economy. Agents earn money in the goods market, but must pay a time-varying fixed cost to enter the asset market. Suppose the Home country has an increase in money growth. This leads to inflation, which increases the costs of not participating in the financial market, so more agents enter the financial market. They show that as money growth increases, the variance of the pricing kernel for the agents participating in the market falls. Nominal interest rates rise, thus leading to the conclusion that the foreign exchange risk premium is negatively correlated with the Home less Foreign nominal interest differential.

In the next section, we examine a literature in which agents are heterogenous in a different way - they have access to different information, and so expectations are not homogenous across all agents.

\section{4.c Models of market dynamics and market microstructure}

All of the models that we have considered up until this point have assumed a strict form of rational expectations, which includes the assumption that there is a publicly available set of information shared by all agents and no private information. However, a large literature examines cases in which market participants have different sets of information and how that may impact exchange rate dynamics. One important strand of that literature has developed models based on the "microstructure" of foreign exchange markets, highlighting the important role for foreign exchange dealers in aggregating private information. ${ }^{42}$ These models show that in an environment in which the exchange rate is determined by orders submitted to traders who then clear the market, order flow - the demand coming from individuals for foreign exchange - will help determine the exchange rate, because the order flow embodies information. Even when underlying demands are determined by portfolio balance, the flows of foreign exchange into and out of markets can play an important role because

\footnotetext{
${ }^{41}$ However, Burnside (2011) disputes the statistical significance of their estimates, to which Lustig and Verdelhan (2011) reply.

${ }^{4}$ See the seminal contributions by Evans and Lyons (2002a, 2002b), Evans (2002, 2010), Jeanne and Rose (2002) and Bacchetta and van Wincoop (2006). Also see Devereux and Engel (2002) and Breedon and Vitale (2010).
} 
of their information content. This approach has received empirical support in a number of studies. ${ }^{43}$ This literature is large and too complex to survey satisfactorily in a small space. Fortunately, Evans (2011) provides a comprehensive synthesis of this literature.

In this section, we briefly touch on two models of heterogeneous information that can be placed easily into the context of the previous rational expectations models discussed in Section 2. Bacchetta and van Wincoop (2006) consider a monetary model in which agents have symmetric, private information. This model sheds some light on the exchange-rate disconnect puzzle mentioned in section 2.b. ${ }^{44}$ Bacchetta and van Wincoop (2010) build a model in which there are dynamics to information aggregation, which can account for the uncovered interest parity puzzle. ${ }^{45}$

To get some intuition of how private information affects the exchange rate, we work through the simple example in Bacchetta and van Wincoop (2006). Suppose the exchange rate is determined by the model in equation (3.10), repeated here for convenience:

$$
s_{t}=(1-b) f_{1 t}+b f_{2 t}+b E_{t} s_{t+1}
$$

Assume that the first fundamental follows a random walk: $f_{1 t+1}=f_{1 t}+\varepsilon_{1 t+1}$. We will assume $\varepsilon_{1 t}$ is a $N\left(0, \sigma_{1}^{2}\right)$, i.i.d. random variable. Assume $f_{2 t}$ is simply a $N\left(0, \sigma_{2}^{2}\right)$, i.i.d. random variable. Clearly the solution for the exchange rate under rational expectations is:

(4.36) $s_{t}=f_{1 t}+b f_{2 t}$.

Now suppose there is a public signal (a signal that all agents receive) about $f_{1 t+1}: v_{t}=f_{1 t+1}+\varepsilon_{v t}$, where $\varepsilon_{v t}$ is a $N\left(0, \sigma_{v}^{2}\right)$, i.i.d. random variable. In that case, agents in essence have two independent signals about $f_{1 t+1}$. There is $v_{t}$, and also, assuming they observe $f_{1 t}$, it is an unbiased signal since $f_{1 t}=f_{1 t+1}-\varepsilon_{1 t}$. Given that the signals are independent, $E_{t} f_{1 t+1}$ is a weighted average of the two signals, with the weight on each signal proportional to the inverse of its variance:

$$
E_{t} f_{t+1}=a f_{1 t}+(1-a) v_{t},
$$

where $a=\sigma_{1}^{-2} /\left(\sigma_{1}^{-2}+\sigma_{v}^{-2}\right)$. From equation (4.35) iterated one period forward, and taking expectations, we have $E_{t} s_{t+1}=(1-b) E_{t} f_{1 t+1}+b E_{t} f_{2 t+1}+b E_{t} s_{t+2}$. Since markets have no signal about the second fundamental, $E_{t} f_{2 t+1}=0$. Markets do not have any news about future fundamentals past period $t+1$, so $E_{t} f_{t+j}=E_{t} f_{t+1}$ for $j \geq 1$, which implies that $E_{t} s_{t+2}=E_{t} s_{t+1}$ given that $f_{1 t}$ follows a random walk. Hence $E_{t} s_{t+1}=E_{t} f_{1 t+1}$. Using (4.35) and (4.37), we find:

$$
s_{t}=(1-b(1-a)) f_{1 t}+b(1-a) v_{t}+b f_{2 t} .
$$

\footnotetext{
${ }^{43}$ See, for example, Evans and Lyons (2002a, 2002b, 2005, 2008), Evans (2002, 2010), Froot and Ramadorai (2005), Berger et. al. (2008), Breedon and Vitale (2010), Chinn and Moore (2011), and Rime et. al. (2010).

${ }^{4}$ See also Bacchetta and van Wincoop (2011) for a model in which there is private information and model uncertainty, which can lead to an unstable relationship between exchange rates and economic fundamentals.

${ }^{45}$ See Bacchetta and van Wincoop (2012) for a survey of these and related papers.
} 
We compare (4.38) to (4.36) in a moment, after we derive the equilibrium exchange rate under the assumption of heterogenous signals. We will use the label "Model 1" to refer to the model with no signal, and "Model 2" to the case of a public signal.

Bacchetta and van Wincoop (2006) build a model in which agents receive a private signal about the future value of the first fundamental: agent $i$ receives the signal $v_{t}^{i}=f_{1 t+1}+\varepsilon_{v t}^{i}$, where $\varepsilon_{v t}^{i}$ is a $N\left(0, \sigma_{v}^{2}\right)$, i.i.d. random variable. We call this "Model 3". In their model, agents are symmetric, so the equilibrium exchange rate is determined by the average expectation of the future exchange rate, $\bar{E}_{t} S_{t+1}$. Equation (4.35) is replaced by:

$$
s_{t}=(1-b) f_{1 t}+b f_{2 t}+b \bar{E}_{t} s_{t+1} .
$$

Agents in the model are assumed not to observe $f_{2 t}$. In their model, $f_{2 t}$ is interpreted as an equilibrium risk premium. The risk premium comes from idiosyncratic "hedging" demands by each agent, but agents receive no signal on the aggregate hedge component.

We can conjecture that the solution to this model is similar to (4.38). The exchange rate will be a function in equilibrium of $f_{1 t}, f_{2 t}$ and the average signal, which Bacchetta and van Wincoop assume is equal to the true future value of the first fundamental, $\bar{v}_{t}=f_{1 t+1}$. We can write this in undetermined coefficients form as: $s_{t}=c_{1} f_{1 t}+c_{2} f_{2 t}+c_{3} f_{1 t+1}$. In this case, the exchange rate itself will provide information about the future fundamentals. Define $g_{t} \equiv\left(s_{t}-c_{1} f_{1 t}\right) / c_{3}$.

Then from the undetermined coefficients solution, we see $f_{1 t+1}=g_{t}+\varepsilon_{g t}$, where $\varepsilon_{g t} \equiv-c_{2} f_{2 t} / c_{3}$. Here, $\varepsilon_{g t}$ is a $N\left(0, \sigma_{g}^{2}\right)$, i.i.d. random variable, where $\sigma_{g}^{2}=\left(c_{2} / c_{3}\right)^{2} \sigma_{2}^{2}$. Each individual has three independent signals about $f_{1 t+1}: f_{1 t}, v_{t}^{i}$, and $g_{t}$. We can write agent $i$ 's expectation about $f_{1 t+1}$ as a weighted average of those signals, with the weight one each proportional to the inverse of its variance:

$$
E_{t}^{i} f_{t+1}=a_{1} f_{1 t}+a_{v} v_{t}^{i}+a_{g} g_{t}
$$

where $a_{j}=\sigma_{j}^{-2} /\left(\sigma_{1}^{-2}+\sigma_{v}^{-2}+\sigma_{g}^{-2}\right), j=1, v, g$. Averaging across all agents, we get:

$$
\bar{E}_{t} f_{1 t+1}=a_{1} f_{1 t}+a_{v} f_{1 t+1}+a_{g} g_{t} .
$$

Using the same logic as in the case of a public signal, we can conclude $\bar{E}_{t} s_{t+1}=\bar{E}_{t} f_{1 t+1}$. Then substituting from (4.41) into (4.39), we find:

$$
s_{t}=\left(1-b\left(1-a_{1}\right)\right) f_{1 t}+b\left(1-a_{1}\right) f_{1 t+1}+b\left(1+\left(a_{g} / a_{v}\right)\right) f_{2 t} .
$$

Compare equation (4.42) to the solution when there is a public signal of $f_{1 t+1}$, given in equation (4.38). If the public signal were perfect, so that $v_{t}=f_{1 t+1}$, the solutions are almost the same, except that under heterogenous private information, the weight on $f_{2 t}$ is greater. That is because in the private signal case, agents individually do not actually know $f_{1 t+1}$. They try to infer $f_{1 t+1}$ based on their information, but they cannot separate out the 
effects of others' expectations of $f_{1 t+1}$ on the exchange rate from the effect of $f_{2 t}$. So when $f_{2 t}$ rises, which causes $s_{t}$ to rise, they attribute some possibility that there has been a permanent increase in $f_{1 t+1}$. Because a permanent increase in the first fundamental has a larger effect on the exchange rate than a transitory increase in the second fundamental in Model 1, this "rational confusion" tends to magnify the effect of an increase in $f_{2 t}$ on the exchange rate.

Bacchetta and van Wincoop (2006) use this model to help account for the "disconnect" between exchange rates and fundamentals. This refers to the lack of a relationship that econometricians find between the exchange rate and the economic fundamentals that are supposed to drive the exchange rate according to models. The success of the econometric enterprise depends on the information that is used to explain exchange rates. Define $\Omega_{t}$ to be the econometrician's information set used to explain $s_{t}$ and let $\sigma^{2} \equiv \operatorname{var}\left(s_{t}-E\left(s_{t} \mid \Omega_{t}\right)\right)$, so that $\sigma^{2}$ is the unexplained exchange rate variance. We will assume that the econometrician is not able to observe $f_{2 t}$, perhaps because it is an umeasurable risk premium or other unmeasurable economic fundamental.

First compare Model 1 to Model 2. In Model 1, if $f_{2 t}$ is not in $\Omega_{t}, \sigma^{2}=b^{2} \sigma_{2}^{2}$. In model 2, if $f_{2 t}$ is not in $\Omega_{t}$ but $f_{1 t}$ and $v_{t}$ are, then $\sigma^{2}=b^{2} \sigma_{2}^{2}$, just as in Model 1 when $f_{2 t}$ is not observed by the econometrician. However, it is likely that the econometrician will not measure all of the public signals that the market uses, so $v_{t}$ is also not in $\Omega_{t}$. Recognizing that $v_{t}=f_{1 t}+\varepsilon_{1 t+1}+\varepsilon_{v t}$, we can rewrite (4.38) as:

$$
s_{t}=f_{1 t}+b(1-a)\left(\varepsilon_{1 t+1}+\varepsilon_{v t}\right)+b f_{2 t} .
$$

Then when $\Omega_{t}$ contains only $f_{1 t}$, we find

$$
\sigma^{2}=b^{2}\left[(1-a)^{2}\left(\sigma_{1}^{2}+\sigma_{v}^{2}\right)+\sigma_{2}^{2}\right]=b^{2}\left[\frac{\sigma_{1}^{4}}{\sigma_{1}^{2}+\sigma_{v}^{2}}+\sigma_{2}^{2}\right] \text {. }
$$

We see that the more precise the signal about $f_{1 t+1}$, which means smaller $\sigma_{v}^{2}$, the greater the disconnect for the econometrician. That is because the stronger the signal the market has about $f_{1 t+1}$, the more important is $\varepsilon_{1 t+1}$ in driving the exchange rate.

Now consider the private information model. If only $f_{2 t}$ is excluded from $\Omega_{t}$, we find that the variance of the econometrician's fit is given by $b^{2}\left(1+\left(a_{g} / a_{v}\right)\right)^{2} \sigma_{2}^{2}$. This is a larger variance than in Model 1 or Model 2 in the case when only $f_{2 t}$ is excluded from $\Omega_{t}$, and this arises from the fact that the rational confusion causes an excess response of the exchange rate to the unobserved variable $f_{2 t}$ in Model 3. Now consider the plausible case in which the econometrician only includes $f_{1 t}$ in $\Omega_{t}$. We can rewrite the solution (4.42) as

$$
s_{t}=f_{1 t}+b\left(1-a_{1}\right) \varepsilon_{1 t+1}+b\left(1+\left(a_{g} / a_{v}\right)\right) f_{2 t} .
$$

In this case

$$
\sigma^{2}=b^{2}\left[\left(1-a_{1}\right)^{2} \sigma_{1}^{2}+\left(1+\left(a_{g} / a_{v}\right)\right)^{2} \sigma_{2}^{2}\right] .
$$


With some effort, it can be shown that the variance in expression (4.46) is larger than the variance in (4.44) that is, when signals are private, the variance of the exchange rate that is unexplained by the econometrician is even larger than when signals are public.

A different sort of information heterogeneity arises in Bacchetta and van Wincoop's (2010) model of the uncovered interest parity puzzle. Their model formalizes an idea raised in Froot and Thaler (1990) and developed informally in Eichenbaum and Evans (1995). The notion is that investors may react slowly to changes in financial markets because it is costly to evaluate new information and costly to adjust portfolios continuously.

Suppose, as in Bacchetta and van Wincoop (2010), the short term interest rate is controlled by monetary policymakers, and follows a simple autoregressive process:

(4.47) $i_{t}-i_{t}^{*}=\rho\left(i_{t-1}-i_{t-1}^{*}\right)+u_{t}, \quad 0<\rho<1$.

Agents hold portfolios of Home and Foreign bonds, which are imperfect substitutes because of foreign exchange risk. Suppose that the Foreign interest rate rises. Ceteris paribus, this leads to an increase in demand for Foreign bonds, which causes the Foreign currency to appreciate. Only some agents, however, enter the market and purchase more Foreign bonds because of the costs of adjustment. The agents that act first will earn an excess return on their Foreign bonds. As time passes, other agents reassess their portfolios and buy foreign bonds, leading to a further appreciation. So, after the initial increase in the Foreign interest rate, the currency appreciates initially but continues to appreciate for some time as the whole market gradually adjusts its portfolio. The early movers might earn a high excess return, but the expected return differential will die out over time. For example, suppose the expected excess return on the Foreign bond has a persistence given by $\delta$ : (4.48) $\lambda_{t}=\delta \lambda_{t-1}-\gamma u_{t}, \quad 0<\delta<1$.

Assume $u_{t}$ has unit variance, and using the fact that $i_{t}-i_{t}^{*}=E_{t} s_{t+1}-s_{t}-\lambda_{t}$, it is straightforward to calculate $\operatorname{cov}\left(E_{t} s_{t+1}-s_{t}, i_{t}-i_{t}^{*}\right)=\frac{-\gamma}{1-\rho \delta}+\frac{1}{1-\rho^{2}}$. This will be negative if $\gamma>\frac{1-\rho \delta}{1-\rho^{2}}$. If the initial reaction of $\lambda_{t}$ is large enough, and $\lambda_{t}$ is sufficiently persistent relative to the interest differential, the model can deliver the negative correlation of the interest differential with the change in the exchange rate.

If some investors are buying Foreign bonds, who is selling them? Bacchetta and van Wincoop assume that the inactive investors maintain the shares of their wealth invested in Home and Foreign bonds constant in between periods of portfolio rebalancing. Since the Foreign currency has appreciated, the value of Foreign bonds increases for these inactive investors, so they must sell some of those bonds in order to maintain the constant share. The infrequent adjustment of portfolios can be optimal because of the cost of reassessing the optimal portfolio and rebalancing.

\section{4.d Deviations from rational expectations}

Perhaps a simpler explanation of the uncovered interest parity puzzle is that even with no private 
information, agents do not form expectations rationally. It is obvious that one could "hardwire" a model of expectations formation that can account for the empirical failure of uncovered interest parity from regression (4.1). There are no explicit ground rules for building models of expectations that deviate from rational expectations. Implicitly, the literature has applied two criteria: that the model of expectations is somehow intuitively plausible, and/or that it has other support in the data beyond its ability to account for the interest parity puzzle.

In the spirit of McCallum (1994), we can modify the New Keynesian model of section 2.b, but assume that the market's expectation of the currency depreciation differs from the rational expectation by a mean-zero, i.i.d. random variable, $u_{t}$ :

$$
\hat{E}_{t}\left(s_{t+1}-s_{t}\right)=E_{t}\left(s_{t+1}-s_{t}\right)+u_{t}
$$

where $\hat{E}_{t}$ refers to the market's expectation, rather than the rational expectation. This model of expectations has a ring of plausibility. Perhaps agents in the market do not make the effort to calculate the fully rational expectations, so that each period they make an error in expectations formation that has a mean of zero and is not persistent, so the deviation from rational expectations is not systematic.

We can combine this assumption with the price adjustment equation and the monetary policy rule of the New Keynesian model of section 2.a. We summarize those equations here:

$$
\begin{aligned}
& \pi_{t}-\pi_{t}^{*}=\delta q_{t}+\beta E_{t}\left(\pi_{t+1}-\pi_{t+1}^{*}\right) \\
& i_{t}-i_{t}^{*}=\sigma\left(\pi_{t}-\pi_{t}^{*}\right)+\varepsilon_{t}-\varepsilon_{t}^{*}
\end{aligned}
$$

Assume uncovered interest parity holds, but using market expectations, so

$$
\hat{E}_{t}\left(s_{t+1}-s_{t}\right)=i_{t}-i_{t}^{*}
$$

Eliminating the interest differential, the system comprised of (4.49)-(4.52) can be written

$$
E_{t} z_{t+1}=B z_{t}+w_{t}
$$

where $z_{t}=\left[\begin{array}{c}\pi_{t}-\pi_{t}^{*} \\ q_{t}\end{array}\right], w_{t}=\left[\begin{array}{c}0 \\ \varepsilon_{t}-\varepsilon_{t}^{*}-u_{t}\end{array}\right], B=\left[\begin{array}{cc}1 / \beta & -\delta / \beta \\ (\sigma \beta-1) / \beta & (\beta+\delta) / \beta\end{array}\right]$.

This system is identical to that of the New Keynesian model, (2.12), except that $\varepsilon_{t}-\varepsilon_{t}^{*}-u_{t}$ replaces $\varepsilon_{t}-\varepsilon_{t}^{*}$ in the second element in the $w_{t}$ vector, and there is no interest-rate smoothing. As in section 2.a, assume (for purposes of making the solution simpler) that $\sigma \beta=1$. Also assume $\varepsilon_{t}$ and $\varepsilon_{t}^{*}$ are serially uncorrelated (so $\rho_{\varepsilon}$ from section 2.a equals zero.) The solution to (4.53) is the same as the solution to (2.12), but replacing $\varepsilon_{t}-\varepsilon_{t}^{*}$ with $\varepsilon_{t}-\varepsilon_{t}^{*}-u_{t}$. From (2.18) we have

$$
\pi_{t}-\pi_{t}^{*}=-\frac{\delta \beta}{\delta+\beta}\left(\varepsilon_{t}-\varepsilon_{t}^{*}-u_{t}\right)
$$

Then from (4.51) we can solve for the interest differential, 


$$
i_{t}-i_{t}^{*}=\frac{\delta+\beta-\sigma \delta \beta}{\delta+\beta}\left(\varepsilon_{t}-\varepsilon_{t}^{*}\right)+\frac{\sigma \delta \beta}{\delta+\beta} u_{t}
$$

From (4.55) as well as (4.49) and (4.52), we find

$$
E_{t} s_{t+1}-s_{t}=\frac{\delta+\beta-\sigma \delta \beta}{\delta+\beta}\left(\varepsilon_{t}-\varepsilon_{t}^{*}-u_{t}\right)
$$

Compariing (4.55) to (4.56), we see immediately that $E_{t}\left(s_{t+1}-s_{t}\right)=i_{t}-i_{t}^{*}$ if there are no expectational errors $\left(u_{t}=0\right)$. However, if $\delta+\beta-\sigma \delta \beta>0$, it is evident that the expectational shock imparts a force that drives $E_{t}\left(s_{t+1}-s_{t}\right)$ and $i_{t}-i_{t}^{*}$ in opposite directions. If the variance of $u_{t}$ is sufficiently large relative to the variance of $\varepsilon_{t}$, this model can even deliver a negative slope coefficient in the familiar interest parity regression, (1.6).

Even though the deviations from rational expectations in equation (4.49) are white noise, these errors induce a correlation between the expected change in the exchange rate and the interest differential. Since $E_{t}\left(s_{t+1}-s_{t}\right)=i_{t}-i_{t}^{*}-u_{t}$, holding interest rates constant, a positive realization of $u_{t}$ implies the Home currency is expected (rationally) to appreciate between $t$ and $t+1$. That is, $E_{t}\left(s_{t+1}-s_{t}\right)$ falls. In this sticky-price framework, and given the stationarity of the real exchange rate, there must be a real Home depreciation at time $t$ in order to generate the expectation of the appreciation. The Home real depreciation raises Home inflation relative to Foreign inflation, inducing a reaction by policymakers in both countries so that $i_{t}-i_{t}^{*}$ rises, which implies a negative correlation between $E_{t}\left(s_{t+1}-s_{t}\right)$ and $i_{t}-i_{t}^{*}$.

Burnside et. al. (2011b) generate a negative correlation between $E_{t}\left(s_{t+1}-s_{t}\right)$ and $i_{t}-i_{t}^{*}$ in a monetary model in which agents receive a signal about future growth of the monetary fundamental. The expectational error that agents make is putting too much weight on the signal they receive. Their signal, in other words, is actually less informative than agents believe. This assumption not only sounds plausible, but, as the paper notes, has empirical support in two forms. First, surveys and experimental data tend to confirm traders overweight their private signals. Second, the model of overconfidence is helpful in explaining anomalies in stock and bond markets.

Begin with a present-value model of the type we have discussed in section 3:

$$
s_{t}=(1-\beta) f_{t}+\beta \hat{E}_{t} s_{t+1}, \quad 0<\beta<1,
$$

where $f_{t}$ is the economic fundamental that drives the exchange rate. $\hat{E}_{t} s_{t+1}$ refers to agents' expectation of $s_{t+1}$, which does not equal the rational expectation, $E_{t} s_{t+1}$, in this model. Assume the fundamental evolves according to:

$$
f_{t+1}-f_{t}=u_{t+1}
$$

where $u_{t+1} \sim$ i.i.d., $N\left(0, \sigma_{u}^{2}\right)$. Agents receive a signal, $v_{t}$ at time $t$ that conveys some information about $u_{t+1}$, but 
does not reveal $u_{t+1}$ perfectly.

In a present-value model, when the expected growth in the fundamental increases holding $f_{t}$ constant, there is both an increase in the expected value of $s_{t+1}-s_{t}$, and a jump up in $s_{t}$. The latter implication can be seen by rewriting (4.57) as $s_{t}=f_{t}+\beta\left(\hat{E}_{t} s_{t+1}-s_{t}\right) /(1-\beta)$. When agents overweight their signal, a positive realization of $v_{t}$ leads them to increase their expectation of $f_{t+1}-f_{t}$ too much. As a result, $\hat{E}_{t} s_{t+1}-s_{t}$ rises too much compared to the rationally expected depreciation, so the increase in $i_{t}-i_{t}^{*}$ is excessive. Also, $s_{t}$ increases more than it would under rational expectations. When the actual value of $f_{t+1}$ is realized in period $t+1$, on average $f_{t+1}-f_{t}$ is less than $E_{t} f_{t+1}-f_{t}$ conditional on a positive realization of the signal $v_{t}$. Then on average $s_{t+1}-s_{t}$ rises less than $E_{t} s_{t+1}-s_{t}$, while $i_{t}-i_{t}^{*}$ has risen more than under rational expectations. This accounts for the downward bias, and possibly even negative coefficient, in the regression of $s_{t+1}-s_{t}$ on $i_{t}-i_{t}^{*}$.

Gourinchas and Tornell (2004) provide another avenue for deviations from rational expectations. They note that evidence from the term structure can be interpreted as markets underestimating the persistence of short-run nominal interest rate changes. Suppose $i_{t}-i_{t}^{*}$ rises, but the market believes the increase is transitory. In period $t+1$, the interest differential, $i_{t+1}-i_{t+1}^{*}$ on average turns out to be greater than the market expected. In the model of Gourinchas and Tornell, an increase in $i_{t}-i_{t}^{*}$ is associated with a Home currency appreciation - a decline in $s_{t}$-as in the models of section 2. In their model, equation (4.52) holds, so an increase in $i_{t}-i_{t}^{*}$ also leads to an expected depreciation - that is the currency appreciates at time $t$ but is expected to depreciate between $t$ and $t+1$ so that $\hat{E}_{t} s_{t+1}-s_{t}$ exactly equals $i_{t}-i_{t}^{*}$. At time $t+1$ investors are surprised (on average) to find that $i_{t+1}-i_{t+1}^{*}$ is higher than they expected, so it is as if there is a positive surprise in $i_{t+1}-i_{t+1}^{*}$ at time $t+1$. On average, the currency appreciates relative to $\hat{E}_{t} s_{t+1}$. So, while $i_{t}-i_{t}^{*}$ equals $\hat{E}_{t} s_{t+1}-s_{t}$, the average change in $s_{t+1}-s_{t}$ is smaller than the change in $i_{t}-i_{t}^{*}$, which can account for the empirical findings of the uncovered interest parity puzzle. Indeed the correlation between $s_{t+1}-s_{t}$ and $i_{t}-i_{t}^{*}$ can be negative if the average (absolute value of the) mistake in the forecast of $i_{t+1}-i_{t+1}^{*}$ is large enough.

Ilut (2012) develops a model of ambiguity aversion that can be seen as providing a foundation for the assumption that agents underestimate the persistence of the interest-rate differential, as in Gourinchas and Tornell (2004). In Ilut's model, agents exhibit ambiguity aversion, which implies that they tend to overweight possible bad outcomes in forming their expectations. In the model, investors seek profit when there is an interest differential. The profit is smaller when the interest differential is less persistent, an outcome which the investors believe is more probable than would be inferred under rational expectations.

\section{4.e Peso problems}

Several recent papers have suggested that the uncovered interest parity puzzle is a mirage - that, in 
essence, the standard errors of the estimated slope coefficient in regression (4.1) are much larger than are generally reported, so that we really cannot reject the null hypothesis of uncovered interest parity. ${ }^{46}$

The "peso problem" is not a statistical bias per se, but a problem that arises when the econometrician's sample is biased. The name arises from the situation that occurred in the 1970's, when the Mexican peso exchange rate was fixed to the dollar, but markets anticipated the devaluation that eventually occurred in 1976. The market's expectation was embodied in forward exchange rates, but any sample of the forward premium that ends before the actual devaluation would find the peso price of a dollar on forward markets persistently larger than the fixed spot rate. Without further information, there is an unexplained bias in the forward rate. The term is used more generally to describe a situation in which there is a large event that may occur but with a small probability, so that a given sample has either no examples of the event or the event occurs less frequently in the sample than its true probability.

Some recent literature ${ }^{47}$ has proposed that the apparent risk-adjusted profitability of the carry trade is really an artifact of the peso problem. Suppose an investor in the Home country follows the strategy of investing $k\left(i_{t}^{*}-i_{t}-\bar{i}\right)$ of the Home currency in the Foreign short-term bond in period $t$, financed by borrowing in the Home currency. ${ }^{48}$ The profits one period later per unit of investment are

$$
\varphi_{t+1} \equiv\left(S_{t+1} / S_{t}\right)\left(1+i_{t}^{*}\right)-\left(1+i_{t}\right)
$$

given in Home currency units. This strategy is on average profitable if

$$
E\left(\varphi_{t+1}\left(i_{t}^{*}-i_{t}-\bar{r}\right)\right)=\operatorname{cov}\left(\varphi_{t+1}, i_{t}^{*}-i_{t}\right)>0,
$$

which is approximately equivalent to the condition that the slope coefficient in regression (4.1) is less than one.

Suppose there are two states of the world, state 1 and 2 . Conditional on state 1 , the profits from this carry trade strategy are expected to be positive, which we denote as $E_{1}\left(\varphi_{t+1}\left(i_{t}^{*}-i_{t}-\bar{i}\right)\right)>0$. State 2 is a state which occurs infrequently, and is one of a "currency crash". ${ }^{49}$ In state $2, E_{2}\left(\varphi_{t+1}\left(i_{t}^{*}-i_{t}-\bar{i}\right)\right)<0$. If state 2 occurs with probability $\pi$, then the true expected profit per unit of investment from the carry trade is:

$$
(1-\pi) E_{1}\left(\varphi_{t+1}\left(i_{t}^{*}-i_{t}-\bar{i}\right)\right)+\pi E_{2}\left(\varphi_{t+1}\left(i_{t}^{*}-i_{t}-\bar{i}\right)\right)
$$

Now suppose in the econometrician's data set, the currency crash state is observed with frequency $\pi^{\prime}$, which is smaller than the true probability, $\pi^{\prime}<\pi$. The econometrician's measured expected profit is

$$
\left(1-\pi^{\prime}\right) E_{1}\left(\varphi_{t+1}\left(r_{t}^{*}-r_{t}-\bar{r}\right)\right)+\pi^{\prime} E_{2}\left(\varphi_{t+1}\left(r_{t}^{*}-r_{t}-\bar{r}\right)\right),
$$

which is greater than the true expected profit given by equation (4.59).

Can a peso problem of this type account for the finding of a slope coefficient less than one in the Fama regression, (4.1)? That is, does it mean that the apparent profitability of the carry trade is just an illusion

\footnotetext{
${ }^{46}$ See for example, Baillie and Bollserslev (2000), Zivot (2000), Bekaert and Hodrick (2001), and West (2012).

${ }^{47}$ See Brunnermeier, et. al. (2009), Burnside et. al. (2011a, 2011c), Farhi et. al. (2009), Farhi and Gabaix (2011), Gourio et. al. (2013).

$48 \bar{i}$ is the mean of $i_{t}^{*}-i_{t}$ in this example.

49 This is the term introduced by Brunnermeier, et. al. (2009).
} 
because the currency crash state has been observed less frequently in the data than its true likelihood of occurring? Burnside et. al. (2006, 2011a, 2011c) use data on foreign exchange options that allow an investor to hedge their carry trade portfolio against large losses in the case of a rare event that has a large negative payoff. They find that the profit from the hedged carry trade is not too different from the unhedged carry trade, suggesting that the potential losses in the currency crash state are not large enough to account for the apparent profitability of the carry trade.

However, when investors are risk averse, profits in all states are discounted by the stochastic discount factor, as in the no-arbitrage condition discussed above equation (4.4). In this case, we can write the noarbitrage condition as:

$$
(1-\pi) E_{1}\left(M_{t+1} \varphi_{t+1}\left(i_{t}^{*}-i_{t}-\bar{i}\right)\right)+\pi E_{2}\left(M_{t+1} \varphi_{t+1}\left(i_{t}^{*}-i_{t}-\bar{i}\right)\right)=0,
$$

where $M_{t+1}$ is the discount factor for nominal returns. It may appear to an econometrician that plausible values of the stochastic discount factor still imply a violation of the no-arbitrage condition:

$$
\left(1-\pi^{\prime}\right) E_{1}\left(M_{t+1} \varphi_{t+1}\left(i_{t}^{*}-i_{t}-\bar{i}\right)\right)+\pi^{\prime} E_{2}\left(M_{t+1} \varphi_{t+1}\left(i_{t}^{*}-i_{t}-\bar{i}\right)\right)>0
$$

But Burnside et. al. (2011a, 2011c) make the case that if the frequency of state 2 is sufficiently underestimated, the stochastic discount factor in state 2 (when there are losses, and the marginal utility of investors is relatively high) could be high enough to account for the apparent failure of the no-arbitrage condition. They conclude that we cannot reject the hypothesis that the risk-adjusted return from the carry trade is expected to be zero, taking into account the peso problem and the variation in the discount factor.

\section{Conclusions}

Although this survey has suggested many different models, it is questionable that the models allow us to explain, even after the fact, the movements in major currency rates. The dollar/euro market is by far the most heavily traded, and that exchange rate is in many ways the most important. Consider the following swings in the dollar price of a euro:

1. November 2005 - July 2008: The price of a euro rises from $\$ 1.17$ to $\$ 1.59$.

2. July 2008 - November 2008: The price of a euro falls from $\$ 1.59$ to $\$ 1.25$.

3. November 2008 - November 2009: The price of a euro rises from $\$ 1.25$ to $\$ 1.50$.

4. November 2009 - May 2010: The price of a euro falls from $\$ 1.50$ to $\$ 1.19$.

5. May 2010 - April 2011: The price of a euro rises from $\$ 1.19$ to $\$ 1.48$.

6. April 2011 - July 2012: The price of a euro falls from $\$ 1.48$ to $\$ 1.22$.

Clearly the post-2007 era has been one of great financial market volatility and stress. That period perhaps presents a laboratory to test and refine theories of the exchange rate. At this stage, we do not have adequate explanations for these exchange-rate swings:

- Was the depreciation of the dollar in the first period associated with the property and equity market boom in the U.S., or does it foretell its bust? What is the mechanism to relate booms and busts to the 
currency value? Or is the change related to monetary policy?

- Why did the dollar appreciate sharply in the second period, which was the apex of the global financial crisis? Was the dollar a "safe haven"? What does that mean?

- Did the appreciation of the euro in the third period represent a return to normality - a reversal of the safe haven motive?

- What accounts for the fall of the euro in the fourth period and rise in the fifth period? Was it comparative ease of monetary policy in the U.S. versus the eurozone?

- The euro's fall in the final period is attributed usually to fears of sovereign default in the eurozone. What mechanism links default risk with currency value?

Answering these questions should provide international economists with plenty of work in the years to come. Currencies are a country's only true national asset (or, in the case of the eurozone, the only asset of the entire currency union.) Understanding their movements surely will shed light on broader asset pricing and macroeconomic questions. While the work of the past fifteen years that is surveyed here has broadened and deepened our understanding of the factors that influence exchange rates, we still are not at the stage where we can provide a convincing explanation for the actual movements in currency values. 


\section{Reference}

Abhyankar, Abhay; Sarno Lucio; and, Giorgio Valente. 2005. "Exchange Rates and Fundamentals: Evidence on the Economic Value of Predictability." Journal of International Economics 66, 325-348.

Adolfson, Malin; Stefan Laséen; Jesper Lindé; and, Mattias Villani. 2007. "Bayesian Estimation of An Open Economy DSGE Model with Incomplete Pass-Through.” Journal of International Economics 72, 481-511.

Adolfson, Malin; Stefan Laséen; Jesper Lindé; and, Mattias Villani. 2008. "Evaluating An Estimated New Keynesian Small Open Economy Model.” Journal of Economic Dynamics and Control 32, 2690-2721.

Alexius, Annika. 2001. "Uncovered Interest Parity Revisited." Review of International Economics 9, 505-517.

Alvarez, Fernando; Andrew Atkeson; and, Patrick Kehoe. 2009. "Time-Varying Risk, Interest Rates and Exchange Rates in General Equilibrium." Review of Economic Studies 76, 851-878.

Andersen, Torben G.; Tim Bollerslev; Francis X. Diebold; and, Clara Vega. 2003. "Micro Effects of Macro Announcements: Real-Time Price Discovery in Foreign Exchange." The American Economic Review 93, 38-62.

Andersen, Torben G.; Tim Bollerslev; Francis X. Diebold; and, Clara Vega. 2007. "Real Time Price Discovery in Global Stock, Bond, and Foreign Exchange Markets." Journal of International Economics 73, 251-277.

Bacchetta, Philippe, and Eric van Wincoop. 2006. "Can Information Heterogeneity Explain the Exchange Rate Determination Puzzle?" The American Economic Review 96, 552-576.

Bacchetta, Philippe, and Eric van Wincoop. 2010. "Infrequent Portfolio Decisions: A Solution to the Forward Discount Puzzle.” American Economic Review 100, 870-904.

Bacchetta, Philippe, and Eric van Wincoop. 2011. "On the Unstable Relationship between Exchange Rates and Macroeconomic Fundamentals.” Working paper, Department of Economics, University of Virginia.

Bacchetta, Philippe, and Eric van Wincoop. 2012. "Modeling Exchange Rates with Incomplete Information." In Jessica James; Ian Marsh; and, Lucio Sarno, eds. Handbook of Exchange Rates. (Wiley).

Backus, David K.; Silverio Foresi; and, Chris I. Telmer. 2001. "Affine Term Structure Models and the Forward Premium Anomaly." The Journal of Finance 56, 279-304.

Backus, David K.; Federico Gavazzoni; Chris Telmer; and, Stanley E. Zin. 2010. "Monetary Policy and the Uncovered Interest Parity Puzzle." National Bureau of Economic Research, working paper no. 16218.

Baillie, Richard T., and Tim Bollerslev. 2000. "The Forward Premium Anomaly is Not as Bad as You Think." Journal of International Money and Finance, 19, 471-488.

Bansal, Ravi, and Magnus Dahlquist. 2000. "The Forward Premium Puzzle: Different Tales from Developed and Emerging Economies.” Journal of International Economics 51, 115-144.

Bansal, Ravi, and Ivan Shaliastovich. 2010. "A Long-Run Risks Explanation of Predictability Puzzles in Bond and Currency Markets." Unpublished working paper, Duke University and Wharton Business School.

Beine, Michel; Gust Janssen; and, Christelle Lecourt. 2009. "Should Central Bankers Talk to the Foreign Exchange Markets?" Journal of International Money and Finance 28, 776-803.

Bekaert, Geert, and Robert J. Hodrick. 2001. "Expectations Hypotheses Tests." The Journal of Finance 56, 1357-1394.

Bekaert, Geert; Robert J. Hodrick; and, David A. Marshall. 1997. "The Implications for First-Order Risk Aversion for Asset Market Risk Premiums.” Journal of Monetary Economics 40, 3-39.

Bekaert, Geert; Min Wei; and, Yuhang Xing. 2007. "Uncovered Interest Rate Parity and The Term Structure." Journal of International Money and Finance 26, 1038-1069.

Benigno, Gianluca. 2004. "Real Exchange Rate Persistence and Monetary Policy Rules." Journal of Monetary Economics 51, 473-502.

Benigno, Gianluca, and Pierpaolo Benigno. 2008. "Exchange Rate Determination under Interest Rate Rules." Journal of International Money and Finance 27, 971-993.

Benigno, Gianluca, and Christoph Thoenissen. 2003. "Equilibrium Exchange Rates and Supply- Side Performance." The Economic Journal 113, 103-124.

Benigno, Ginaluca; Pierpaolo Benigno; and, Salvatore Nisticò. 2012. "Risk, Monetary Policy and The Exchange Rate.” NBER Macroeconomics Annual 2011, 247-309.

Berger, David W.; Alain P. Chaboud; Sergey V. Chernenko; Edward Howorka,; and, Jonathan H. Wright. 2008. "Order Flow and Exchange Rate Dynamics in Electronic Brokerage System Data." Journal of International Economics 75, 93-109. 
Bergin, Paul R. 2006. "How Well Can the New Open Economy Macroeconomics Explain the Exchange Rate and Current Account?" Journal of International Money and Finance 25, 675-701.

Betts, Caroline, and Michael B. Devereux. 1996. "The Exchange Rate in A Model of Pricing-to-Market." European Economic Review 40, 1007-1021.

Betts, Caroline, and Michael B. Devereux. 2000. "Exchange Rate Dynamics in A Model of Pricing-to-Market." Journal of International Economics 50, 215-244.

Bilson, John F.O. 1981. “The 'Speculative Efficiency' Hypothesis.” Journal of Business 54, 435-451.

Bjørnland, Hilde C. 2009. "Monetary Policy and Exchange Rate Overshooting: Dornbusch was Right after All." Journal of International Economics 79, 64-77.

Blanchard, Oliver; Francesco Giavazzi; and, Filipa Sa. 2005. "International Investors, the U.S. Current Account, and the Dollar." Brookings Papers on Economic Activity 1, 1-49.

Blanchard, Olivier J., and Charles M. Kahn. 1980. "The Solution of Linear Difference Models under Rational Expectations." Econometrica 48, 1305-1311.

Brandt, Michael W.; John H. Cochrane; and, Pedro Santa-Clara. "International Risk Sharing is Better than You Think, or Exchange Rates are too Smooth." Journal of Monetary Economics 53, 671-698.

Breedon, Francis, and Paolo Vitale. 2010. "An Empirical Study of Portfolio-Balance and Information Effects of Order Flow on Exchange Rates.” Journal of International Money and Finance 29, 504-524.

Brunnermeier, Markus K.; Stefan Nagel; and, Lasse Pedersen. 2009. "Carry Trades and Currency Crashes." NBER Macroeconomics Annual 2008, 313-347.

Burnside, Craig. 2011. "The Cross Section of Foreign Currency Risk Premia and Consumption Growth Risk: Comment." American Economic Review 101, 3456-3476.

Burnside, Craig; Martin Eichenbaum; and, Sergio Rebelo. 2008. "Carry Trade: The Gains of Diversification." Journal of the European Economic Association 6, 581-588.

Burnside, Craig; Martin Eichenbaum; and, Sergio Rebelo. 2011c. "Carry Trade and Momentum in Currency Markets.” Annual Review of Financial Economics 3, 511-535.

Burnside, Craig; Martin Eichenbaum; Isaac Kleshchelski; and, Sergio Rebelo. 2006. "The Returns to Currency Speculation." National Bureau of Economic Research, working paper no. 12489.

Burnside, Craig; Martin Eichenbaum; Isaac Kleshchelski; and, Sergio Rebelo. 2011a. "Do Peso Problems Explain the Returns to the Carry Trade?" Review of Financial Studies. 24, 853-891.

Burnside, Craig; Bing Han; David Hirshleifer; and, Tracy Yue Wang. 2011b. "Investor Overconfidence and the Forward Premium Puzzle." Review of Economic Studies 78, 523-558.

Calvo, Guillermo A., and Carmen M. Reinhart. 2002. "Fear of Floating." The Quarterly Journal of Economics 117, 379-408.

Campbell, John Y., and John H. Cochrane. 1999. "By Force of Habit: A Consumption-Based Explanation of Aggregate Stock Market Behavior.” Journal of Political Economy 107, 205-251.

Campbell, John Y., and Robert J. Shiller. 1988. "The Dividend-Price Ratio and Expectations of Future Dividends and Discount Factors." Review of Financial Studies 1, 195-228.

Cavallo, Michele, and Fabio Ghironi. 2002. "Net Foreign Assets and the Exchange Rate: Redux Revived." Journal of Monetary Economics 49, 1057-1097.

Cerra, Valerie, and Sweta Chaman Saxena. 2010. "The Monetary Model Strikes Back: Evidence from the World." Journal of International Economics 81, 184-196.

Chaboud, Alain P., and Jonathan H. Wright. 2005. "Uncovered Interest Parity: It Works, But Not for Long." Journal of International Economics 66, 349-362.

Chari, V. V.; Patrick J. Kehoe; and, Ellen R. McGrattan. 2002. "Can Sticky Price Models Generate Volatile and Persistent Real Exchange Rates?" The Review of Economic Studies 69, 533-563.

Chen, Yu-Chin, and Kenneth Rogoff. 2003. "Commodity Currencies." Journal of International Economics 60, 133-160.

Chen, Yu-Chin; Kenneth S. Rogoff; and, Barbara Rossi. 2010. "Can Exchange Rates Forecast Commodity Prices?" The Quarterly Journal of Economics 125, 1145-1194.

Cheung, Yin-Wong; Menzie D. Chinn; and, Antonio Garcia Pascual. 2005. "Empirical Exchange Rate Models of the Nineties: Are Any Fit to Survive?” Journal of International Money and Finance 24, 1150-1175. 
Chinn, Menzie D. 2006. "The Partial Rehabilitation of Interest Rate Parity in the Floating Rate Era: Longer Horizons, Alternative Expectations, and Emerging Markets.” Journal of International Money and Finance $25,7-21$.

Chinn, Menzie D., and Guy Meredith. 2004. "Monetary Policy and Long-Horizon Uncovered Interest Parity." IMF Staff Papers 51, 409-430.

Chinn, Menzie D., and Michael J. Moore. 2011. "Order Flow and the Monetary Model of Exchange Rates: Evidence from a Novel Data Set." Journal of Money, Credit and Banking 43, 1599-1624.

Clarida, Richard; Josh Davis; and, Niels Pedersen. 2009. "Currency Carry Trade Regimes: Beyond the Fama Regression." Journal of International Money and Finance 28, 1375-1389.

Clarida, Richard; Jordi Gali; and, Mark Gertler. 2002. "A Simple Framework for International Monetary Policy Analysis." Journal of Monetary Economics 49, 879-904.

Clarida, Richard H.; Lucio Sarno; Mark P. Taylor; and, Giorgio Valente. 2003. "The Out-of-Sample Success of Term Structure Models as Exchange Rate Predictors: A Step Beyond." Journal of International Economics 60, 61-83.

Clarida, Richard H., and Daniel Waldman. 2008. "Is Bad News About Inflation Good News for the Exchange Rate? And If So, Can That Tell Us Anything about the Conduct of Monetary Policy?" In Asset Prices and Monetary Policy (NBER) 371-396.

Clark, Todd E., and Kenneth D. West. 2006. "Using Out-of-Sample Mean Squared Prediction Errors to Test the Martingale Difference Hypothesis." Journal of Econometrics 135, 155-186.

Cochrane, John H. 2005. Asset Pricing: Revised Edition. (Princeton: Princeton University Press).

Colacito, Riccardo, and Mariano Massimiliano Croce. 2011. "Risks for the Long-Run and the Real Exchange Rate.” Journal of Political Economy 119, 153-181.

Colacito, Riccardo, and Mariano Massimiliano Croce. 2013. "International Asset Pricing with Recursive Preferences." Journal of Finance, forthcoming.

Corsetti, Giancarlo; Luca Dedola; and, Sylvain Leduc. 2008. "International Risk Sharing and the Transmission of Productivity Shocks." Review of Economic Studies 75, 443-473.

Devereux, Michael B., and Charles Engel. 2002. "Exchange Rate Pass-Through, Exchange Rate Volatility, and Exchange Rate Disconnect." Journal of Monetary Economics 49, 913-940.

Diebold, Francis X., and Roberto S. Mariano. 1995. "Comparing Predictive Accuracy." Journal of Business and Economic Statistics 13, 253-263.

Disyatat, Piti, and Gabriele Galati. 2007. "The Effectiveness of Foreign Exchange Intervention in Emerging Market Countries: Evidence From the Czech Koruna." Journal of International Money and Finance 26, 383-402.

Dominguez, Kathryn M. E. 2003. "The Market Microstructure of Central Bank Intervention." Journal of International Economics 59, 25-45.

Dominguez, Kathryn M. E. 2006. "When Do Central Bank Interventions Influence Intra-Daily and LongerTerm Exchange Rate Movements?” Journal of International Money and Finance 25, 1051-1071.

Dominguez, Kathryn M. and Jeffrey Frankel. 1993. "Does Foreign Exchange Intervention Matter? The Portfolio Effect.” American Economic Review 83, 1356-1369.

Dornbusch, Rudiger. 1976. "Expectations and Exchange Rate Dynamics." Journal of Political Economy 84, 1161-1176.

Dotsey, Michael, and Margarida Duarte. 2008. "Nontraded Goods, Market Segmentation, and Exchange Rates." Journal of Monetary Economics 55, 1129-1142.

Duarte, Margarida, and Alan C. Stockman. 2005. "Rational Speculation and Exchange Rates." Journal of Monetary Economics 52, 3-29

Dubas, Justin M.; Byung-Joo Lee; and, Nelson C. Mark. 2010. "A Multinomial Logit Approach to Exchange Rate Policy Classification with An Application to Growth." Journal of International Money and Finance 29, 1438-1462.

Ehrmann, Michael, and Marcel Fratzscher. 2005. "Exchange Rates and Fundamentals: New Evidence from Real-Time Data." Journal of International Money and Finance 24, 317-341.

Eichenbaum, Martin, and Charles L. Evans. 1995. "Some Empirical Evidence on the Effects of Shocks to Monetary Policy on Exchange Rates.” The Quarterly Journal of Economics 110, 975-1009. 
Eichengreen, Barry, and Raul Razo-Garcia. 2006. "The International Monetary System in the Last and Next 20 Years.” Economic Policy 21, 393-442.

Enders, Zeno; Müller, Gernot J.; and, Almuth Scholl. 2011. "How Do Fiscal and Technology Shocks Affect Real Exchange Rates?: New Evidence for the United States." Journal of International Economics 83, 5369.

Engel, Charles. 1996. "The Forward Discount Anomaly and the Risk Premium: A Survey of Recent Evidence." Journal of Empirical Finance 3, 123-192.

Engel, Charles. 2000. "Long-Run PPP May Not Hold After All." Journal of International Economics 51, 243273.

Engel, Charles. 2005. "Some New Variance Bounds for Asset Prices." Journal of Money, Credit and Banking 37, 949-955.

Engel, Charles; Nelson C. Mark; and, Kenneth D. West. 2008. "Exchange Rate Models are Not as Bad as You Think.” NBER Macroeconomics Annual 2007, 381-441.

Engel, Charles, and Kenneth D. West. 2004. "Accounting for Exchange Rate Variability in Present Value Models when the Discount Factor is Near One." American Economic Review, Papers and Proceedings 94, 119-125.

Engel, Charles, and Kenneth D. West. 2005. "Exchange Rates and Fundamentals." Journal of Political Economy 113, 485-517.

Engel, Charles, and Kenneth D. West. 2006. "Taylor Rules and the Deutschemark-Dollar Real Exchange Rate." Journal of Money, Credit and Banking 38, 1175-1194.

Epstein, Larry G., and Stanley E. Zin. 1989. "Substitution, Risk Aversion, and the Temporal Behavior of Consumption and Asset Returns: A Theoretical Framework." Econometrica 57, 937-969.

Evans, Martin D. D. 2002. "FX Trading and Exchange Rate Dynamics." The Journal of Finance 57, 24052447.

Evans, Martin D. D. 2010. “Order Flows and the Exchange Rate Disconnect Puzzle.” Journal of International Economics 80, 58-71.

Evans, Martin D.D. 2011. Exchange Rate Dynamics. (Princeton: Princeton University Press).

Evans, Martin D. D., and Richard K. Lyons. 2002a. "Order Flow and Exchange Rate Dynamics." Journal of Political Economy 110, 170-180.

Evans, Martin D. D., and Richard K. Lyons. 2002b. "Informational Integration and FX Trading." Journal of International Money and Finance 21, 807-831.

Evans, Martin D. D., and Richard K. Lyons. 2005. “Do Currency Markets Absorb News Quickly?” Journal of International Money and Finance 24, 197-217.

Evans, Martin D. D., and Richard K. Lyons. 2008. "How Is Macro News Transmitted to Exchange Rates?" Journal of Financial Economics 88, 26-50.

Fama, Eugene F. 1984. "Forward and Spot Exchange Rates.” Journal of Monetary Economics 14, 319-338.

Farhi, Emmanuel, and Xavier Gabaix. "Rare Disasters and Exchange Rates." Working paper, Harvard University.

Farhi, Emmanuel; Samuel P. Fraiberger; Xavier Gabaix; Romain Ranciere; and, Adrien Verdelhan. 2009. "Crash Risk in Currency Markets." Working paper, Harvard University.

Fatum, Rasmus. 2010. "Foreign Exchange Intervention When Interest Rates Are Zero: Does the Portfolio Balance Channel Matter after All?" Federal Reserve Bank of Dallas, Globalization and Monetary Policy Institute Working Paper, No. 57.

Fatum, Rasmus, and Michael Hutchison. 1999. "Is Intervention a Signal of Future Monetary Policy? Evidence from the Federal Funds Futures Market.” Journal of Money, Credit and Banking 31, 54-69.

Fatum, Rasmus, and Barry Scholnick. 2006. "Do Exchange Rates Respond to Day-to-Day Changes in Monetary Policy Expectations When No Monetary Policy Changes Occur?" Journal of Money, Credit and Banking 38, 1641-1657.

Faust, Jon, and John H. Rogers. 2003. "Monetary Policy's Role in Exchange Rate Behavior." Journal of Monetary Economics 50, 1403-1424.

Faust, Jon; John H. Rogers; and, Jonathan H. Wright. 2003. "Exchange Rate Forecasting: the Errors We've Really Made." Journal of International Economics 60, 35-59. 
Faust, Jon; John H. Rogers; Shing-Yi B. Wang; and, Jonathan H. Wright. 2007. "The High-Frequency Response of Exchange Rates and Interest Rates to Macroeconomic Announcements." Journal of Monetary Economics 54, 1051-1068.

Frankel, Jeffrey A. 1979. "On the Mark: A Theory of Floating Exchange Rates Based on Real Interest Differentials.” The American Economic Review 69, 610-622.

Frankel, Jeffrey, and Jumana Poonawala. 2010. "The Forward Market in Emerging Currencies: Less Biased Than in Major Currencies.” Journal of International Money and Finance 29, 585-598.

Frankel, Jeffrey; Sergio L. Schmukler; and, Luis Servén. 2004. "Global Transmission of Interest Rates: Monetary Independence and Currency Regime.” Journal of International Money and Finance 23, 701-733.

Fratzscher, Marcel. 2006. "On the Long-Term Effectiveness of Exchange Rate Communication and Interventions." Journal of International Money and Finance 25, 146-167.

Fratzscher, Marcel. 2008. "Oral Interventions Versus Actual Interventions in Fx Markets - An Event-Study Approach.” The Economic Journal 118, 1079-1106.

Fratzscher, Marcel. 2009. "How Successful is the G7 in Managing Exchange Rates?" Journal of International Economics 79, 78-88.

Froot, Kenneth A., and Tarun Ramadorai. 2005. "Currency Returns, Intrinsic Value and Institutional-Investor Flows." Journal of Finance 60, 1535-1566.

Froot, Kenneth, and Richard H. Thaler. 2001. "Anomalies: Foreign Exchange." Journal of Economic Perspectives 4, 179-192.

Ganelli, Giovanni. 2005. "The New Open Economy Macroeconomics of Government Debt." Journal of International Economics 65, 167-184.

Ghironi, Fabio. 2008. "The Role of Net Foreign Assets in a New Keynesian Small Open Economy Model." Journal of Economic Dynamics and Control 32, 1780-1811.

Gourinchas, Pierre-Olivier, and Helene Rey. 2007. "International Financial Adjustment." Journal of Political Economy 115, 665-773.

Gourinchas, Pierre-Olivier, and Aaron Tornell. 2004. "Exchange Rate Puzzles and Distorted Beliefs.” Journal of International Economics 64, 303-333.

Gourio, François; Michael Siemer; and, Adrien Verdelhan. 2013. "International Risk Cycles.” Journal of International Economics, forthcoming.

Groen, Jan J.J. 2000. "The Monetary Exchange Rate Model as A Long-Run Phenomenon." Journal of International Economics 52, 299-319.

Groen, Jan J.J. 2005. "Exchange Rate Predictability and Monetary Fundamentals in a Small Multi-Country Panel." Journal of Money, Credit and Banking 37, 495-516.

Hagen, Jürgen, and Jizhong Zhou. 2007. "The Choice of Exchange Rate Regimes in Developing Countries: A Multinomial Panel Analysis.” Journal of International Money and Finance 26, 1071-1094.

Hau, Harald. 2000. "Exchange Rate Determination: the Role of Factor Price Rigidities and Nontradeables." Journal of International Economics 50, 421-447.

Ho, Wai-Ming. 2004. "The Liquidity Effects of Foreign Exchange Intervention.” Journal of International Economics 63, 179-208.

Hodrick, Robert. 1987. The Empirical Evidence on the Efficiency of Forward and Futures Foreign Exchange Markets (Harwood: Chur).

Husain, Aasim M.; Ashoka Mody; and, Kenneth S. Rogoff. 2005. "Exchange Rate Regime Durability and Performance in Developing versus Advanced Economies." Journal of Monetary Economics 52, 35-64.

Ilut, Cosmin. 2012. "Ambiguity Aversion: Implications for the Uncovered Interest Parity Puzzle." American Economic Journal:Macroeconomics 4, 33-65.

Ito, Takatoshi. 2003. "Is Foreign Exchange Intervention Effective?: The Japanese Experience in the 1990s." In Paul Mitzen (ed.), Monetary History, Exchange Rates and Financial Markets, Essays in Honour of Charles Goodhart 2, Edward Elgar, UK.

Jeanne, Olivier, and Andrew K. Rose. 2002. "Noise Trading and Exchange Rate Regimes." The Quarterly Journal of Economics 117, 537-569.

Jordà, Òscar, and Alan M. Taylor 2012. "The Carry Trade and Fundamentals: Nothing to Fear but FEER itself." Journal of International Economics, forthcoming. 
Jung, Yongseung. 2007. "Can the New Open Economy Macroeconomic Model Explain Exchange Rate Fluctuations?" Journal of International Economics 72, 381-408.

Juvenal, Luciana. 2011. "Sources of Exchange Rate Fluctuations: Are They Real or Nominal?" Journal of International Money and Finance 30, 849-876.

Kaminsky, Graciela L., and Karen K. Lewis. 1996. "Does Foreign Exchange Intervention Signal Future Monetary Policy?" Journal of Monetary Economics 37, 285-312.

Kearns, Jonathan, and Roberto Rigobon. 2005. "Identifying the Efficacy of Central Bank Interventions: Evidence from Australia and Japan.” Journal of International Economics 66, 31-48.

Kilian, Lutz. 1999. "Exchange Rates and Monetary Fundamentals: What Do We Learn from Long-Horizon Regressions?" Journal of Applied Econometrics 14, 491-510.

Kim, Soyoung, and Nouriel Roubini. 2000. "Exchange Rate Anomalies in the Industrial Countries: A Solution with A Structural VAR Approach.” Journal of Monetary Economics 45, 561-586.

Kollmann, Robert. 2001. "The Exchange Rate in A Dynamic-Optimizing Business Cycle Model with Nominal Rigidities: A Quantitative Investigation.” Journal of International Economics 55, 243-262.

Kollmann, Robert. 2004. "Welfare Effects of a Monetary Union: The Role of Trade Openness." Journal of the European Economic Association 2, 289-301.

Kumhof, Michael. 2010. "On the Theory of Sterilized Foreign Exchange Intervention." Journal of Economic Dynamics and Control 34, 1403-1420.

Landry, Anthony. 2009. "Expectations and Exchange Rate Dynamics: A State-Dependent Pricing Approach." Journal of International Economics 78, 60-71.

Lewis, Karen. K. 1995. “Are Foreign Exchange Intervention and Monetary Policy Related and Does It Really Matter?" Journal of Business 68, 185-214.

Levy-Yeyati, Eduardo, and Federico Sturzenegger. 2003. "To Float or to Fix: Evidence on the Impact of Exchange Rate Regimes on Growth." The American Economic Review 93, 1173-1193..

Lubik, Thomas A., and Frank Schorfheide. 2006. "A Bayesian Look at New Open Economy Macroeconomics.” NBER Macroeconomics Annual 2005, 313-366.

Lustig, Hanno, and Adrien Verdelhan. 2007. "The Cross Section of Foreign Currency Risk Premia and Consumption Growth Risk." The American Economic Review 97, 89-117.

Lustig, Hanno, and Adrien Verdelhan. 2011. "The Cross Section of Foreign Currency Risk Premia and Consumption Growth Risk:Reply.” The American Economic Review 101, 3477-3500.

Lustig, Hanno; Nick Roussanov; and, Adrien Verdelhan. 2011. "Common Risk Factors in Currency Markets." Review of Financial Studies 24, 3731-3777.

Mark, Nelson C. 1995. "Exchange Rates and Fundamentals: Evidence on Long-Horizon Predictability." The American Economic Review 85, 201-218.

Mark, Nelson C. 2009. "Changing Monetary Policy Rules, Learning, and Real Exchange Rate Dynamics." Journal of Money, Credit and Banking 41, 1047-1070.

Mark, Nelson C., and Donggyu Sul. 2001. "Nominal Exchange Rates and Monetary Fundamentals: Evidence from A Small Post-Bretton Woods Panel.” Journal of International Economics 53, 29-52.

McCallum, Bennett. 1994. "A Reconsideration of the Uncovered Interest Parity Relationship." Journal of Monetary Economics 33, 105-132.

McCracken, Michael W., and Stephen G. Sapp. 2005. "Evaluating the Predictability of Exchange Rates Using Long-Horizon Regressions: Mind Your p's and q's!” Journal of Money, Credit and Banking 37, 473-494.

Meese Richard A., and Kenneth Rogoff. 1983. "Empirical Exchange Rate Models of the Seventies: Do They Fit out of Sample?" Journal of International Economics 14, 3-24.

Menkhoff, Lukas; Lucio Sarno; Maik Schmeling; and, Andreas Schrimpf. 2012a. "Carry Trades and Global Foreign Exchange Volatility." Journal of Finance 67, 681-718.

Menkhoff, Lukas; Lucio Sarno; Maik Schmeling; and, Andreas Schrimpf. 2012b. "Currency Momentum Strategies." Journal of Financial Economics, forthcoming.

Molodtsova, Tanya; Alex Nikolsko-Rzhevskyy; and, David H. Papell. 2008. "Taylor Rules with Real-Time Data: A Tale of Two Countries and One Exchange Rate." Journal of Monetary Economics 55, S63-S79.

Molodtsova, Tanya; Alex Nikolsko-Rzhevskyy; and, David H. Papell.2011. "Taylor Rules and the Euro." Journal of Money, Credit and Banking 43, 535-552. 
Molodtsova, Tanya, and David H. Papell. 2009. "Out-of-Sample Exchange Rate Predictability with Taylor Rule Fundamentals.” Journal of International Economics 77, 167-180.

Moore, Michael J., and Maurice J. Roche. 2002. "Less of A Puzzle: A New Look At the Forward Forex Market.” Journal of International Economics 58, 387-411.

Moore, Michael J., and Maurice J. Roche. 2010. "Solving Exchange Rate Puzzles with Neither Sticky Prices Nor Trade Costs.” Journal of International Money and Finance 29, 1151-1170.

Neely, Christopher J. 2005. "An Analysis of Recent Studies of the Effect of Foreign Exchange Intervention." Federal Reserve Bank of St. Louis Working Paper No. 2005-030B.

Neely, Christopher J. 2011. "A Foreign Exchange Intervention in an Era of Restraint." Federal Reserve Bank of St. Louis Review 93, 303-324.

Obstfeld, Maurice, and Kenneth Rogoff. 1995a. "Exchange Rate Dynamics Redux." Journal of Political Economy 103, 624-660.

Obstfeld, Maurice, and Kenneth Rogoff. 1995b. "The Mirage of Fixed Exchange Rates." Journal of Economic Perspectives 9, 73-96.

Obstfeld, Maurice, and Kenneth Rogoff. 2001. "The Six Major Puzzles in International Macroeconomics. Is There a Common Cause?" NBER Macroeconomics Annual 2000, 339-390.

Pasquariello, Paolo. 2010. "Central Bank Intervention and the Intraday Process of Price Formation in the Currency Markets." Journal of International Money and Finance 29, 1045-1061.

Rapach, David E., and Mark E. Wohar. 2002. "Testing the Monetary Model of Exchange Rate Determination: New Evidence from A Century of Data." Journal of International Economics 58, 359-385.

Reinhart, Carmen M., and Kenneth S. Rogoff. 2004. "The Modern History of Exchange Rate Arrangements: A Reinterpretation.” The Quarterly Journal of Economics 119, 1-48.

Reitz, Stefan, and Mark P. Taylor. 2008. "The Coordination Channel of Foreign Exchange Intervention: A Nonlinear Microstructural Analysis." European Economic Review 52, 55-76.

Rime, Dagfinn; Lucio Sarno; and, Elvira Sojli. 2010. "Exchange Rate Forecasting, Order Flow and Macroeconomic Information." Journal of International Economics 80, 72-88.

Rogoff, Kenneth. 1996. "The Purchasing Power Parity Puzzle.” Journal of Economic Literature 34, 647-668.

Sarno, Lucio, and Mark P. Taylor. 2001. "Official Intervention in the Foreign Exchange Market: Is It Effective and, If So, How Does It Work?” Journal of Economic Literature 39, 839-868.

Scholl, Almuth, and Harald Uhlig. 2008. "New Evidence on the Puzzles: Results from Agnostic Identification on Monetary Policy and Exchange Rates." Journal of International Economics 76, 1-13.

Shambaugh, Jay C. 2004. "The Effect of Fixed Exchange Rates on Monetary Policy." The Quarterly Journal of Economics 119, 301-352.

Shiller, Robert J. 1981. "Do Stock Prices Move Too Much to Be justified by Subsequent Changes in Dividends?" The American Economic Review 71, 421-436.

Tavlas George; Harris Dellas; and, Alan C. Stockman. 2008. "The Classification and Performance of Alternative Exchange-Rate Systems.” European Economic Review 52, 941-963.

Taylor, Mark P., and David A. Peel. 2000. "Nonlinear Adjustment, Long-Run Equilibrium and Exchange Rate Fundamentals." Journal of International Money and Finance 19, 33-53.

Verdelhan, Adrien. 2010. "A Habit-Based Explanation of the Exchange Rate Risk Premium." The Journal of Finance 65, 123-146.

Vitale, Paolo. 2003. "Foreign Exchange Intervention: How to Signal Policy Objectives and Stabilise the Economy." Journal of Monetary Economics 50, 841-870.

Wang, Jian. 2010. "Home Bias, Exchange Rate Disconnect, and Optimal Exchange Rate Policy." Journal of International Money and Finance 29, 55-78.

Wang, Jian, and Jason J. Wu. 2012. "The Taylor Rule and Forecast Intervals for Exchange Rates." Journal of Money, Credit and Banking 44, 103-144.

West, Kenneth D. 1988. "Dividend Innovations and Stock Price Volatility." Econometrica 56, 37-61.

West, Kenneth D. 2012. "Econometric Analysis of Present Value Models When the Discount Factor is near One." Journal of Econometrics. Forthcoming.

Zivot, Eric. 2000. "Cointegration and Forward and Spot Exchange Rate Regressions." Journal of International Money and Finance 19, 785-812. 


\section{Technical Appendix to "Exchange Rates and Interest Parity"}

\section{Derivation of results in section 2.a}

To derive the Phillips curve, $\pi_{H t}=\delta\left(w_{t}-a_{t}-p_{H t}\right)+\beta E_{t} \pi_{H t+1}$, take the equation

$$
p_{H t}=(1-\theta) \tilde{p}_{H t}+\theta p_{H t-1}
$$

and substitute for $\tilde{p}_{H t}$ from $\tilde{p}_{H t}=(1-\theta \beta)\left(w_{t}-a_{t}\right)+\theta \beta E_{t} \tilde{p}_{H t+1}$ to get:

$$
p_{H t}=(1-\theta)(1-\theta \beta)\left(w_{t}-a_{t}\right)+(1-\theta) \theta \beta E_{t} \tilde{p}_{H t+1}+\theta p_{H t-1} .
$$

Then note that $p_{H t}=(1-\theta) \tilde{p}_{H t}+\theta p_{H t-1}$ implies $(1-\theta) E_{t} \tilde{p}_{H t+1}=E_{t} p_{H t+1}-\theta p_{H t}$, so we have:

$$
\begin{aligned}
p_{H t} & =(1-\theta)(1-\theta \beta)\left(w_{t}-a_{t}\right)+\theta \beta\left(E_{t} p_{H t+1}-\theta p_{H t}\right)+\theta p_{H t-1} \\
& =(1-\theta)(1-\theta \beta)\left(w_{t}-a_{t}-p_{H t}\right)+(1-\theta) p_{H t}+\theta \beta\left(E_{t} p_{H t+1}-p_{H t}\right)+\theta p_{H t-1}
\end{aligned} .
$$

Rearranging this slightly gives us the Phillips curve.

Turning to the model given by:

$$
\begin{aligned}
& E_{t} z_{t+1}=B z_{t}+w_{t}, \\
& \text { where } z_{t}=\left[\begin{array}{c}
\pi_{t}-\pi_{t}^{*} \\
q_{t} \\
i_{t-1}
\end{array}\right], w_{t}=\left[\begin{array}{c}
0 \\
\varepsilon_{t}-\varepsilon_{t}^{*} \\
\varepsilon_{t}-\varepsilon_{t}^{*}
\end{array}\right], B=\left[\begin{array}{ccc}
1 / \beta & -\delta / \beta & 0 \\
(\sigma \beta-1) / \beta & (\beta+\delta) / \beta & \alpha \\
\sigma & 0 & \alpha
\end{array}\right] .
\end{aligned}
$$

In the solution presented in the text, we assume $\sigma+\alpha=1 / \beta$. In this case, we can write:

$$
B=\left[\begin{array}{ccc}
1 / \beta & -\delta / \beta & 0 \\
\alpha & (\beta+\delta) / \beta & \alpha \\
(1 / \beta)-\alpha & 0 & \alpha
\end{array}\right] .
$$

The eigenvalues of $B$ are the values of $\mu$ that satisfy

$$
\left|\begin{array}{ccc}
(1 / \beta)-\mu & -\delta / \beta & 0 \\
\alpha & ((\beta+\delta) / \beta)-\mu & \alpha \\
(1 / \beta)-\alpha & 0 & \alpha-\mu
\end{array}\right|=0
$$

Clearly one root is $1 / \beta$. The associated row eigenvector is $\left[1 \frac{\delta}{\beta+\delta-1}\left(\frac{\delta}{\beta+\delta-1}\right) \frac{\alpha \beta}{1-\alpha \beta}\right]$. 
We can factor out $\frac{1}{\beta}-\mu$ in the determinant, to write (A.1) as $\left(\frac{1}{\beta}-\mu\right)\left(\left(1+\frac{1}{\beta}-\mu\right)(\alpha-\mu)-\frac{\alpha \delta}{\beta}\right)=0$. The other two eigenvalues then must satisfy $\left(1+\frac{1}{\beta}-\mu\right)(\alpha-\mu)-\frac{\alpha \delta}{\beta}=0$, and are given by the expression in the text for $\mu_{1}>1$ and $\mu_{2}<1$. It should be clear that $\mu_{1}>1$ because:

$$
\mu_{1}=\frac{1}{2}\left(1+\alpha+\delta / \beta+\sqrt{(1+\alpha+\delta / \beta)^{2}-4 \alpha}\right)>\frac{1}{2}\left(1+\alpha+\sqrt{(1+\alpha)^{2}-4 \alpha}\right)=1
$$

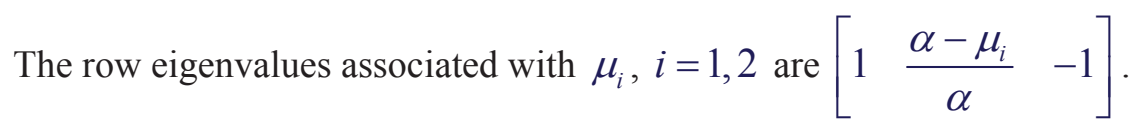

Diagonalizing the matrix $B$, we can write:

$$
E_{t} x_{t+1}=\mathrm{M} x_{t}+y_{t}
$$

Where $x_{t}=D z_{t}, y_{t}=D w_{t} . \mathrm{M}$ is the diagonal matrix whose $i, i$ th element is the $i$ th eigenvalue (that is, $1 / \beta$, $\mu_{1}$ and $\mu_{2}$.) $D$ is the matrix whose $i$ th row is the row eigenvector associated with the $i$ th eigenvalue.

Therefore, the first row of equation (A.3) is given by the equation:

$$
\begin{aligned}
& E_{t} \pi_{t+1}+\left(\frac{\delta}{\beta+\delta-1}\right) E_{t} q_{t+1}+\left(\frac{\delta}{\beta+\delta-1}\right) \frac{\alpha \beta}{1-\alpha \beta} i_{t} \\
= & \frac{1}{\beta}\left[\pi_{t}+\left(\frac{\delta}{\beta+\delta-1}\right) q_{t}+\left(\frac{\delta}{\beta+\delta-1}\right) \frac{\alpha \beta}{1-\alpha \beta} i_{t-1}\right]+\left(\frac{\delta}{\beta+\delta-1}\right)\left(1+\frac{\alpha \beta}{1-\alpha \beta}\right)\left(\varepsilon_{t}-\varepsilon_{t}^{*}\right)
\end{aligned}
$$

We can take the forward solution to this equation. In the case in which $\varepsilon_{t}-\varepsilon_{t}^{*}$ is i.i.d., we find:

$$
\pi_{t}+\left(\frac{\delta}{\beta+\delta-1}\right) q_{t}+\left(\frac{\delta}{\beta+\delta-1}\right) \frac{\alpha \beta}{1-\alpha \beta} i_{t-1}=-\left(\frac{\beta \delta}{\beta+\delta-1}\right)\left(\frac{1}{1-\alpha \beta}\right)\left(\varepsilon_{t}-\varepsilon_{t}^{*}\right)
$$

The second row of equation (A.3) is given by:

$$
E_{t} \pi_{t+1}+\left(\frac{\alpha-\mu_{1}}{\alpha}\right) E_{t} q_{t+1}-i_{t}=\mu_{1}\left[\pi_{t}+\left(\frac{\alpha-\mu_{1}}{\alpha}\right) q_{t}-i_{t-1}\right]-\frac{\mu_{1}}{\alpha}\left(\varepsilon_{t}-\varepsilon_{t}^{*}\right)
$$

The forward solution to this equation when $\varepsilon_{t}-\varepsilon_{t}^{*}$ is i.i.d. is given by:

$$
\alpha \pi_{t}+\left(\alpha-\mu_{1}\right) q_{t}-\alpha i_{t-1}=\varepsilon_{t}-\varepsilon_{t}^{*}
$$

The third row of equation (A.3) is given by the equation 


$$
E_{t} \pi_{t+1}+\left(\frac{\alpha-\mu_{2}}{\alpha}\right) E_{t} q_{t+1}-i_{t}=\mu_{2}\left[\pi_{t}+\left(\frac{\alpha-\mu_{2}}{\alpha}\right) q_{t}-i_{t-1}\right]-\frac{\mu_{2}}{\alpha}\left(\varepsilon_{t}-\varepsilon_{t}^{*}\right)
$$

We can use (A.5) and (A.7) to solve for each of $\pi_{t}$ and $i_{t-1}$ in terms of $q_{t}$ and $\varepsilon_{t}-\varepsilon_{t}^{*}$. Substitute those solutions into (A.8), and make use of the facts that $\mu_{1} \mu_{2}=\alpha$ and $\mu_{1}+\mu_{2}=1+\alpha+\delta / \beta$ to arrive at the solution in the text for the real exchange rate:

$$
q_{t}=\mu_{2} q_{t-1}+\frac{(1-\beta)(1-\alpha \beta)-\delta}{(1-\alpha \beta)\left[(1-\beta)\left(\alpha-\mu_{1}\right)+\delta \mu_{1}\right]}\left(\varepsilon_{t}-\varepsilon_{t}^{*}\right) .
$$

Next, we want to prove that the coefficient on $\varepsilon_{t}-\varepsilon_{t}^{*}$ is negative. This is not straightforward.

Write $\frac{N}{D}=\frac{(1-\beta)(1-\alpha \beta)-\delta}{(1-\alpha \beta)\left[(1-\beta)\left(\alpha-\mu_{1}\right)+\delta \mu_{1}\right]}$,

where $N=(1-\beta)(1-\alpha \beta)-\delta$ and $D=(1-\alpha \beta)\left[(1-\beta)\left(\alpha-\mu_{1}\right)+\delta \mu_{1}\right]$. Define $X \equiv-N$.

Then

$$
D=(1-\alpha \beta)\left[\alpha(1-\beta)+\mu_{1}(X-\alpha \beta(1-\beta))\right] .
$$

Note that:

$$
\begin{aligned}
& 1+\alpha+\frac{\delta}{\beta}=\frac{\beta(1+\alpha)+(1-\beta)(1-\alpha \beta)}{\beta}+\frac{\delta-(1-\beta)(1-\alpha \beta)}{\beta} \\
&=\frac{1+\alpha \beta^{2}}{\beta}+\frac{X}{\beta} \\
&\left(1+\alpha+\frac{\delta}{\beta}\right)^{2}-4 \alpha=\left(\frac{1+\alpha \beta^{2}}{\beta}+\frac{X}{\beta}\right)^{2}-\frac{4 \alpha \beta^{2}}{\beta^{2}}
\end{aligned}
$$

and,

$$
=\left(\frac{1-\alpha \beta^{2}}{\beta}\right)^{2}+\frac{2 X\left(1+\alpha \beta^{2}\right)}{\beta^{2}}+\frac{X^{2}}{\beta^{2}}
$$

Hence,

$$
\begin{aligned}
\mu_{1} & =\frac{1}{2}\left(1+\alpha+\delta / \beta+\left((1+\alpha+\delta / \beta)^{2}-4 \alpha\right)^{1 / 2}\right) \\
& =\frac{1}{2}\left\{\frac{1+\alpha \beta^{2}}{\beta}+\frac{X}{\beta}+\left[\left(\frac{1-\alpha \beta^{2}}{\beta}\right)^{2}+\frac{2 X\left(1+\alpha \beta^{2}\right)}{\beta^{2}}+\frac{X^{2}}{\beta^{2}}\right]^{1 / 2}\right\} . \\
& =\frac{1}{2 \beta}\left\{1+\alpha \beta^{2}+X+\left[\left(1-\alpha \beta^{2}\right)^{2}+2 X\left(1+\alpha \beta^{2}\right)+X^{2}\right]^{1 / 2}\right\}
\end{aligned}
$$


Note that when $X=0$, of course $N=0$. Also, when $X=0$, we can see from (A.10) that $\mu_{1}=\frac{1}{\beta}$, which then implies from (A.9) that $D=0$. Clearly when $X>0$, we have $N<0$, and when $X<0$, we have $N>0$. We will now prove that $\frac{d D}{d X}>0$, which will imply $X>0$, we have $D>0, N<0$ and when $X<0$, we have $D<0, N>0$. This will prove that when $X \neq 0, \frac{N}{D}<0$.

Since $\alpha<1$ and $\beta<1$, from (A.9) if $\frac{d \mu_{1}(X-\alpha \beta(1-\beta))}{d X}>0$ then $\frac{d D}{d X}>0$.

We have:

$$
\frac{d \mu_{1}(X-\alpha \beta(1-\beta))}{d X}=\mu_{1}+(X+\alpha \beta(1-\beta)) \frac{d \mu_{1}}{d X} .
$$

In turn, from (A.10),

$$
\begin{aligned}
\frac{d \mu_{1}}{d X} & =\frac{1}{2 \beta}\left[1+\left(1+\alpha \beta^{2}+X\right)\right]\left[\left(1-\alpha \beta^{2}\right)^{2}+2 X\left(1+\alpha \beta^{2}\right)+X^{2}\right]^{-1 / 2} \\
& =\left[\left(1-\alpha \beta^{2}\right)^{2}+2 X\left(1+\alpha \beta^{2}\right)+X^{2}\right]^{-1 / 2} \mu_{1}
\end{aligned}
$$

Hence,

$$
\frac{d \mu_{1}(X-\alpha \beta(1-\beta))}{d X}=\mu_{1}\left[1+\frac{X-\alpha \beta(1-\beta)}{\left[\left(1-\alpha \beta^{2}\right)^{2}+2 X\left(1+\alpha \beta^{2}\right)+X^{2}\right]^{1 / 2}}\right]
$$

Clearly if $X-\alpha \beta(1-\beta) \geq 0$, then $\frac{d \mu_{1}(X-\alpha \beta(1-\beta))}{d X}>0$, so $\frac{d D}{d X}>0$. If $X-\alpha \beta(1-\beta)<0$, then $\frac{d \mu_{1}(X-\alpha \beta(1-\beta))}{d X}>0$ if

$$
\left[\left(1-\alpha \beta^{2}\right)^{2}+2 X\left(1+\alpha \beta^{2}\right)+X^{2}\right]^{1 / 2}>\alpha \beta(1-\beta)-X
$$

Since both sides of this inequality must be positive if we are assuming $X-\alpha \beta(1-\beta)<0$, then we can square both sides and preserve the inequality:

$$
\left(1-\alpha \beta^{2}\right)^{2}+2 X\left(1+\alpha \beta^{2}\right)+X^{2}>\alpha^{2} \beta^{2}(1-\beta)^{2}+X^{2}-2 X \alpha \beta(1-\beta)
$$

or

$$
\left(1-\alpha \beta^{2}\right)^{2}-\alpha^{2} \beta^{2}(1-\beta)^{2}+2 X(1+\alpha \beta)>0
$$

Recalling that $X=\delta-(1-\beta)(1-\alpha \beta)$, then $\frac{d \mu_{1}(X-\alpha \beta(1-\beta))}{d X}>0$ when $X-\alpha \beta(1-\beta)<0$ if: 


$$
\left(1-\alpha \beta^{2}\right)^{2}-\alpha^{2} \beta^{2}(1-\beta)^{2}+2 \delta(1+\alpha \beta)-(1-\beta)(1-\alpha \beta)(1+\alpha \beta)>0
$$

After simplifying and canceling terms, this condition is equivalent to:

$$
\beta\left[\beta(1-\alpha)^{2}+1-\beta\right]+2 \delta(1+\alpha \beta)>0 .
$$

This condition is clearly satisfied. So we have proven $\frac{d \mu_{1}(X-\alpha \beta(1-\beta))}{d X}>0$ and hence $\frac{d D}{d X}>0$ when $X-\alpha \beta(1-\beta) \geq 0$ and when $X-\alpha \beta(1-\beta)<0$ (assuming $X \neq 0$ ), so $\frac{d D}{d X}>0$ when $X \neq 0$. This proves that when $X \neq 0, \frac{N}{D}<0$.

Now take the case of $X \rightarrow 0$. By l'Hôpital's Rule, $\left.\frac{N}{D} \rightarrow \frac{(d N / d X)}{(d D / d X)}\right|_{X=0}$. Of course, $d N / d X=-1$. So we need only calculate $\left.\frac{d D}{d X}\right|_{X=0}$. Using the algebra above, we find

$$
\left.\frac{d D}{d X}\right|_{X=0}=\frac{(1-\alpha \beta)^{2}}{\beta\left(1-\alpha \beta^{2}\right)}>0
$$

Hence, as $X \rightarrow 0, \frac{N}{D}$ converges to a negative number.

When $\alpha=0$ and $\sigma \beta=1$, the model simplifies to:

$$
E_{t}\left[\begin{array}{c}
\pi_{t+1}-\pi_{t+1}^{*} \\
q_{t+1}
\end{array}\right]=\left[\begin{array}{cc}
1 / \beta & -\delta / \beta \\
0 & (\beta+\delta) / \beta
\end{array}\right]\left[\begin{array}{c}
\pi_{t}-\pi_{t}^{*} \\
q_{t}
\end{array}\right]+\left[\begin{array}{c}
0 \\
\varepsilon_{t}-\varepsilon_{t}^{*}
\end{array}\right]
$$

We can solve the second equation of this system using forward iteration to get the solution in the text:

$$
q_{t}=\frac{-\beta}{\delta+\beta} \sum_{j=0}^{\infty}\left(\frac{\beta}{\delta+\beta}\right)^{j} E_{t}\left(\varepsilon_{t+j}-\varepsilon_{t+j}^{*}\right)
$$

Then the first equation can be solved by forward iteration to give the equation in the text:

$$
\pi_{t}-\pi_{t}^{*}=\delta E_{t} \sum_{j=0}^{\infty} \beta^{j} q_{t+j}
$$

Now, to see what happens when there is news about future values of $\varepsilon_{t+j}^{R} \equiv \varepsilon_{t+j}-\varepsilon_{t+j}^{*}$, in the case in which $\varepsilon_{t}^{R}=\rho_{\varepsilon} \varepsilon_{t-1}^{R}+\omega_{t}$, it is helpful to write out (A.11) term by term: 


$$
\begin{aligned}
& q_{t}=\frac{-\beta}{\delta+\beta}\left\{\varepsilon_{t}^{R}+\left(\frac{\beta}{\delta+\beta}\right)\left(\rho_{\varepsilon} \varepsilon_{t}^{R}+E_{t} \omega_{t+1}\right)+\left(\frac{\beta}{\delta+\beta}\right)^{2}\left(\rho_{\varepsilon}^{2} \varepsilon_{t}^{R}+\rho_{\varepsilon} E_{t} \omega_{t+1}+E_{t} \omega_{t+2}\right)+\ldots\right\} \\
& =\frac{-\beta}{\delta+\beta}\left\{\left[1+\left(\frac{\beta}{\delta+\beta}\right) \rho_{\varepsilon}+\left(\frac{\beta}{\delta+\beta}\right)^{2}+\ldots\right]\left(\rho_{\varepsilon}^{2}+\left(\frac{\beta}{\delta+\beta}\right) E_{t} \omega_{t+1}+\left(\frac{\beta}{\delta+\beta}\right)^{2} E_{t} \omega_{t+2}+\ldots\right)\right\}
\end{aligned}
$$

This gives us the equation in the text:

$$
q_{t}=-\left(\frac{\beta}{\delta+\beta\left(1-\rho_{\varepsilon}\right)}\right)\left[\varepsilon_{t}^{R}+N_{t}\right], \quad \text { where } N_{t} \equiv E_{t} \sum_{j=1}^{\infty}\left(\frac{\beta}{\delta+\beta}\right)^{j} \omega_{t+j} .
$$

\section{Derivation of results in section 3.b}

In this section, for the exchange-rate equation given by:

$$
s_{t+k}-s_{t}=\left(1-\alpha^{k}\right)\left(f_{1 t}-s_{t}\right)+\sum_{i=1}^{k} \varepsilon_{t+i}+\frac{b}{1-b \alpha} \sum_{j=1}^{k} \alpha^{k-j} u_{t+j}
$$

the claim is that the R-squared for the $k$-horizon regression of $s_{t+k}-s_{t}$ on $f_{1 t}-s_{t}$ is given by:

$$
R_{k}^{2}=\frac{\left(1-\alpha^{k}\right)^{2} \operatorname{var}\left(u_{t}\right)}{2\left(1-\alpha^{k}\right) \operatorname{var}\left(u_{t}\right)+\left[k\left(1-\alpha^{2}\right)(1-b \alpha)^{2} / b^{2}\right] \operatorname{var}\left(\varepsilon_{t}\right)}
$$

We have from (A.12)

$$
\operatorname{var}\left(s_{t+k}-s_{t}\right)=\left(1-\alpha^{k}\right)^{2} \operatorname{var}\left(f_{1 t}-s_{t}\right)+k \operatorname{var}\left(\varepsilon_{t}\right)+\left(\frac{b}{1-b \alpha}\right)^{2}\left(\alpha^{2(k-1)}+\alpha^{2(k-1)}+\ldots+1\right) \operatorname{var}\left(u_{t}\right) .
$$

Since, according to the text, $f_{1 t}-s_{t}=\frac{-b}{1-b \alpha} f_{2 t}$, we have

$$
\operatorname{var}\left(f_{1 t}-s_{t}\right)=\left(\frac{b}{1-b \alpha}\right)^{2} \operatorname{var}\left(f_{2 t}\right)=\left(\frac{b}{1-b \alpha}\right)^{2} \frac{1}{1-\alpha^{2}} \operatorname{var}\left(u_{t}\right) \text {. }
$$

Also, $\alpha^{2(k-1)}+\alpha^{2(k-1)}+\ldots+1=\frac{1-\alpha^{2 k}}{1-\alpha^{2}}$

Substituting into (A.14), we have:

$$
\operatorname{var}\left(s_{t+k}-s_{t}\right)=\left(1-\alpha^{k}\right)^{2}\left(\frac{b}{1-b \alpha}\right)^{2} \frac{1}{1-\alpha^{2}} \operatorname{var}\left(u_{t}\right)+k \operatorname{var}\left(\varepsilon_{t}\right)+\left(\frac{b}{1-b \alpha}\right)^{2} \frac{1-\alpha^{2 k}}{1-\alpha^{2}} \operatorname{var}\left(u_{t}\right)
$$

The "explained" variance is given by:

$$
\left(1-\alpha^{k}\right)^{2} \operatorname{var}\left(f_{1 t}-s_{t}\right)=\left(1-\alpha^{k}\right)^{2}\left(\frac{b}{1-b \alpha}\right)^{2} \frac{1}{1-\alpha^{2}} \operatorname{var}\left(u_{t}\right)
$$

The R-squared is given by the ratio of (A.16) to (A.15), which simplifies to (A.13). 


\section{$\underline{\text { Derivation of results in section 4.b }}$}

Proof that $\operatorname{cov}\left(E_{t} d_{t+1}, r_{t}-r_{t}^{*}\right)<0$ in the Epstein-Zin model with asymmetric preferences, $\alpha \neq \alpha^{*}$, $\rho=\rho^{*}, \alpha, \alpha^{*}<0$ and $0<\rho<1$, but no idiosyncratic shocks:

We have from the text:

$$
E_{t} d_{t+1}=\left(\gamma_{u}^{r}-\gamma_{u}^{* r}\right) u_{t}^{c}=\frac{1}{2}\left[\alpha(\alpha-\rho)-\alpha^{*}\left(\alpha^{*}-\rho\right)\right] u_{t}^{c}
$$

Then $r_{t}-r_{t}^{*}=E_{t} d_{t+1}-\lambda_{t}$, where

$$
\lambda_{t}=\frac{1}{2}\left(\left(\lambda_{x}^{r}\right)^{2}-\left(\lambda_{x}^{* r}\right)^{2}\right) u_{t}^{c}=\frac{1}{2}\left[(1-\alpha)^{2}-\left(1-\alpha^{*}\right)^{2}\right] u_{t}^{c}=\frac{1}{2}\left[\alpha(\alpha-2)-\alpha^{*}\left(\alpha^{*}-2\right)\right] u_{t}^{c}
$$

So, $r_{t}-r_{t}^{*}=\frac{1}{2}\left\{\left[\alpha(\alpha-\rho)-\alpha^{*}\left(\alpha^{*}-\rho\right)\right]-\left[\alpha(\alpha-2)-\alpha^{*}\left(\alpha^{*}-2\right)\right]\right\} u_{t}^{c}$.

Then,

$$
\begin{aligned}
& \operatorname{cov}\left(E_{t} d_{t+1}, r_{t}-r_{t}^{*}\right)=\frac{1}{4}\left\{\left[\alpha(\alpha-\rho)-\alpha^{*}\left(\alpha^{*}-\rho\right)\right]^{2}-\left[\alpha(\alpha-\rho)-\alpha^{*}\left(\alpha^{*}-\rho\right)\right]\left[\alpha(\alpha-2)-\alpha^{*}\left(\alpha^{*}-2\right)\right]\right\} \\
& =\frac{1}{4}\left\{\left[\alpha(\alpha-\rho)-\alpha^{*}\left(\alpha^{*}-\rho\right)\right]^{2}-\left[\alpha(\alpha-\rho)-\alpha^{*}\left(\alpha^{*}-\rho\right)\right]\left[\alpha(\alpha-\rho)+\alpha(\rho-2)-\alpha^{*}\left(\alpha^{*}-\rho\right)-\alpha^{*}(\rho-2)\right]\right\} \\
& =\frac{1}{4}\left[\alpha(\alpha-\rho)-\alpha^{*}\left(\alpha^{*}-\rho\right)\right]\left[\alpha(2-\rho)-\alpha^{*}(2-\rho)\right] \\
& =\frac{1}{4}\left[\alpha\left(\alpha+\alpha^{*}-\rho\right)-\alpha^{*}\left(\alpha^{*}+\alpha-\rho\right)\right](2-\rho)\left(\alpha-\alpha^{*}\right) \\
& =\frac{1}{4}\left(\alpha+\alpha^{*}-\rho\right)(2-\rho)\left(\alpha-\alpha^{*}\right)^{2}<0
\end{aligned}
$$

\section{Deriviation of results in section 4.c}

We derive the difference in the variance of the unexplained exchange rate movement under private signals versus public signals.

From the text, we have

$$
\operatorname{var}(\text { public })=b^{2}\left[\frac{\sigma_{1}^{4}}{\sigma_{1}^{2}+\sigma_{v}^{2}}+\sigma_{2}^{2}\right]=b^{2}\left[\frac{v_{1}^{2}}{v_{1}+v_{v}}+v_{2}\right]
$$

where we have adopted the simplifying notation $v_{i}=\sigma_{i}^{2}, \forall i$.

In the case of private information, from the text we have:

$$
\operatorname{var}(\text { private })=b^{2}\left[\left(1-a_{1}\right)^{2} v_{1}+\left(1+\left(a_{g} / a_{v}\right)\right)^{2} v_{2}\right]
$$

In this expression, using equations from the text,

$$
a_{1}=\frac{v_{1}^{-1}}{v_{1}^{-1}+v_{v}^{-1}+v_{g}^{-1}}=\frac{v_{v} v_{g}}{v_{v} v_{g}+v_{1} v_{g}+v_{1} v_{v}}, \text { so }
$$


(A.19) $\left(1-a_{1}\right)^{2}=\frac{v_{1}^{2}\left(v_{g}+v_{v}\right)^{2}}{D^{2}}$, where $D \equiv v_{v} v_{g}+v_{1} v_{g}+v_{1} v_{v}$.

Also, we have $a_{g}=\frac{v_{1} v_{v}}{D}$ and $a_{v}=\frac{v_{1} v_{g}}{D}$, so $\frac{a_{g}}{a_{v}}=\frac{v_{v}}{v_{g}}$, and therefore $\left(1+\frac{a_{g}}{a_{v}}\right)^{2}=\left(\frac{v_{v}+v_{g}}{v_{g}}\right)^{2}$.

Then, from the text, since $\varepsilon_{g t} \equiv-c_{2} f_{2 t} / c_{3}$, we have $\sigma_{g}^{2}=\left(c_{2} / c_{3}\right)^{2} \sigma_{2}^{2}$, or

$$
v_{2}=\left(\frac{c_{3}}{c_{2}}\right)^{2} v_{g} \text {, where from the text we have } c_{3}=b\left(1-a_{1}\right) \text { and } c_{2}=b\left(1+\frac{a_{g}}{a_{v}}\right)=b\left(\frac{v_{v}+v_{g}}{v_{g}}\right)
$$

Then

(A.20) $v_{2}=\left(\frac{\left(1-a_{1}\right) v_{g}}{v_{v}+v_{g}}\right)^{2} v_{g}$

which then gives us that

(A.21) $\left(1+\frac{a_{g}}{a_{v}}\right)^{2} v_{2}=\left(\frac{v_{v}+v_{g}}{v_{g}}\right)^{2}\left(\frac{\left(1-a_{1}\right) v_{g}}{v_{v}+v_{g}}\right)^{2} v_{g}=\left(1-a_{1}\right)^{2} v_{g}$.

We can now rewrite the expression (A.18), using (A.19) and (A.21) as:

(A.22) $\operatorname{var}($ private $)=b^{2}\left(1-a_{1}\right)^{2}\left(v_{1}+v_{g}\right)=b^{2} \frac{v_{1}^{2}\left(v_{g}+v_{v}\right)^{2}\left(v_{1}+v_{g}\right)}{D^{2}}$.

Next, use (A.20) to write $v_{2}=\left(\frac{v_{1} v_{g}}{D}\right)^{2} v_{g}$. We can interpret this last equation as simply an implicit definition of $v_{g}$. We can use it to replace $v_{2}$ in expression (A.17) for the variance under public information. Then with that substitution, we can use (A.22) and (A.17) to get:

$$
\begin{aligned}
\operatorname{var}(\text { private })-\operatorname{var}(\text { public }) & =b^{2}\left\{\frac{v_{1}^{2}\left(v_{g}+v_{v}\right)^{2}\left(v_{1}+v_{g}\right)}{D^{2}}-\left[\frac{v_{1}^{2}}{v_{1}+v_{v}}+\left(\frac{v_{1} v_{g}}{D}\right)^{2} v_{g}\right]\right\} \\
& =\frac{b^{2} v_{1}^{2}}{D^{2}}\left\{\left(v_{g}+v_{v}\right)^{2}\left(v_{1}+v_{g}\right)-\left[\frac{D^{2}}{v_{1}+v_{v}}+v_{g}^{3}\right]\right\} \\
& =\frac{b^{2} v_{1}^{2}}{D^{2}\left(v_{1}+v_{v}\right)}\left\{\left(v_{g}+v_{v}\right)^{2}\left(v_{1}+v_{g}\right)\left(v_{1}+v_{v}\right)-\left[\left(v_{v} v_{g}+v_{1} v_{g}+v_{1} v_{v}\right)^{2}+v_{g}^{3}\left(v_{1}+v_{v}\right)\right]\right\} \\
& =\frac{b^{2} v_{1}^{2}}{D^{2}\left(v_{1}+v_{v}\right)}\left\{v_{v}\left[v_{g}\left(v_{1}+v_{g}\right)\left(v_{1}+v_{v}\right)+v_{1} v_{v}^{2}\right]\right\}>0
\end{aligned}
$$

